\title{
ESTIMATIVA DA EVAPOTRANSPIRAÇĀO DE ÁREAS DE FLORESTA E PASTAGEM NA AMAZÔNIA PELO MÉTODO DE PRIESTLEY-TAYLOR
}

SYLVIA ELAINE MARQUES DE FARIAS

Meteorologista

Orientador: Prof. Dr. ANTONIO ROBERTO PEREIRA

Dissertaçāo apresentada à Escola Superior de Agricultura "Luiz de Queiroz”, Universidade de São Paulo, para obtenção do titulo de Mestre em Agronomia, Área de Concentração:

Fisica do Ambiente Agricola.

\author{
P I R A C I C A B A \\ Estado de São Paulo - Brasil \\ Maio - 2000
}




\section{ERRATAS}

Pag. 9 - Onde se lê:

... com baixas velocidade o método falhou devido a problemas associados com o protelar dos anemômetros mecânicos.

Leia-se: ... a problemas associados com o retardamento dos anemômetros mecânicos.

Pag. 12

** Pereira et al., 1997(b)

Pag. 26, a equação 21 é válida para $\beta \neq-1$.

Pag 41. Os respectivos títulos das tabelas 5 e 6 são:

Tabela 5 - Balanço de energia na hora de Rn máximo, para os dias julianos na Fazenda N. S.. Aparecida (Ji-Paraná, RO) e Boa Sorte (Marabá, PA).

Tabela 6 - Balanco de energia há hora de Rn máximo, para os dias julianos na Fazenda Dimona (Manaus, AM).

Pag. 62. Na Tabela 6, onde se lê: biomassa $\left(\mathrm{MJ} \mathrm{m}^{-2} \mathrm{~d}^{-1}\right)$, leia-se: resíduo $\left(\mathrm{MJm}^{-2} \mathrm{~d}^{-1}\right)$. Pag. 71.

PEREIRA, A. R.; VILLA NOVA, N.A.; SENTELHAS, P.C. O parâmetro de PriestleyTaylor, para estimativa da evapotranspiração de referência na escala mensal. Revista Brasileira de Agrometeorologia, v.5, n.1, p.83-87, 1997b.

PEREIRA, A. R.; VILLA NOVA, N.A.; SEDIYAMA, G.C. Evapo(transpi)ração. Piracicaba, Fealq. 183p.1997a. 


\section{Dados internacionais de Catalogação na Publicação (CIP) DIVISĀO DE BIBLIOTECA E DOCUMENTAÇĀO - Campus "Luiz de Oueiroz"/USP}

Farias, Sylvia Elaine Marques de Estimativa da evapotranspiração pelo método de Priestley-Taylor em áreas de floresta e pastagem na Amazônia / Sylvia Elaine Marques de Farias. - - Piracicaba, 2000.

$$
75 \text { p. : il. }
$$

Dissertação (mestrado) - - Escola Superior de Agricultura Luiz de Queiroz, 2000. Bibliografia.

1. Efeito do calor 2. Equipamento agricola 3. Evapotranspiraçāo 4. Floresta amazônica 5. Impacto ambiental 6. Pastagem I. Titulo

CDD 551.572 
A meus pais Luis Farias e Maria Marques, pelo incentivo, dedicação, amor e apoio incondicional em todos os momentos de minha vida.

\section{DEDICO}

Para Yasmin, Gabriela, Carolline

e ... a que vem chegando...

OFEREÇO 


\section{AGRADECIMENTOS}

Ao Prof. Dr. Antonio Roberto Pereira, pela orientação na conclusão deste trabalho, apoio e confiança.

Aos Professores Nilson Augusto Villa Nova e Gilberto Fisch, pelas sugestões e valiosas discussões.

Aos professores e funcionários do curso de Agrometeorologia/Esalq, em especial aos professores Luiz Roberto Angelocci, Sérgio Moraes e Paulo Sentelhas pelos ensinamentos e amizade.

Aos amigos de curso, Rafael Ferreira da Costa, Késia Silva, Evandro Righ, Karen Mattos, Glauco Rolim, Jeane Portela, Alailson Santiago, Fabio Marin e Marcius Graco, pela amizade, companherismo e solidadriedade em todas as etapas conquistadas.

Aos amigos sempre presentes, Jeane Portela, Alailson Santiago, Rosa Santos, Solange Silva, José Luiz Cabral, Ednaldo Santos, Lucieta Martorano e Isabel Serrano, pelo exemplo de despreendimento pessoal e amizade, nos momentos alegres e de adversidades.

A Coordenação de Aperfeiçoamento de Pessoal de Nivel Superior (CAPES), pela bolsa de estudos concedida.

Aos colegas da Vila Estudantil da ESALQ, pelos momentos felizes.

Aqueles que contribuiram para a realizaçāo deste trabalho, o meu MUITO OBRIGADA. 


\section{S U M Á R I O}

LISTA DE FIGURAS

LISTA DE TABELAS

RESUMO

SUMMARY

1 - INTRODUÇÃO 1

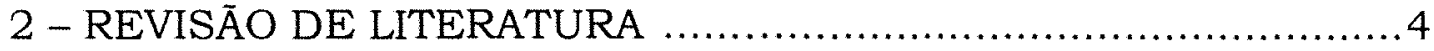

2.1 - Conceitos e Definições ..............................................4

2.2 - Fatores que afetam a Evapotranspiração ........................ 5

2.3 - Evapotranspiração de Florestas …..............................

2.4 - O Método de Priestley-Taylor .................................... 9

2.5 - O Método da Correlação dos Vórtices Turbulentos ........... 15

3 - MATERIAL E MÉTODOS .............................................. 17

3.1 - Localização dos Sitios ........................................ 17

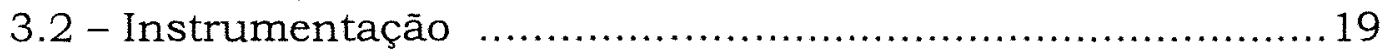

3.2 .1 - Hydra .................................................... 19

3.2.2 - Estações Meteorológicas Automáticas (EMA) ...........21

3.3 - Método da Correlação dos Vórtices Turbulentos .............23

3.4 - Método de Priestley-Taylor e a Parametrização proposta por Pereira e Villa Nova (1992) ....................................25

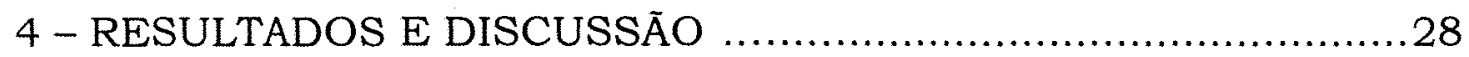

4.1 - Estimativa da Evapotranspiração pelo Método de Priestley-Taylor ................................................28

4.1 .1 - Escala Horária ..........................................28

4.1 .2 - Escala Diária .............................................61

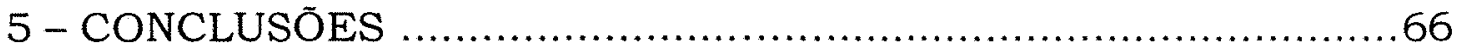

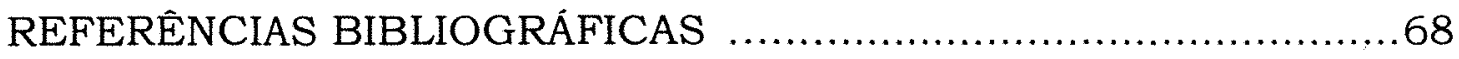




\section{LISTA DE FIGURAS}

Figura 1 - Áreas experimentais do Projeto ABRACOS …...................... 18

Figura 2 - (A) Esquema do instrumento Hydra e (B) equipamento Hydra montado na Fazenda Nossa Senhora Aparecida - Ji-

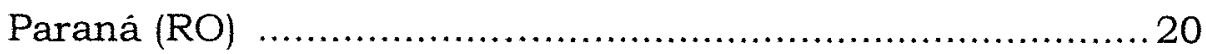

Figura 3 - Fluxo de calor latente para os sitios na Floresta, com $\alpha$ propostos por Pereira e Villa Nova (1992), para as colunas

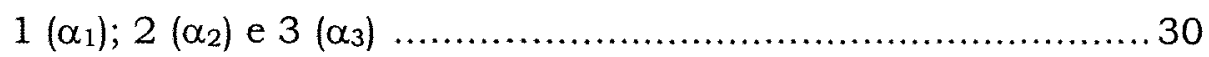

Figura 4 - Fluxo de calor latente para os sitios na pastagem, com $\alpha$ propostos por Pereira e Villa Nova (1992), para as colunas $1\left(\alpha_{1}\right) ; 2\left(\alpha_{2}\right)$ e $3\left(\alpha_{3}\right)$

Figura 5 - Fluxo de calor latente, na escala horária, para as Reservas Biológica do Jaru (Ji-Paraná, RO) e Vale do Rio Doce (Marabá, PA), para A (1992), B e D (1993) e C (1994). Coluna 1: Dias com melhores estimativas; Coluna 2: Dias com piores estimativas

Figura 6 - Fluxo de calor latente, na escala horária, para as Fazendas Nossa Senhora Aparecida (Ji-Paraná, RO) e para Fazenda Boa Sorte (Marabá, PA) para: A (1992), B e D (1993) e C (1994)

Figura 7 - Fluxo de calor latente, na escala horária, para a Fazenda Dimona, Manaus, AM, para 1990 (coluna A) e 1991 (coluna B)

Figura 8 - Balanço de energia medido pelo Hydra para as Reservas Biológica do Jaru (Ji-Paraná RO) e Vale do Rio Doce (Marabá PA), para: A (1992), B e D (1993) e C (1994) 
Figura 9 - Balanço de energia medido pelo Hydra para as Fazendas Nossa Senhora Aparecida (Ji-Paraná RO) e Boa Sorte (Marabá PA), para: A (1992), B e D (1993) e C (1994)

Figura 10 - Balanço de energia medido pelo Hydra para a Fazenda Dimona (Manaus, AM) para: A (1990) e B (1991)

Figura 11 - Comparação entre o fluxo de calor latente medido e a Radiação líquida, na escala horária, para as Reservas Biológica do Jaru (Ji-Paraná RO) e Vale do Rio Doce (Marabá, PA), para: A (1992), B e C (1993) e C (1994) .......... 43

Figura 12 - Comparação entre o fluxo de calor latente medido e a Radiação líquida, na escala horária, para as Fazendas Nossa Senhora Aparecida (Ji-Paraná RO) e Boa Sorte (Marabá PA), para: A (1992), B e D (1993) e C (1994)

Figura 13 - Comparaçāo entre o fluxo de calor latente medido e a Radiação liquida, na escala horária, para a Fazenda Dimona (Manaus AM), para: A (1990), B (1991)

Figura 14 - Diferença entre o fluxo de calor latente estimado (PriestleyTaylor) e o medido (HYDRA), na escala horária, para as Reservas Biológica do Jaru (Ji-Paraná RO) e Vale do Rio Doce (Marabá, PA), para: A (1992), B e D (1993), C (1994) ... 47

Figura 15 - Diferença entre o fluxo de calor latente estimado (PriestleyTaylor) e o medido (HYDRA), na escala horária, para as Fazendas Nossa Senhora Aparecida (Ji-Paraná, RO) e Boa Sorte (Marabá, PA), para: A (1992), B e D (1993), C (1994) .. 48

Figura 16 - Diferença entre o fluxo de calor latente estimado (PriestleyTaylor) e o medido (HYDRA), na escala horária, para a Fazenda Dimona (Manaus AM) para: A (1990), B (1991)

Figura 17 - Fluxo de calor sensivel e parâmetro de Priestley-Taylor medido durante todo o perido do experimento, na escala horária, para as Reservas Biológica do Jaru e Boa Sorte (coluna 1), e Fazendas Nossa Senhora Aparecida e Boa Sorte (coluna 2), para: A (1992), B e D (1993) e C (1994) .....50 
Figura 18 - Fluxo de calor sensivel e parâmetro de Priestley-Taylor medido durante todo o periodo do experimento, na escala horária, para a Fazenda Dimona (Manaus, AM) para: A (1990) e B (1991)

Figura 19 - Fluxo de calor sensivel e $\alpha$, medidos na escala horária, para as Reservas Biológica do Jaru (Ji-Paraná, RO), e Vale do Rio Doce (Marabá, PA), para: A (1992); B e D (1993); C (1994)

Figura 20 - Fluxo de calor sensivel e $\alpha$, medidos na escala horária, para as Fazendas Nossa Senhora Aparecida (Ji-Paraná, RO), e Boa Sorte (Marabá PA), para: A (1992); B e D (1993); C (1994)

Figura 21 - Fluxo de calor sensivel e $\alpha$, medidos na escala horária, para a Fazenda Dimona (Manaus, PA), para: A (1990); B (1991)

Figura 22- Parâmetro de Priestley-Taylor, na escala horária, para as Reservas Biológica do Jarú (Ji-Paranâ, RO) e Vale do Rio Doce (Marabá, PA), para: A (1992); B e D (1993); C (1994) ... 55

Figura 23- Parâmetro de Priestley-Taylor, na escala horária, para as Fazendas Nossa Senhora Aparecida (Ji-Paraná, RO) e Vale do Rio Doce (Marabá, PA), para: A (1992); B e D (1993); C (1994)

Figura 24- Parâmetro de Priestley-Taylor, na escala horária, para a Fazenda Dimona (Manaus, MA), para: A (1990); e B (1991) . 57

Figura 25 - Variação horária de $\alpha$ (medido e estimado) e da razão de Bowen, para as Reservas Biológica do Jaru (Ji-Paraná, RO) e Vale do Rio Doce (Marabá, PA), para: A (1992); B e D (1993); C (1994)

Figura 26 - Variaçāo horária de $\alpha$ (medido e estimado) e da razão de Bowen, para as Fazendas Nossa Senhora Aparecida (JiParaná RO) e Boa Sorte (Marabá, PA), para: A (1992), B (1993); e C (1994) 
Figura 27 - Variação horária de $\alpha$ (medido e estimado) e da razão de Bowen, para a Fazenda Dimona (Manaus, AM), para: A

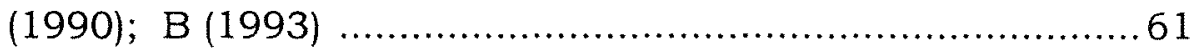




\section{LISTA DE TABELAS}

Tabela 1 - Valores de alfa para diferentes superficies evapotranspirantes, sob diversas escalas de tempo e

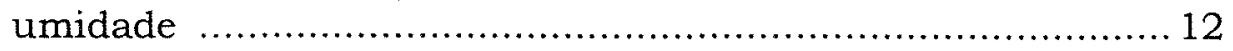

Tabela 2 - Período do Experimento para os sitios Pastagem, Projeto ABRACOS

Tabela 3 - Balanço de energia na hora de $\mathrm{Rn}$ máximo, para os dias Julianos na Reserva Biológica Jaru (Ji-Paraná, RO) e Vale do Rio Doce (Marabá, PA)

Tabela 4 - Valores máximos medidos de Rn, LE, H e G para os dias Julianos nas Fazendas Nossa Senhora Aparecida (JiParaná, RO) e Boa Sorte (Marabá, PA)

Tabela 5 - Valores máximos medidos de $\mathrm{Rn}, \mathrm{LE}, \mathrm{H}$ e $\mathrm{G}$ para os dias Julianos na Fazenda Dimona em Manaus (AM)

Tabela 6 - Total diário dos fluxos de energia, parâmetro de PriestleyTaylor (estimado e medido) biomassa e variáveis meteorológicas para os dias analisados na Floresta .............62 62

Tabela 7- Quociente diário dos fluxos de energia para o dias analisados na Floresta

Tabela 8 - Total diärio dos fluxos de energia, parâmetro de PriestleyTaylor (estimado e medido) variáveis meteorológicas para os dias analisados na pastagem

Tabela 9 - Quociente diário dos fluxos de energia para o dias analisados na Floresta .............................................6 63

Tabela 10 - Valores médios para $\alpha$ para os sitios na floresta .................6 64

Tabela 11 - Valores médios para $\alpha$ para os sitios na pastagem 


\title{
ESTIMATIVA DA EVAPOTRANSPIRAÇÃO PELO MÉTODO DE PRIESTLEY-TAYLOR EM ÁREAS DE FLORESTA E PASTAGEM NA AMAZÔNIA.
}

\author{
Autor: SYLVIA ELAINE MARQUES DE FARIAS \\ Orientador: Prof. Dr. ANTONIO ROBERTO PEREIRA
}

\section{RESUMO}

Foi estimado o calor latente pelo método de Priestley e Taylor (1972), segundo a proposição de Pereira e Villa Nova (1992), para o parâmetro $\alpha$ e comparado com o calor latente medido (método das correlaçōes dos turbilhões), para cada sitio (floresta e pastagem) e época do experimento, no âmbito do projeto ABRACOS (1990-1994), nas escalas horárias e diárias. A localização dos sitios diferiram segundo a estação seca, extensão espacial das áreas de pastagem e a proximidade do oceano. Os sítios experimentais estão localizados na parte central (Manaus, AM), oriental (Marabá, PA) e sudoeste (Ji-Paraná, RO) da Amazônia, compreendendo cinco sitios do Projeto ABRACOS. Os sitios estão assim localizados: a) Área desmatada próxima a Manaus, Fazenda Dimona ( $2^{\circ} 19^{\prime} \mathrm{S}, 60^{\circ} 19^{\prime} \mathrm{W}$; $80 \mathrm{~m}$ ); b) Imediações de Marabá, Fazenda Boa Sorte $\left(5^{\circ} 10^{\prime} \mathrm{S}, 48^{\circ} 45^{\prime} \mathrm{W} ; 170 \mathrm{~m}\right)$, e Reserva Vale do Rio Doce $\left(5^{\circ} 45^{\prime} \mathrm{S}\right.$, $\left.49^{\circ} 10^{\top} \mathrm{W} ; 150 \mathrm{~m}\right)$; c) Ji-Paraná, RO, próximo o limite Sudoeste da floresta,

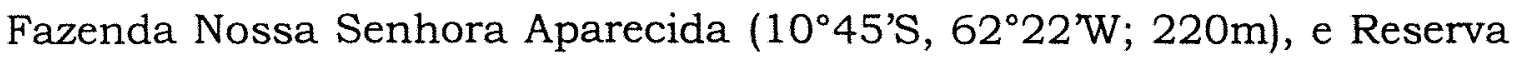
Jaru $\left(10^{\circ} 5^{\prime} \mathrm{S}, 61^{\circ} 55^{\prime} \mathrm{W} ; 120 \mathrm{~m}\right)$. Os resultados obtidos apresentaram boas correlações entre o calor latente estimado (Priestley-Taylor) e o 
medido (Hydra). As melhores correlações foram obtidas para os sitios florestas, situação também observada para a correlação entre o parâmetro de Priestley-Taylor estimado (Pereira e Villa Nova) e o medido (Hydra). Na escala horária, na maioria dos casos, o calor latente estimado superestimou o calor latente medido. Na escala diária, se constatou que as melhores estimativas encontradas, tanto para o calor latente quanto para o parâmetro de Priestley-Taylor, foi observada para os dias em que foram encontrados os maiores fluxos de energia (radiação líquida e calor sensivel). Foi verificado que o parâmetro de Priestley-Taylor é uma função do calor sensivel. 


\title{
ESTIMATE OF EVAPOTRANSPIRATION FOR THE METHOD OF PRIESTLEY-TAYLOR IN AREAS OF FOREST AND PASTURE IN AMAZONIA.
}

\author{
Author: SYLVIA ELAINE MARQUES DE FARIAS \\ Adviser: Prof. Dr. ANTONIO ROBERTO PEREIRA
}

\section{SUMMARY}

It was dear the latent heat for the method of Priestley and Taylor (1972), according to proposition Pereira and Villa Nova (1992), for the parameter the and compared with the measured latent heat (method of the correlations of the whirls), to each ranch (forest and pastagem) and time of the experiment, in the ambit of the project ABRACOS (19901994), in the hourly and daily scales. The location of the ranches differed according to the station it evaporates, space extension of the pasture areas and the proximity of the ocean. The experimental ranches are located in the central part (Manaus, AM), oriental (Marabá, PA) and Southwest (Ji-Paraná, RO) of Amazonia, understanding five ranches of the Projeto ABRAÇOS. The ranches are like this located: the) close deforested Area Manaus, Fazenda Dimona (2 $\left.2^{\circ} 19^{\prime} \mathrm{S}, 60^{\circ} 19^{\circ} \mathrm{W} ; 80 \mathrm{~m}\right)$; b) Environs of Marabá, Fazenda Boa Sorte $\left(5^{\circ} 10^{\prime} \mathrm{S}, 48^{\circ} 45^{\circ} \mathrm{W} ; 170 \mathrm{~m}\right)$, and Reservation is Vale do Rio Doce $\left(5^{\circ} 45^{\prime} \mathrm{S}, 49^{\circ} 10^{\prime} \mathrm{W}\right.$; $\left.150 \mathrm{~m}\right)$; c) Ji-Paraná, RO, close the Southwest limit of the forest, Fazenda Nossa Senhora Aparecida $\left(10^{\circ} 45^{\prime} \mathrm{S}, 62^{\circ} 22^{\prime} \mathrm{W} ; 220 \mathrm{~m}\right)$, and Reserves Jaru $\left(10^{\circ} 5^{\prime} \mathrm{S}, 61^{\circ}\right.$ $\left.55^{\circ} \mathrm{W} ; 120 \mathrm{~m}\right)$. The obtained results presented good correlations among 
the dear latent heat (Priestley-Taylor) and the measured (Hydra). The best correlations were obtained to the ranches forests, situation also observed for the correlation among the parameter of dear PriestleyTaylor (Pereira and Villa Nova) and the measured (Hydra). In the hourly scale, in most of the cases, the dear latent heat overestimated the measured latent heat. In the daily scale, it was verified that the best found estimates, so much for the latent heat as for the parameter of Priestley-Taylor, it was observed for the days in that were found the largest flows of energy (liquid radiation and sensitive heat). it was verified that the parameter of Priestley-Taylor is a function of the sensible heat flux. 


\section{1 - INTRODUÇÃo}

Em uma breve revisão histórica sobre o tema da evapotranspiração, foi observado que o assunto já merecia certa importância desde tempos remotos. $O$ interesse formal na área de evaporação teve início nos anos 600 a 500 a.C. Aristóteles revelou o conceito com uma vaga noção do que seja calor latente, embora ele não acreditasse na relação causa-efeito entre vento e evaporação. Descartes, antagonicamente ao pensamento aristotélico, defendia que a evaporação seria causada pelo calor do Sol e seria equivalente à agitação das particulas, iniciando-se assim, a experimentação como parte essencial das investigações científicas (Sediyama, 1996).

De forma geral, o termo evapotranspiração é usado para descrever o processo conjunto de evaporação da água do solo e da transpiração das plantas. As perdas de água das superficies terrestres para a atmosfera, possui um interesse comum para os estudiosos sobre este assunto, levando-se em consideração que a evapotranspiração possui grande importância no ciclo hidrológico.

As mudanças de fase, líquido-vapor e vice-versa, provê um mecanismo para a redistribuição da energia dentro de um ecossistema através da atmosfera. A energia absorvida e liberada durante as mudanças de estado da água tem importante papel, não só nas condições atmosféricas locais, como também na circulação geral.

Partindo-se do ponto de vista da importância do ecossistema amazônico, nas ultimas décadas, a floresta Amazônica tem despertado a 
atenção da comunidade científica tanto pelo desmatamento em grande escala, como pela influência deste, no clima regional e local. Sua importância para outras regiões, deve-se ao fato dela ser uma fonte de energia, a qual é carregada pela circulação geral da atmosfera para outras regiōes. A região Amazônica corresponde a $8 \%$ do cinturão latitudinal $\left(10^{\circ} \mathrm{N}-10^{\circ} \mathrm{S}\right)$, que representa $34 \%$ da superficie terrestre (ou $88 \times 10^{6} \mathrm{~km}^{2}$ ), dos quais $23 \%$ são áreas continentais, sendo metade destas cobertas por florestas naturais (Molion, 1988 e Molion, 1990).

Quanto as trocas de energia entre a superficie e a atmosfera, já foram realizados diversos experimentos científicos com o objetivo de se compreender melhor as interações entre as variáveis que envolvem dois tipos de ambientes, a floresta natural e as áreas de pastagens (área desmatada). Dentre os diversos experimentos, ressaltase o Projeto ABRACOS (Estudo Anglo-Brasileiro de Observação do Clima da Amazônia) cujo objetivo foi melhorar os modelos de previsão do tempo, em decorrência dos possiveis impactos climáticos, causados pela substituição da vegetação natural por cultivos agricolas ou pastos (Gash et al., 1996). Durante a realização desse experimento foram feitas medidas micrometeorológicas para três setores distintos na Amazônia (sudoeste, centro e leste). As medidas envolveram equipamentos sofisticados e pessoal especializado, adotando-se de metodologia internacionalmente definida como padrão micrometeorológico de estimativa de fluxos atmosféricos.

A água é um excelente moderador térmico devido ao seu alto calor específico, sendo o fluxo de calor latente fundamental na partição de energia disponivel à superficie. A substituição de floresta nativa por pastagens causa alteraçōes na partição do saldo de radiação, sendo tal fato relatado por diversos autores, entre eles Gash e Shuttleworth (1991), Lyra et al. (1994) e Souza (1997). Para a estimativa da 
evapotranspiração, no âmbito do ABRACOS, foi utilizado o equipamento Hydra, um dispositivo bastante sensivel, desenvolvido pelo Instituto de Hidrologia, Wallingford (IH/UK) (Shuttleworth et al., 1988; Wright et al., 1992), que utiliza a técnica de correlação dos vórtices turbulentos. Uma desvantagem deste método é que os instrumentos não são ainda robustos para medidas por longo periodo e não funcionam adequadamente se deixados sem uma manutenção diária.

Para se evitar essa situação, existem métodos que utilizam medidas produzidas por sensores mais robustos, porém, menos precisos, mas que podem gerar informações, até por algumas semanas, sem necessidade de manutenção diária. Para o caso do fluxo de calor latente, destaca-se aquele proposto por Priestley e Taylor (1972), que necessita apenas de medidas do saldo de radiação, do fluxo de calor sensivel no solo (no caso de vegetação de porte pequeno), e da temperatura do ar imediatamente acima da superficie evapotranspirante.

O presente estudo objetivou estimar.a evapotranspiração de áreas com florestas e com pastagem, para três sítios experimentais distintos (sudeste, central e leste da Amazônia) todos no âmbito do Projeto ABRACOS (1990-1994). O fluxo de calor latente estimado por correlação dos vórtices turbulentos, aqui adotado como padrão, será comparado com aquele estimado pelo método de Priestley e Taylor (1972), tanto na escala horária, quanto na diária. Foi também verificado se a parametrização proposta por Pereira e Villa Nova (1992), para o parâmetro de Priestley-Taylor, resulta em uma boa estimativa do fluxo de calor latente na região Amazônica. 


\section{2 - REVISÃO DE LITERATURA}

\section{1 - Conceitos e Definiçōes}

Evapotranspiração é o termo utilizado para a ocorrência simultânea de dois processos (físico e biofísico) comuns na natureza: evaporação e transpiração. A evaporação é o processo físico pelo qual uma substância (no caso a água) passa do estado líquido para o gasoso. E transpiração é a evaporação da água utilizada nos processo metabólicos das plantas, através dos estômatos. A evapotranspiração representa o transporte de água da superficie continental de volta para a atmosfera, sendo o contrário da precipitação (Thornthwaite, 1948). Penman (1948) demostrou que na ausência de qualquer controle na superficie terrestre, a evaporação depende unicamente das condições meteorológicas.

Dentro do termo evapotranspiração foram definidos conceitos segundo a disponibilidade de água (umidade) no solo e do poder (capacidade) evaporante do ar. Evapotranspiração Potencial é aquela onde as perdas ocorrem livremente no limite superior, ou seja, quando em nenhum instante, a demanda atmosferica é restringida por falta de suprimento de água no conjunto solo- planta (Costa et al.,1998). No entanto, quando não há umidade disponivel em quantidade suficiente a evapotranspiração freqüentemente é menor do que a que se verifica caso houvesse água plenamente disponivel no solo, sendo essa denominada de evapotranspiração real (Ayoade, 1996). 
Define-se evapotranspiração de equilíbrio como a menor evapotranspiração possivel de uma superficie sem restrição hidrica e pode ser calculada simplesmente em função da disponibilidade radiativa e da temperatura (Slater e McIlroy, 1961).

\section{2 - Fatores que afetam a Evapotranspiração}

$\mathrm{Na}$ atmosfera, é a troposfera a camada que detém a maior quantidade de água com cerca de $75 \%$ da massa gasosa total da atmosfera, e conseqüentemente a totalidade do vapor d'água e de aerossóis (Ayoade, 1996), e nessa camada, acontecem as principais trocas de energia. Dividindo a troposfera em camadas, segundo os mecanismos dominantes para as trocas de energia, encontramos a camada laminar ou superficial, que marca a interface entre o solo e a atmosfera. A transferência de energia nesta camada acontece por condução e difusão molecular; sendo as trocas de calor e umidade bastante lentas (camada limite laminar). Imediatamente acima, encontra-se a camada de atrito, cuja espessura depende do aquecimento/resfriamento da superficie (camada limite planetária). A transferência vertical de calor nesta camada ocorre predominantemente por meio de turbulência, isto é, por meio de movimentos de redemoinhos. A seguir, encontra-se a atmosfera livre, camada isenta dos efeitos do atrito, onde os ventos são mais fortes e determinados por sistemas meteorológicos de meso e escala sinótica. A transferência vertical de energia nesta camada, ocorre principalmente pela formação de nuvens. A água evaporada da superficie é transportada para o alto como vapor, e quando se condensa para formar as nuvens ocorre a liberação do calor latente (Ayoade, 1996). 
O suprimento de água para a atmosfera é proveniente da superficie terrestre através do solo nú, das superficies aquáticas e da transpiração das plantas. Dada a importância da água para plantas e animais, existe a preocupação com a evapotranspiração no ciclo hidrológico.

Evapotranspiração é um processo complexo influenciado por fatores como radiação líquida, estrutura do dossel, umidade, velocidade do vento, e estatus fisiológicos da água na vegetação (Baldocchi et al., 1985).

Evapotranspiração é um assunto relativamente simples do ponto de vista teórico, porém, no lado prático das medições, torna-se bastante complexo e dificil, principalmente em áreas remotas (Ometto, 1981).

A evapotranspiração é controlada pela disponibilidade de energia, pela demanda atmosférica, e pelo suprimento de água do solo às plantas. Penman (1956) alertava para o aspecto fundamental do balanço de radiação da superfície evaporante. A rugosidade da superficie é outro aspecto a ser considerado quando se compara resultados obtidos em vegetação com portes diferentes, pois ela impõe turbilhonamento mais intenso e trocas mais rápidas em áreas mais rugosas (Pereira et al., 1997).

A evapotranspiração pode ser estimada usando-se fórmulas ou modelos. Muitas delas são empíricas e não permitem estimativas razoáveis em locais diferentes daqueles para os quais elas foram deduzidas. As fórmulas que são teóricas, por natureza, são aplicáveis em qualquer lugar, embora tenham suas limitações. As fórmulas teóricas de evaporação se baseiam, em duas abordagens fundamentais a aerodinâmica e a do balanço energético. $\mathrm{Na}$ abordagem aerodinâmica, o fluxo de vapor, que advém de uma superficie onde ocorre evaporação, 
está relacionado ao processo de difusão turbulenta. A evaporação é expressa como uma função da velocidade do vento e do gradiente de pressão de vapor sobre a superfície evaporante. Isso exige a árdua e dificil tarefa de medir a velocidade do vento e a pressão do vapor na superficie onde ocorre evaporação ou perto dela, e num outro nivel, acima dela (Ayoade, 1996). A evapotranspiração de um sistema é dificil de ser medida e, muitas vezes, é praticamente impossivel sua determinação direta. Geralmente, calcula-se a evapotranspiração a partir de métodos empiricos em função de dados meteorológicos, e de coeficientes ajustados (Ribeiro et al., 1979).

Em função dos fatores (solo, planta e atmosfera) que afetam a evapotranspiração de suas complexas relações e das dificuldades técnicas à sua determinação, desenvolveram-se diversos métodos na tentativa de quantificá-la, dentre os quais pode-se citar o método de Priestley e Taylor (1972).

\section{3 - Evapotranspiração de Florestas}

Com o desenvolvimento de métodos e técnicas para se conhecer a evapotranspiração em culturas agricolas, consideráveis esforços foram dedicados para se entender, medir e calcular a evapotranspiração de florestas. Em principio, vários autores consideram complexas estas medidas (Shuttleworth e Calder, 1979; Baldocchi et al., 1985; Fritschen e Simpson, 1985).

Com relação a evapotranspiração, as culturas agrícolas diferem das florestas principalmente pelo porte. Shuttleworth e Calder (1979), caracterizando as florestas com relação às culturas agricolas, apontam o tamanho como fator principal. Em decorrência do tamanho, as florestas são aerodinamicamente mais rugosas. Devido a isso, 
quantidades significativas de calor sensivel são trocadas entre o ar e as folhas de forma que, mesmo em climas úmidos, a advecção do calor sensivel pode ser uma importante fonte de energia para a transpiração em florestas.

Com relação a outros fatores referentes às medidas da evapotranspiração em florestas, Fritschen e Simpson (1985) enumeram diversos fatores que influenciam as medidas e a modelagem dos processos calor sensivel e latente nas florestas. Segundo eles, a complexidade se origina da presença dos fatores solo-planta; pode existir múltiplas camadas de plantas; mudanças nos dosseis com a idade e a estação; aumento da profundidade das raizes com o desenvolvimento da copa; controle da taxas da transpiração ou evaporação pelos estômatos das plantas; reflexão de radiação da planta e mudanças na estrutura com a rugosidade; e por fim, o mecanismo de "feedback" que possui a planta o qual altera seu desenvolvimento e partição da fotossíntese em relação ao stress continuado.

Pesquisas foram feitas nas ultimas décadas para calcular e medir a evapotranspiração em florestas. Estas, foram ao longo dos anos, desenvolvendo-se apartir de metodologias e técnicas. Shuttleworth e Calder (1979) avaliaram a equação de Priestley-Taylor para estimar a evapotranspiração de floresta. Eles concluíram que devido à advecção e à altura da vegetação, o método de Priestley-Taylor é de uso limitado e advertem contra seu uso indiscriminado, e sugerem que o modelo seja ajustado empiricamente incluindo o termo de interceptação de água das chuvas.

Vários métodos foram utilizados para a estimativa da evapotranspiração em florestas, desde a instalação de lisimetros a técnicas mais aprimoradas como a da correlação dos vórtices turbulentos. 
Apesar dos gradientes de temperatura e de umidade do ar sobre o dossel serem pequenos devido à turbulência gerada pela rugosidade, a técnica da razão de Bowen foi usada com sucesso considerável (McNaugnton e Black, 1973; Black, 1979). O método de correlação dos vórtices turbulentos foi igualmente usados com sucesso razoável para determinar fluxos de energia em florestas. A correlação de vórtices foi usada para obter o fluxo de calor sensivel $(\mathrm{H})$. O fluxo de calor latente, foi calculado então combinando $\mathrm{H}$ com outras condiçōes medidas. Quando a velocidade do vento era moderada, o método obteve boas estimativas. Com baixas velocidades o método falhou devido a problemas associados com o protelar dos anemômetros mecânicos.

Fritschen e Simpson (1985) avaliaram a aplicação de diversos métodos para a determinação direta da evapotranspiração de florestas. Eles concluíram que os métodos da correlação dos vórtices turbulentos e do balanço de energia são apropriados para florestas. No entanto, apesar de no passado o método da correlação dos vórtices ser considerado complicado operacionalmente, devido a sua dificuldade instrumental, atualmente, esse método é bem mais plausivel.

Métodos meteorológicos - desses métodos, o método da

correlação do vórtices turbulentos não requer qualquer suposição (princípios) sobre os valores da difusividade dos vórtices Fritschen e Simpson (1985).

\section{4 - O Método de Priestley-Taylor}

Analisando observações lisimétricas de evapotranspiração, em condições aparentemente não advectivas, Priestley e Taylor (1972) propuseram uma simplificação da equação de Penman (1948), mantendo apenas o termo que contém o balanço de radiação corrigido 
por um coeficiente de ajuste $(\alpha)$. Em suma, $\alpha$ contém a radiação liquida particionada entre fluxo de calor e evaporação (Viswanadham et al., 1991). Esse método simplifica a estimativa da evapotranspiração, podendo ser acoplado a modelos numéricos de previsão do tempo, visto que a radiação liquida pode ser obtida em larga escala, por satélites meteorológicos. Em escala local, a radiação líquida pode ser estimada com observações obtidas rotineiramente em postos meteorológicos (Ometto, 1981, Pereira et al., 1998).

Bruin e Holtslac (1982) entendem que o método de PriestleyTaylor se aplica a superficies saturadas, especialmente as superficies de água livre e de solos cultivados sob condições de alta umidade. O modelo também foi testado para solo sob condições de restrição hídrica (Priestley e Taylor, 1972; Williams et al., 1978; Davies e Allen, 1973; Barton, 1979; Mukammal e Neumann, 1977; Sentelhas, 1998).

A vantagem da substituição do termo aerodinâmico da equação de Penman (1948) por uma constante $\alpha$, foi a de eliminar a necessidade de se especificar o mecanismo turbulento de transferência de calor, estes muito mais complexos de serem determinados. A determinação inicial de $\alpha$ foi feita por Priestley e Taylor (1972), que analisaram 11 conjuntos de informações, sendo três deles coletados em superficies vegetadas; um sobre solo nú recém arado, e outros sete, sobre superficies de água. Esse parâmetro, variou entre 1,08 e 1,34, sendo 1,26 o seu valor médio. $O$ parâmetro $\alpha$, variou conforme a cobertura da superficie, $\alpha=1,267$ (evaporação de superficies de água); $\alpha$ $=1,08$ (evaporação de solo nú) e $\alpha=1,323$ (evaporação de superficies vegetadas).

O método de Priestley-Taylor foi testado sob diferentes condiçōes de umidade, cobertura do solo, culturas e também sob variadas escala de tempo, (Tabela 1 ). 
Os valores do parâmetro de Priestley-Taylor variam significativamente dependendo da temperatura do ar e tendem a 1,26 para temperaturas entre 15 e $30^{\circ} \mathrm{C}$ (Davies e Allen, 1973; Stewart e Rouse, 1977). Thompson (1975) verificou valores de $\alpha=1,26$ para superficies úmidas. O valor de $\alpha$ depende da natureza da superficie e para floresta é próximo da unidade (Barton, 1979). Barton (1979) também sugere, assim como Davies e Allen (1973), que se $\alpha$ for uma função da umidade do solo na superficie, e que pode ser mais geral se $\alpha$ é modificado levando-se em conta as trocas que influem na umidade do solo sob condições não potenciais. Williams et al. (1978), não encontrou relação consistente entre $\alpha$ e a umidade do solo. Marsh et al. (1981) sugeriu uma equação relacionando $\alpha$ para a umidade do solo em um local no alto Ártico, concluindo que a relação foi especifica para o local. O valor de $\alpha$ decresce com o aumento da razão LE/Rn (Thompson, 1975; Pereira et al., 1997). Tanner e Jury (1976) afirmam que, quando os valores de $\mathrm{Rn}$ em 24 horas foram usados, $\alpha$ foi 1,35 $\pm 0,10$, dependendo da cultura e do clima local; no entanto, para valores diurnos de $\mathrm{Rn}$ com $\alpha$ foi menor. Jury e Tanner (1975) mostraram que $\alpha$ aumentou com advecção e sugeriram um procedimento para adaptação para condições advectivas. Kanemasu et al. (1980) constataram que mesmo com a correção de Jury e Tanner (1975), a evapotranspiração foi grosseiramente subestimada em condições de advecção. O valor de $\alpha$ varia linearmente com o fluxo de calor sensivel seguindo tendência positiva, nas escalas horárias e diária (Pereira e Villa Nova, 1992). 
Tabela 1 - Valores de alfa para diferentes superficies evapotranspirantes, sob diversas escalas de tempo e umidade.

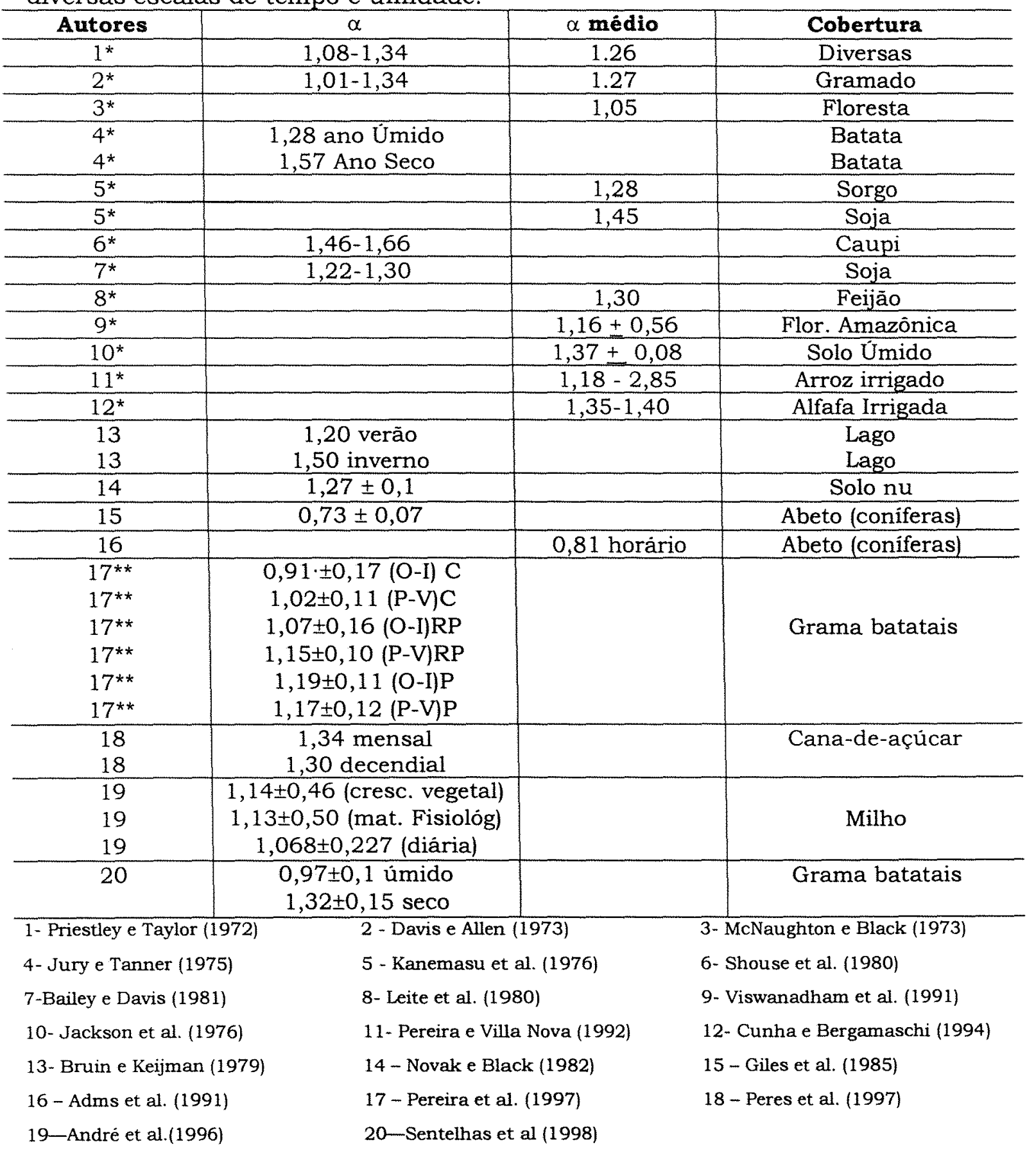

- ${ }^{\star}$ Fonte: Pereira et al, 1997a e 1997b; (O-I) Outono Inverno; (P-V) Primavera Verão; C Campinas; RP - Ribeirão Preto; P - Pindamonhagaba. 
Quanto às escalas de tempo, o parâmetro de Priestley-Taylor varia tanto na escala horária, como na diária, e na sazonal. $\mathrm{Na}$ escala horária, $\alpha$ varia continuamente para condições de saturação do solo (Priestley e Taylor, 1972; Bruin e Keijman, 1979; Tsann-Wang, 1977; Bailey e Davis, 1981; Choudhury e Idso, 1985; Viswanadram et al., 1991; Pereira e Villa Nova, 1992) e também sob condições de deficiência hídrica (Tsann-Wang, 1977). Aplicando-se o método ao longo do dia, para condições potenciais de evapotranspiraçāo, a variação de $\alpha$ tendeu a 1,26 (Priestley e Taylor, 1972; Davis e Allen, 1973; Jury e Tanner, 1975; Kanemasu et al., 1976; Stewart e Rouse, 1976 e 1977; Bruin e Keijman, 1979; Pereira e Villa Nova, 1992). No entanto, para uma cultura de arroz irrigado o valor de $\alpha=1,26$ não representa condições de advecção (Pereira e Villa Nova, 1992).

$\mathrm{Na}$ escala mensal, Cunha e Bergamaschi (1994), encontraram $\alpha=1,40 \pm 0,06$, para cultura da alfafa. Para cana-deaçúcar, sob as condiçōes climáticas de Araras, SP, Peres et al. (1997), encontraram $\alpha=1,34$, na escala mensal, e 1,30 na escala decendial, obtendo $\alpha$ médio de 1,32 .

$\mathrm{Na}$ escala sazonal, Bruin e Keijman (1979) observaram que mesmo para um lago, $\alpha$ apresentou uma variação entre verão e inverno, ou seja, $\alpha=1,20$ (verão) e 1,50 (inverno). Bailey e Davis (1981) mostraram que $\alpha$ decresce com o aumento no déficit de água no solo. A variação de $\alpha$ apresentou tendência de seguir a distribuição das chuvas durante o ano, sendo maior em periodos úmidos. Em periodos secos, ficou evidenciado o efeito advectivo resultando em valores elevados de $\alpha$ (Pereira, et al., 1997). Pereira e Villa Nova (1997), encontraram na escala sazonal diferentes valores de $\alpha$, para grama batatais (Paspalum notatum Flugge) em três cidades do Estado de São Paulo, utilizando evapotranspirometros de drenagem. Em Campinas o valor $\alpha$ obtido foi 


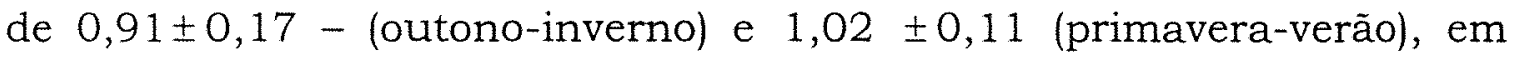
Ribeirão Preto $\alpha=1,07 \pm 0,16$ (outono-inverno) e 1,15 $\pm 0,10$ (primaveraverão), e em Pindamonhagaba $\alpha=1,19 \pm 0,11$ (outono-inverno) $\mathrm{e}$ $1,17 \pm 0,12$ (primavera-verão).

Considerando-se as variáveis de larga escala, $\alpha$ é primariamente determinado pela resistência da superficie e cresce assintoticamente com essa resistência. Simulaçōes numéricas para o modelo na camada limite atmosférica mostram que $(\alpha)$ não tem valor fixo, nem universal (Bruin, 1983; Lhomme, 1997).

$\mathrm{Na}$ escala horária, o parâmetro de Priestley-Taylor varia ao longo do dia, mostrando diferentes relaçōes, por exemplo: em forma de U, com minimo por volta do meio dia (Tsann-Wang, 1977; Bailey e Davies, 1981: Choudnury e Idso, 1985; Viswanadham, et al., 1991); em outros casos, o valor mínimo ocorre logo cedo, aumentando durante o dia (Bruin e Keijman, 1979) atingindo valores extremamente altos (Choudnury e Idso, 1985). À medida que a disponibilidade de água diminuiu $\alpha$ também decresceu linearmente (Priestley e Taylor, 1972; Williams et al., 1978), parabolicamente (Davies e Allen, 1973; Barton, 1979) e em forma sigmóide (Mukammal e Neumann, 1977). Tais variaçōes de $\alpha$ parecem estar associadas ao tipo de vegetação, ou seja, ao seu sistema radicular. A capacidade das raizes em explorar o solo e por sua vez, ficam mais suscetiveis às condições de disponibilidade hidrica (Pereira, 1990).

Usando duas séries de dados obtidos em duas florestas, Shuttleworth e Calder (1979) concluiram que o método de PriestleyTaylor é de uso limitado para vegetação alta onde existem grandes trocas turbulentas. No entanto, Viswanadham et al. (1991), usando a técnica de correlação de vórtices sobre a floresta Amazônica, encontraram que o método de Priestley-Taylor poderia ser aplicado com 
bons resultados. Ao avaliarem o parâmetro de Priestley-Taylor para a Amazônia, eles verificaram que $\alpha$, além de ser uma função da velocidade do vento, e das resistências aerodinâmicas e superficial, também sofre influência da advecção. Além disso, o método deve ser usado para intervalos de tempo de um dia ou menos, devido à sensibilidade das variações de $\alpha$.

Ribeiro (1994) constatou, para a parte leste da Amazônia (Marabá, PA), variação sazonal do parâmetro $\alpha$, com valores maiores na estação seca, sendo os valores médio de 1,26 para a pastagem e de 1,31 para a floresta.

\section{5 - O Método da Correlação dos Vórtices Turbulentos}

Esse método está baseado nos redemoinhos que acontecem na atmosfera, onde turbilhões mais aquecidos e mais úmidos gerados próximos à superfície são deslocados verticalmente, sendo substituidos por turbilhões menos aquecidos e mais ou menos úmidos, resultando em transporte vertical dessas propriedades atmosféricas.

O método da correlação dos turbilhões foi proposto por Swinbank, em 1951, e requer um pequeno valor para a constante de tempo (centésimo de segundo), anemômetros verticais e sensores de pressão de vapor. Esses instrumentos, são utilizados em conjunto com microprocessadores e sistemas automáticos de aquisição de dados, que facilitam a utilização do método para medições de rotina de campo (Sediyama, 1996).

As interações entre atmosfera e superficie originam turbilhões que ao longo do tempo, irão se misturar aleatoriamente a outros turbilhões mudando de posição e de nivel. Num escoamento turbulento, ocorrem variaçōes nas propriedades atmosféricas a cada 
momento. Este método só é aplicado com instrumentação sofisticada, sendo justificado apenas em projetos de pesquisa de pequena duração, pois necessita de medidas das flutuações instantâneas das propriedades atmosféricas (Pereira et al., 1997). 


\section{3- MATERIAL E MÉTODOS}

Os dados micrometeorológicos aqui utilizados são provenientes do Projeto ABRACOS (Anglo-Brazilian Amazonian Climate Observation Study) cujo objetivo foi coletar informações em ambiente de floresta nativa e pastagem, para analisar possiveis mudanças climáticas associadas ao desmatamento.

O periodo de dados disponiveis foi de 1990 a 1994, para três locais na Amazônia, compreendendo sítios de floresta e de pastagem: JiParaná - RO (sudoeste); Manaus - AM (central) e Marabá - PA (Leste).

Os dados micrometeorológicos são provenientes de estações meteorológicas automáticas (EMA) e as medidas de fluxos foram realizadas pelo equipamento HYDRA, descrito na seção 3.2.

Os dados estão disponiveis na home page do Instituto Nacional de Pesquisas Espaciais/Centro de Previsão do Tempo e Estudos Climáticos, INPE/CPTEC (http://www.cptec.inpe.br/abracos).

\section{1 - Localização dos Sitios}

A área estudada se limita a cinco sitios experimentais, compreendendo floresta e pastagem. Os sítios florestais são áreas nativas, enquanto que as pastagens correspondem a antigas florestas onde a vegetação primitiva foi substituida por vegetação rasteira.

Embora os sitios experimentais sejam todos amazônicos, as localidades diferem com relação a duração da estação seca, à extensão 
espacial das áreas de pastagem, e à proximidade ao Oceano Atlântico. As áreas do projeto ABRACOS, compreendem os Estados do Amazonas, Pará e Rondônia (Figura 1).

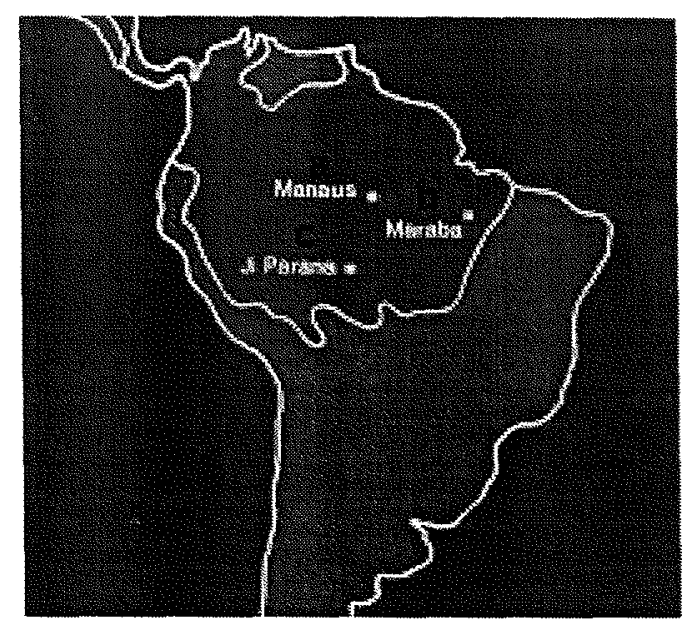

Figura 1 - Áreas experimentais do Projeto ABRACOS. FONTE: Instituto de Hydrologia (HI); 1994

A localização dos sitios experimentais é a seguinte:

a) Área desmatada próxima a Manaus, AM central: Fazenda Dimona ( $\left.2^{\circ} 19^{\prime} \mathrm{S}, 60^{\circ} 19^{\prime} \mathrm{W} ; 80 \mathrm{~m}\right)$;

b) Imediações de Marabá, PA, próxima à margem oriental da floresta: Fazenda Boa Sorte ( $\left.5^{\circ} 10^{\prime} \mathrm{S}, 48^{\circ} 45^{\prime} \mathrm{W} ; 170 \mathrm{~m}\right)$, e Reserva Vale do Rio Doce (545's, 49¹0`W; 150m);

c) Ji-Paraná, RO, próximo ao limite Sudoeste da floresta: Fazenda Nossa

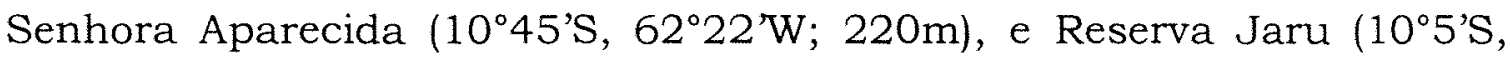
$\left.61^{\circ} 55^{`} \mathrm{~W} ; 120 \mathrm{~m}\right)$.

Como complementação deste item, nas Tabelas 2 e 3 são apresentados os anos em que ocorreram o experimento, assim como as datas (início e fim) para cada um dos sítios. 
Tabela 2 - Periodo do Experimento para os sitios Pastagem, Projeto ABRACOS

\begin{tabular}{l|c|c|c}
\hline Sitios (PASTAGEM) & Ano & \multicolumn{2}{|c}{ EXPERIMENTO } \\
\cline { 3 - 4 } & & Inicio & Fim \\
\hline Faz. Dimona - Manaus (AM) & 1990 & 18 Setembro & 2 Novembro \\
& 1991 & 29 Junho & 11 Setembro \\
\hline & 1992 & 06 Agosto & 7 Outubro \\
Faz. Nossa Senhora Aparecida - & 1993 & 31 de Março & 28 de Julho \\
Ji-Paraná (RO) & 1994 & 11 de Agosto & 24 de Agosto \\
\hline Faz. Boa Sorte - Marabá (PA) & 1993 & 05 de Agosto & 26 de Outubro \\
\hline
\end{tabular}

Tabela 3 - Periodo do Experimento para os sitios Floresta, Projeto ABRACOS

\begin{tabular}{l|c|c|c}
\hline Sitios (FLORESTA) & \multirow{2}{*}{ Ano } & \multicolumn{2}{|c}{ EXPERIMENTO } \\
\cline { 2 - 4 } & & Inicio & Fim \\
\hline Reserva Jaru - Ji-Paraná (RO) & 1992 & 08 Agosto & 7 Outubro \\
\cline { 2 - 4 } & 1993 & 4 de Abril & 26 de Julho \\
\cline { 2 - 4 } & 1994 & 13 de Agosto & 25 de Agosto \\
\hline Reserva Vale - Marabá (PA) & 1993 & 18 de Agosto & 27 de Outubro \\
\hline
\end{tabular}

\section{2 - Instrumentação}

Os fluxos de calor latente e calor sensivel foram medidos com o Hydra (descrito detalhadamente por Lloyd et al., 1984; Shuttleworth et al., 1988; e Wright et al., 1992), que é um dispositivo eletrônico de correlação de vórtices desenvolvido pelo Instituto de Hidrologia, de Wallingford $(\mathrm{IH} / \mathrm{UK})$. As medidas de radiação liquida, fluxo de calor no solo, velocidade do vento, umidade especifica e temperatura do ar foram obtidas usando-se estação meteorológica automática (EMA).

\subsection{1 - Hydra}

O Hydra (modelo MK2) é um sistema eletrônico de medida, de coleta, e de processamento de dados, controlado por microprocessador. As medidas obtidas dos diversos sensores são 
tomadas com uma freqüência de $10 \mathrm{~Hz}$ (10 vezes por segundo) e calculase os fluxos de calor, de vapor e de momentum, em tempo real. Essa técnica é bastante atraente porque proporciona medidas diretas desses fluxos a partir de algumas suposições teóricas. $O$ equipamento é mostrado na Figura 2A e B.

(A)

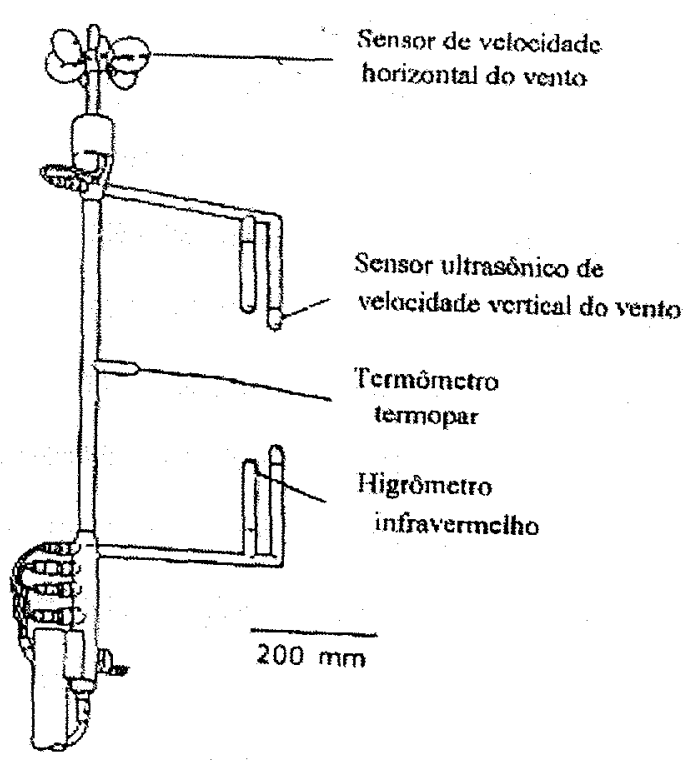

(B)

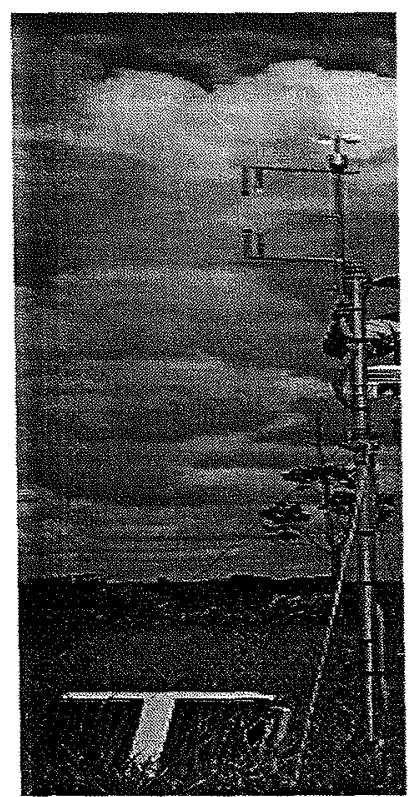

Figura 2 - (A) Esquema do instrumento Hydra e (B) equipamento Hydra montado na Fazenda Nossa Senhora Aparecida - Ji-Paraná (RO). FONTE: (A) Dallarosa, 1996; Instituto de Hidrologia (HI) 1994.

Cada medida é armazenada em memória, sendo utilizada para posterior cálculo do valor médio da variável, na freqüência de 10 ciclos por segundo, e também dos desvios, em relação à média, de cada valor medido. A correlação entre os desvios instantâneos de duas variáveis fornecem uma estimativa do fluxo no intervalo de tempo. Como o elemento transportado é um turbilhão que se desloca verticalmente, há necessidade de se medir a velocidade de deslocamento vertical e seu sentido (para cima ou para baixo). Os desvios dessa velocidade vertical 
serão correlacionados com os desvios de outras variáveis resultando nos respectivos fluxos turbulentos.

Portanto, o sistema é constituido de um anemômetro sônico para a medida da velocidade vertical (Shuttleworth et al., 1992); um higrômetro de absorção de feixe único, de $26 \mu \mathrm{m}$ (Moore, 1983), para medida da concentração de vapor d'água na atmosfera naquela posição; um termopar, com espessura de $50 \mu \mathrm{m}$, para medida da temperatura do ar entre os sensores sônicos; e um anemômetro propulsor (de concha), de resposta rápida, para medida da velocidade horizontal. Os sensores estão interligados ao microprocessador (RCA 1920, CMOS), acoplado ao Hydra, permitindo os cálculos dos fluxos diretamente, das variâncias e dos valores médios, sendo os dados armazenados num módulo de estado sólido (G.K. Instruments) substituivel, de onde são retirados por meio de uma interface para posterior análise em microcomputador. A energia para operação do sistema era fornecida por baterias automotivas, que eram recarregadas por painéis solares.

Segundo Dallarosa (1996), o Hydra não fornece medidas confiáveis em condições de alta umidade, pois os sensores levam geralmente uma hora para secar após uma chuva. Portanto, os dados produzidos com até 03 horas da precipitação não foram utilizados nas análises.

\subsection{2 - Estações Meteorológicas Automáticas (EMA)}

A Estação Meteorológica Automática (Didcot Instruments Co Ltd, Abingdon-UK), utilizada nos experimentos, forneceu medidas horárias obtidas por um microprocessador (CR10 data logger, Campbell Scientific). A calibração desses instrumentos foi efetuada pela comparação com instrumental micrometeorológico, com a finalidade de 
otimizar os dados pela estação automática (Wright et al., 1992). A estação meteorológica automática (EMA) era constituída de uma unidade lógica contendo o software que gerencia sua operação da mesma, e armazena os dados que são retirados por meio de um módulo de armazenagem (SM192, Campbell Scientific). Os dados são médias horárias obtidas de valores integrados das variáveis meteorológicas a cada $10 \mathrm{~min}$. O sistema de alimentação era constituído de uma bateria automotiva recarregada por painéis solares.

A EMA possuia:

- Psicrômetro- conjunto composto por um pequeno ventilador e dois termômetros de resistência de platina sendo, um seco e outro molhado, desenvolvido pelo Instituto de Hidrologia (IH/UK), com precisão de $\pm 0,1^{\circ} \mathrm{C}$.

- Solarimetro - tipo CM-5 Kipp \& Zonen (Delft, Netherlands) para medir radiação solar global (direta + difusa) e radiação refletida pela superficie. As medidas da energia solar são feitas entre 0,3 e 3,0 $\mu \mathrm{m}$, e com precisão de $\pm 1 \%$.

- Radiômetro liquido - tipo Q6 (REBS, Seattle, USA), constituído de uma micropilha diferencial com face dupla, sensivel a todos os comprimentos de onda, e protegido das intempéries por um invólucro de polietileno. A calibração indicou um erro inferior a $3 \%$.

- Pluviômetro de balança - tipo DRG3 (Didcot Instr. Co Ltd, Abingdon, UK) constituído de um cilindro de aço inoxidável, com $200 \mathrm{~mm}$ de diâmetro. Especificações técnicas indica uma resolução de leitura de $0,2 \mathrm{~mm}$.

- Anemômetro Horizontal - tipo DWR 201, de concha metálica de desenho simples e robusto, fornecendo medidas de velocidade horizontal do vento (em $\mathrm{m} . \mathrm{s}^{-1}$ ) associado a um catavento do tipo DWD 103, fornecendo a indicação da direção do vento, em graus (a partir 
do Norte e no sentido horário), ambos da Didcot Instruments (Abingdon, UK).

- Placas de fluxo de calor no solo - modelo 610 (Thornthwaite, Elmer, New Jersey, USA), instalados a profundidade de $5 \mathrm{~cm}$, fornecendo medidas de fluxo de calor no solo $\left(\mathrm{em} \mathrm{Wm}^{-2}\right)$.

\section{3 - Método da Correlação dos Vórtices Turbulentos}

Um turbilhão ao se deslocar verticalmente induz o aparecimento de uma corrente vertical com velocidade (w). Sob estas condições, a densidade de fluxo vertical $(\mathrm{F})$ de uma propriedade atmosférica qualquer $(\mathrm{P})$, num dado instante, é dada por :

$$
\mathrm{F}=-\mathrm{wP}
$$

A densidade de fluxo média $\overline{(F)}$, para uma dado intervalo de tempo é dada pela média do produto $\overline{w P}$. Assim, podemos expressar $\bar{F}$ como:

$$
\bar{F}=-\overline{w P}
$$

Como $\bar{w}=0 ;$ logo, $\bar{w} \cdot \bar{P}=0$, significando que o produto $w P$ deve ser obtido a cada instante, antes de se obter o valor médio do produto ou seja:

$$
\overline{w P}=\frac{\sum w_{i} P_{i}}{N}
$$

sendo, $\mathrm{N}$ o número de observações, e $\mathrm{i}=1,2, \ldots, \mathrm{N}$.

Num escoamento turbulento, em função da movimentaçāo dos turbilhões, as propriedades atmosféricas variam a cada instante. Nesse periodo $(\Delta \mathrm{t})$, obtém-se uma velocidade média $(\bar{w})$ dada pela expressão:

$$
\bar{w}=(\Delta t)^{-1} \int_{t i}^{t f} w d t
$$


Para um dado instante, a velocidade vertical (w) será dada por:

$$
w=\bar{w}+w
$$

sendo $w^{\prime}$ o desvio da média, também chamado de perturbação ou flutuação.

Tendo em vista que o escoamento seja composto por um escoamento médio, sobreposto por um escoamento turbulento, originando desta forma, a teoria da perturbação (notação de Reynolds), três regras básicas são consideradas:

Admitido-se que a e b sejam quantidades variáveis, e que admitem média e desvio, e que c seja uma constante, tem-se:

1 - a média da soma é igual a soma das médias, isto é:

$$
\overline{a+b}=\bar{a}+\bar{b}
$$

2 - a média do produto de uma constante por uma variável é igual ao produto da constante pela média da variável, ou seja:

$$
\overline{c a}=c \bar{a}
$$

3 - a média do produto entre a média de uma variável e outra variável é igual ao produto das duas variáveis, sendo:

$$
\overline{\bar{a} b}=\bar{a} \bar{b}=\overline{a b}
$$

Aplicando-se essas três regras à equação da velocidade horizontal instantânea (w) tem-se:

$$
\begin{gathered}
w=\bar{w}+w \\
\bar{w}=\overline{\bar{w}+w}=\overline{\bar{w}}+\bar{w}=\bar{w}+\bar{w}
\end{gathered}
$$

Usando-se a notação de Reynolds, a equação da densidade de fluxo resulta em:

$$
\begin{gathered}
-\bar{F}=\overline{\left(\bar{w}+w^{\prime}\right)(\bar{P}+P)}=\overline{\overline{w P}+\bar{w} P^{\prime}+w^{\prime} \bar{P}+w^{\prime} P^{\prime}} \\
-\bar{F}=\overline{\bar{w} \bar{P}}+\bar{w} \overline{P^{\prime}}+\overline{w^{\prime}} \overline{\bar{P}}+\overline{w^{\prime} P^{\prime}}
\end{gathered}
$$




$$
-\bar{F}=\bar{w} \vec{P}+\overline{w^{\prime} P}
$$

pois próximo à superficie, $\bar{w}=0$ e $\bar{w}^{\prime}=\bar{P}^{\prime}=0$. Assim, a densidade média de fluxo turbulento é dada principalmente pela média do produto das flutuações da velocidade vertical ( $\mathrm{w}^{\prime}$ ) e da propriedade atmosférica ( $\mathrm{P}^{\prime}$ ) que está sendo transportada.

No caso da propriedade transportada ser o calor sensivel

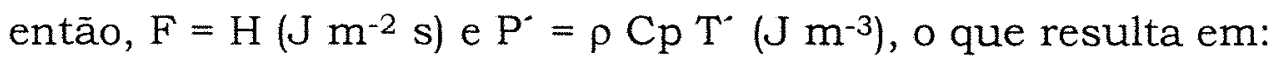

$$
H=-\rho \cdot C p \cdot \bar{w} \cdot T^{.}
$$

Similarmente para o calor latente, $\mathrm{P}^{\prime}=\rho \lambda \mathrm{q}^{\prime}\left(\mathrm{J} \mathrm{m}^{-3}\right)$ e $\mathrm{F}=\lambda \mathrm{E}\left(\mathrm{J} \mathrm{m}^{-2} \mathrm{~s}\right)$, ou seja:

$$
\lambda E=-\rho \lambda \overline{w^{\prime} q^{\prime}}=-\rho \lambda(\varepsilon / p) \overline{w^{\prime} e^{\prime}}
$$

sendo: Cp o calor específico do ar à pressão constante (=1005 $\left.\mathrm{J} \mathrm{kg}^{-1} \mathrm{~K}^{-1}\right)$; $\lambda$ é o calor latente de evaporação $\left(\lambda=2,45 \mathrm{MJ} \mathrm{kg}^{-1}\right.$, para $\left.\mathrm{T}=20^{\circ} \mathrm{C}\right) ; \mathrm{q}$ a umidade específica do $\operatorname{ar}(\mathrm{q}=\varepsilon \mathrm{e} / \mathrm{p}) ; \varepsilon=0,622$ é a razão entre a massa molecular do vapor d'água $\left(\cong 18 \mathrm{~g} \mathrm{~mol}^{-1}\right)$ e a massa molecular do ar $(\cong 29 \mathrm{~g}$ $\left.\mathrm{mol}^{-1}\right), \mathrm{p}$ é a pressão atmosférica, e e é a pressão atual de vapor atmosférico.

\section{4 - O Método de Priestley-Taylor e a Parametrização proposta por Pereira e Villa Nova (1992).}

O método de Priestley-Taylor é representado pela equação:

$$
\lambda E=\alpha[s /(s+\gamma)](R n-G) .
$$

em que: $\lambda E$ é o fluxo de calor latente; $\alpha$ é o coeficiente de PriestleyTaylor; s é a tangente à curva de tensão de saturação do vapor d'água 
no ponto dado pela temperatura do ar; $\gamma$ o coeficiente psicrométrico; Rn a radiação liquida e $\mathrm{G}$ o fluxo de calor no solo.

Fazendo-se $\alpha=1$, a equação acima, estima a evapotranspiração de equilibrio definida por Slatyer e McIlroy (1961). O fator $s /(s+\gamma)$ conhecido como $\mathrm{W}$, é uma função fraca da temperatura do ar e pode ser estimado pelas equações propostas por Wilson e Rouse (1972) e Viswanadham et al. (1991), sendo

Para $0^{\circ} \mathrm{C} \leq \mathrm{T} \leq 16^{\circ} \mathrm{C}$

$$
\mathrm{W}=0,407+0,0145 \mathrm{~T}
$$

Para $16,1^{\circ} \mathrm{C} \leq \mathrm{T} \leq 31^{\circ} \mathrm{C}$

$$
\mathrm{W}=0,483+0,0101 \mathrm{~T}
$$

Para $31,1^{\circ} \mathrm{C} \leq \mathrm{T} \leq 50^{\circ} \mathrm{C}$

$$
\mathrm{W}=0,634+0,0054 \mathrm{~T}
$$

A razão entre o calor sensivel $(\mathrm{H})$ e o calor latente (LE) foi proposto por Bowen em 1926, sendo

$$
\beta=\frac{H}{L E}
$$

O balanço de energia com a razão de Bowen ( $\beta$ ) para uma vegetação de pequeno porte, pode ser descrita por:

$$
L E=\frac{R n-G}{1+\beta}, \text { para } \beta \neq 1
$$

Igualando-se as Equaçōes 16 e 21, resulta em

$$
\alpha=\frac{1}{[w(1+\beta)]}
$$

Estudando o balanço de energia de uma cultura de arroz irrigado para três séries de dados, uma representativa de arroz para Campinas, SP, e duas outras para Davis, Califórnia, sob a condição de ocorrência de chuva (até $20 \mathrm{~mm}$ ) até três dias antes das observações, Pereira e Villa Nova (1992) concluíram que a variação de $(\alpha)$ é governada 
principalmente pela densidade de fluxo de calor sensivel (H). A partir de uma relação linear positiva encontrada entre $\alpha$ e $\mathrm{H}$, foram determinadas as relações estatísticas:

$$
\begin{aligned}
& \hat{\alpha}=1,44+3,1810^{-3} \mathrm{H} \text { para Campinas, } \mathrm{SP} \\
& \hat{\alpha}=1,33+2,7810^{-3} \mathrm{H} \text { para Davis, } \mathrm{CA} \\
& \hat{\alpha}=1,46+3,4210^{-3} \mathrm{H} \text { para Davis, } \mathrm{CA} \\
& \text { sendo, } \mathrm{H}\left(\mathrm{W} \mathrm{m}^{-2}\right) \text { o fluxo de calor sensivel. }
\end{aligned}
$$

As equações 23, 24 e 25, tanto para Campinas, SP, quanto para Davis, foram calculadas para a cultura de arroz irrigado e grama. As relações estatísticas encontradas para Davis, CA foram encontradas como os dados de Pruit e Lourence em 1966 (Equação 24) e com os dados de Morgan et al., para 1971 (Equação 25).

Para a estimativa do calor latente, foram considerados os dias sem precipitação, no periodo diurno entre 8 e 17 horas. O calor latente e o parâmetro de Priestley-Taylor estimado foi comparado com o medido nas escalas horárias e diárias. O calor latente foi estimado testando-se as relações estatísticas propostas por Pereira e Villa Nova (1992) para $\alpha$ e comparado com o calor latente medido (método da correlaçāo dos turbilhões).

Diante da melhor correlação obtida com $\alpha$ proposto por Pereira e Villa Nova, foram feitas outras correlações, considerando-se cada dia juliano separadamente. Para este estudo, foi considerado para cada sitio (floresta e pastagem) o dia juliano com o maior e o menor coeficiente angular. A proposição feita por Pereira e Villa Nova, ou seja, a equação que apresentou o melhor resultado foi comparada com o parâmetro de Priestley-Taylor medido. Neste estudo representado pela Equação 22. 


\section{4 - RESULTADOS E DISCUSSÃO}

\section{1 - Estimativa da Evapotranspiração pelo Método de Priestley- Taylor}

\subsection{1 - Escala Horária}

As correlações obtidas entre os fluxos de calor latente estimado pelo método de Priestley e Taylor com $\alpha$ proposto por Pereira e Villa Nova (1992) e medidos pelo Hydra, para todos os sitios do Projeto ABRACOS são apresentadas nas Figuras 3 e 4 . Nessas Figuras estão incluidos os dados referentes a todo o periodo em que ocorreu o experimento (1990/1994), sendo dispostas em três colunas. $\mathrm{Na}$ coluna 1 , são mostrados os resultados referente aos valores do parâmetro de Priestley-Taylor estimados pela equação $\alpha_{1}=1,33+2,7810^{-3} \mathrm{H}$; desenvolvida para Davis, CA. Na coluna 2, as estimativas foram com $\alpha_{2}$ $=1,44+3,1810^{-3} \mathrm{H}$, desenvolvida para Campinas, SP; e na coluna $3, \alpha_{3}$ $=1,46+3,4210^{-3} \mathrm{H}$, também desenvolvida para Davis, $\mathrm{CA}$, porém com outro conjunto de dados. Nessas Figuras, as linhas de A a C representam a Reserva Biológica do Jaru, respectivamente, para 1992, 1993 e 1994; enquanto que a linha D representa a Reserva Vale, para 1993. Na Figura 4, as linhas E e F são para pastagem na Fazenda Dimona (1990 e 1991).

Tanto na floresta quanto na pastagem, os coeficientes angulares das retas de regressão linear forçados pela origem $(Y=b$ X) 
que mais se aproximaram da unidade (declividade $=1$ ) foram aqueles da primeira coluna, ou seja, onde os valores observados de $b$, foram maiores, obtendo-se assim, a melhor precisão. Quanto aos valores de $\mathrm{R}^{2}$, estes foram considerados apenas como uma idéia de acurácia dos dados. Observa-se que os coeficientes angulares são pouco maiores nas florestas que nas pastagens, representando melhores estimativas na primeira condição. Em todas as situações, houve superestimativa, sendo que nas áreas de floresta elas variaram de 11,3\% (Figura 3A1) a 22\% (Figura 3C3). Comparando-se apenas os resultados relativos ao parâmetro $\alpha_{1}$, que produziu as melhores estimativas, observa-se que a superestimativa ficou entre $11,3 \%$ e $16 \%$ (Figura 3C1).

No caso das pastagens, a superestimativa variou de $14,3 \%$ (Figura 4B1) a 26,7\% (Figura 4A2). Novamente, comparando-se apenas as estimativas com $\alpha_{1}$, com os melhores resultados, a variação ficou entre $14,3 \%$ e $22,6 \%$ (Figura $4 \mathrm{~A} 1$ ).

Os resultados apresentados nas Figuras 3 e 4, indicam que as melhores estimativas para o fluxo de calor latente foram aquelas em que $\alpha_{1}=1,33+2,7810^{-3} \mathrm{H}$, e doravante os resultados e as análises serão feitas apenas para $\alpha_{1}$.

Foram correlacionados o calor latente estimado (PriestleyTaylor) com o medido (Hydra) para cada dia juliano, segundo o sítio (floresta ou pastagem) e a época do experimento. As Figuras 5, 6 e 7, mostram as correlações. $\mathrm{Na}$ primeira coluna, estão dispostos os dias com as melhores estimativas, enquanto na segunda coluna, estão dispostos os dias com as piores estimativas. As linhas, relacionadas as letras A, B, C e D, referem-se aos sitios e aos anos em que ocorreram o experimento.

Foi observado que tanto para a floresta quanto para a pastagem, a estimativa de Priestley-Taylor superestimou o calor latente 
medido pelo Hydra, exceto para o dia juliano 188 (Figura 6B1), apresentando uma boa estimativa, sendo a correlação quase perfeita (coeficiente angular $\approx 1$ ).
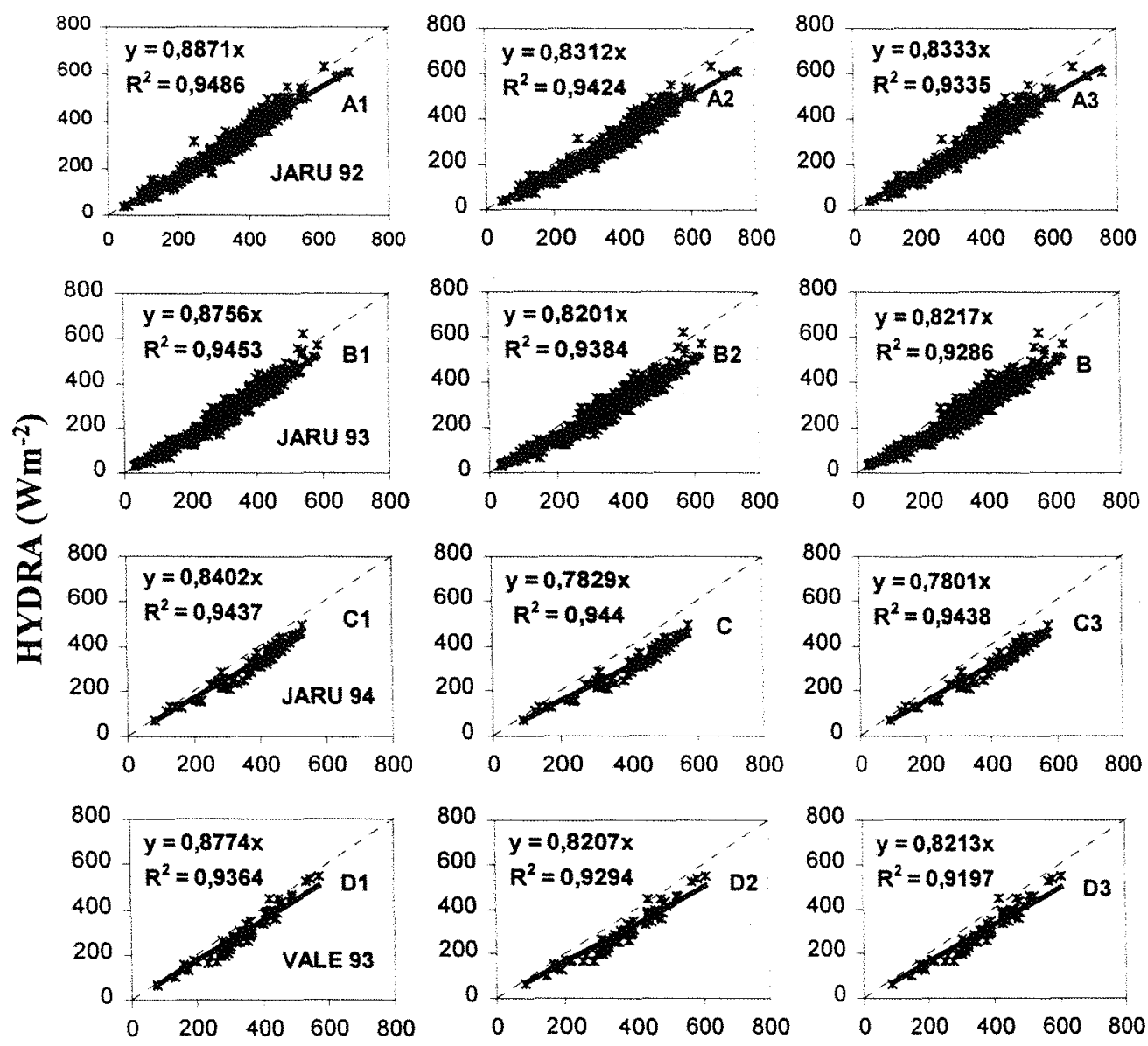

\section{PRIESTLEY-TAYLOR $\left(\mathrm{Wm}^{-2}\right)$}

Figura 3 - Fluxo de calor latente para os sítios na floresta, com $\alpha$ propostos por Pereira e Villa Nova (1992), para as colunas $1\left(\alpha_{1}\right) ; 2\left(\alpha_{2}\right)$ e $3\left(\alpha_{3}\right)$.

Considerando todos os outros dias para os sitios em questão, foi verificado que a maior superestimativa $(38,37 \%)$ ocorreu para o dia juliano 226 (Figura $6 \mathrm{~A} 2$ ) e a menor $(\approx 2 \%$ ) foi verificada para o dia juliano 188 (Figura 6B1) ambos os casos observados na pastagem. 

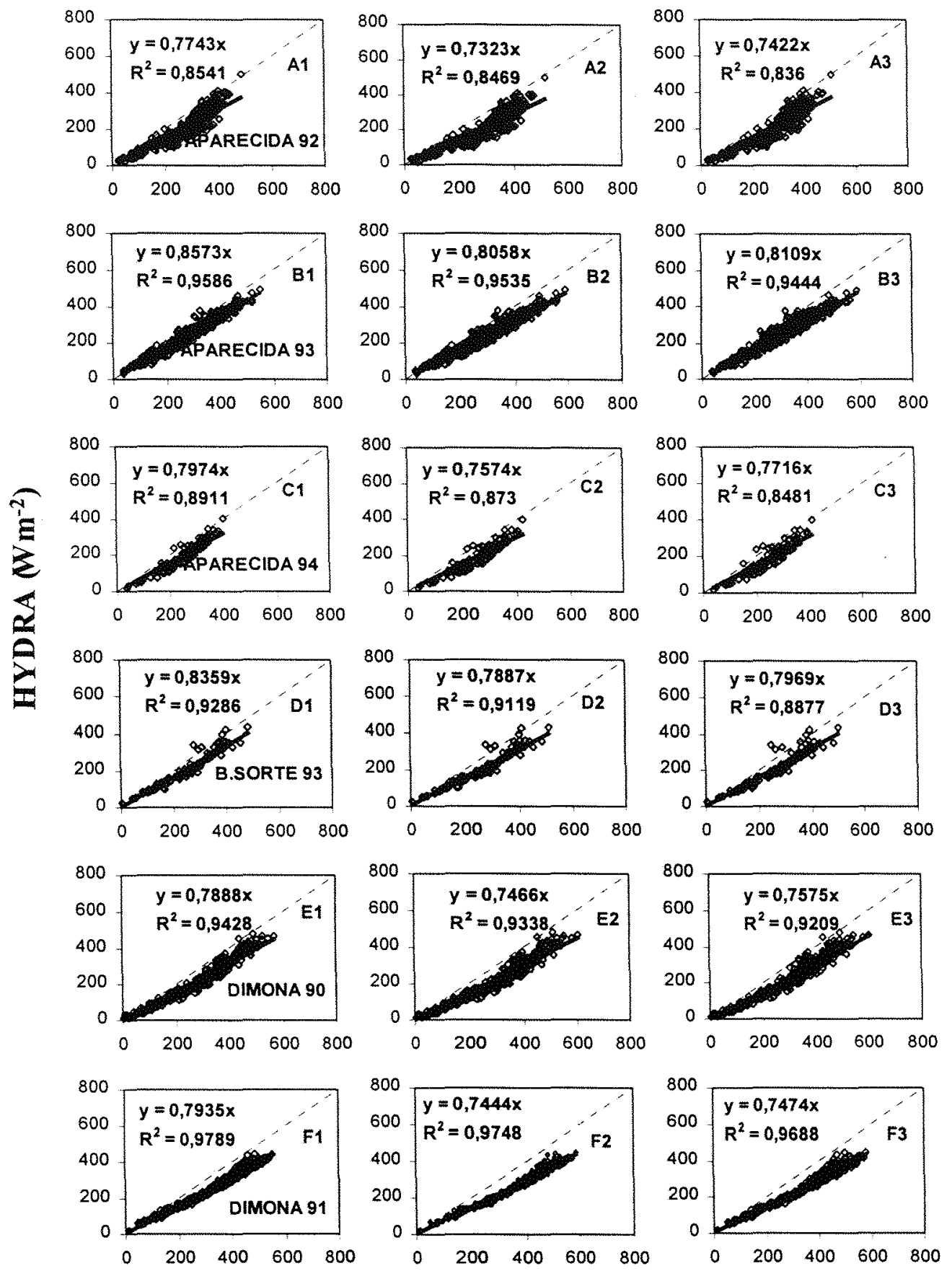

PRIESTLEY-TAYLOR ( $\left.\mathrm{W} \mathrm{m}^{-2}\right)$

Figura 4 - Fluxo de calor latente para os sitios na pastagem, com $\alpha$ propostos por Pereira e Villa Nova (1992), para as colunas $1\left(\alpha_{1}\right) ; 2\left(\alpha_{2}\right)$ e $3\left(\alpha_{3}\right)$. 
Com relação a floresta, a melhor estimativa $(3,22 \%)$ foi observada para o dia juliano 195 (Figura 5B1), enquanto que o dia juliano 233 (Figura 5C2), apresentou a maior estimativa, sendo de $19,65 \%$.

Comparando-se o ano de 1994 entre floresta (Figura 5C1 e $5 \mathrm{C} 2$ ) e pastagem, (Figura $6 \mathrm{C} 1$ e $6 \mathrm{C} 2$ ) para Ji-Paraná, observou-se que praticamente não houve diferenças entre as superestimativas para os dias julianos 288 e 233. Para o dia juliano 288, foi de apenas $1,5 \%$ e para o dia juliano 233 , foi de $7,4 \%$, sempre apresentado as melhores estimativas na floresta.

Para a Fazenda Dimona, a melhor estimativa foi observada no dia juliano 282 (Figura 7A1), sendo o desvio médio de apenas +2 , $66 \%$. A pior estimativa, também ocorreu para 1990 , com $+34,48 \%$, no dia juliano 303 (Figura 7A2).

As melhores estimativas na floresta, considerando-se apenas (coluna 1 somente foram superadas pelos dias julianos $188 \mathrm{e}$ 283 observados na pastagem, enquanto que, na coluna 2 , as melhores estimativas foram observadas na floresta.

Considerando-se apenas a primeira coluna $\left(\alpha_{1}\right)$ das Figuras $3,4,5,6$ e 7 , observa-se que os sitios pastagens, apresentaram as maiores amplitudes com relação as estimativas que os sitios florestas. Esta constatação deve estar relacionada as condições de umidade entre os dois ambientes, ou seja, as florestas são mais úmidas que as pastagens e podem ser consideradas como superficies sem restrição hidrica. 

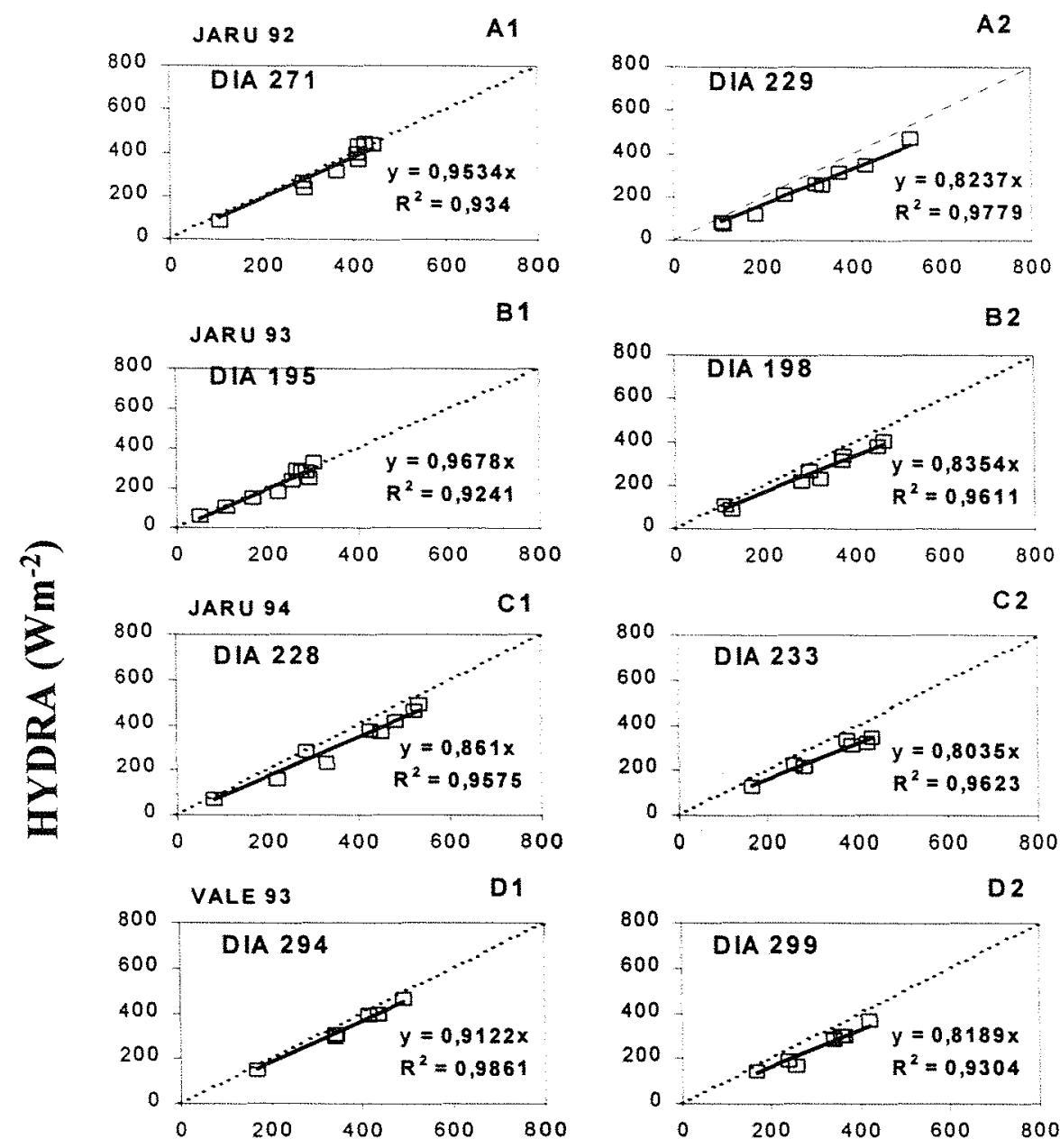

\section{PRIESTLEY-TAYLOR $\left(\mathrm{Wm}^{-2}\right)$}

Figura 5 - Fluxo de calor latente, na escala horária, para as Reservas Biológica do Jaru (Ji-Paraná, RO) e Vale do Rio Doce (Marabá, PA), para A (1992), B e D (1993) e C (1994). Coluna 1: Dias com melhores estimativas; Coluna 2: Dias com piores estimativas. 

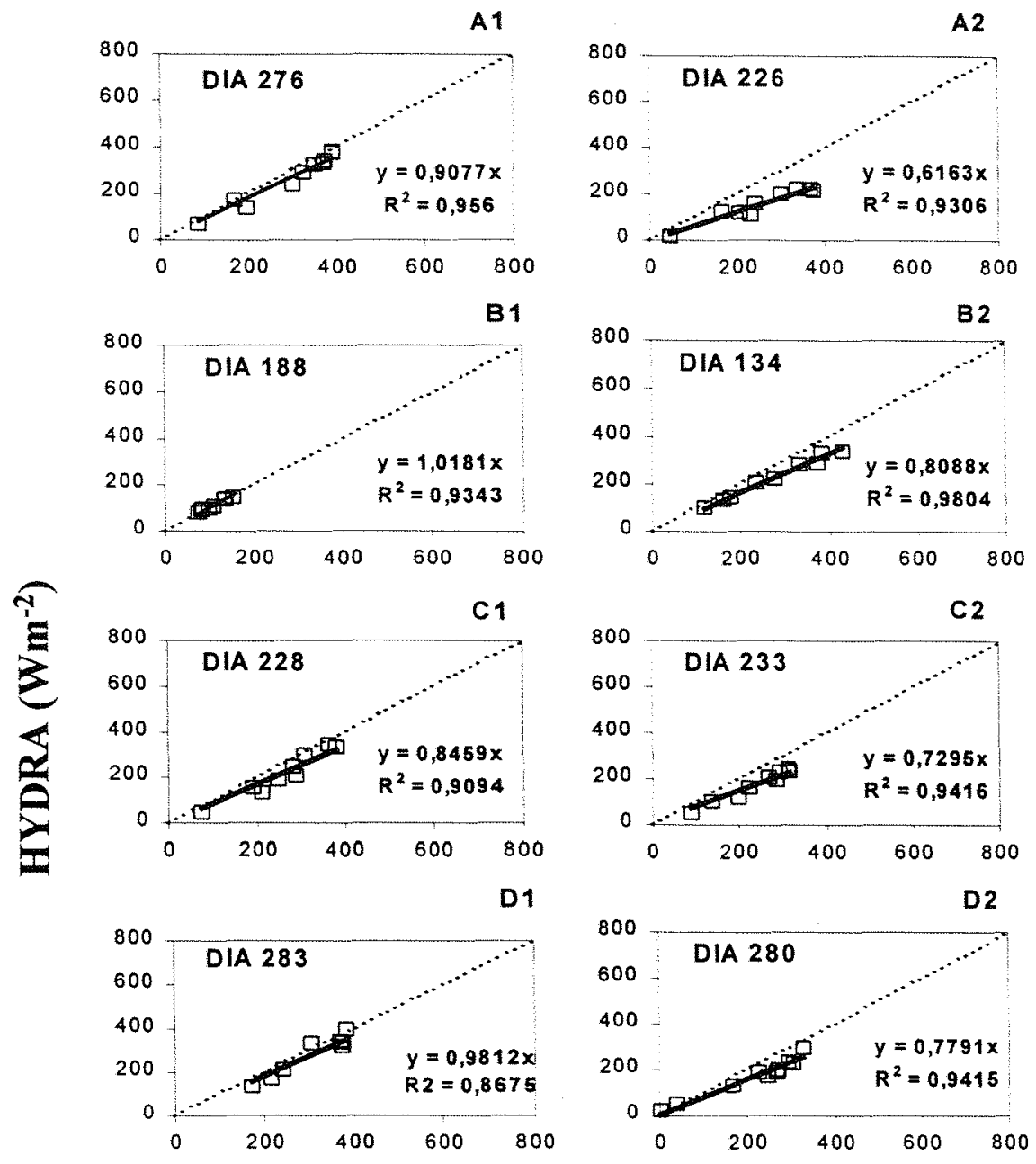

PRIESTLEY-TAYLOR ( $\left.\mathrm{Wm}^{-2}\right)$

Figura 6 - Fluxo de calor latente, na escala horária, para as Fazendas Nossa Senhora Aparecida (Ji-Paraná, RO) e para Fazenda Boa Sorte (Marabá, PA) para: A (1992), B e D (1993) e C (1994). 

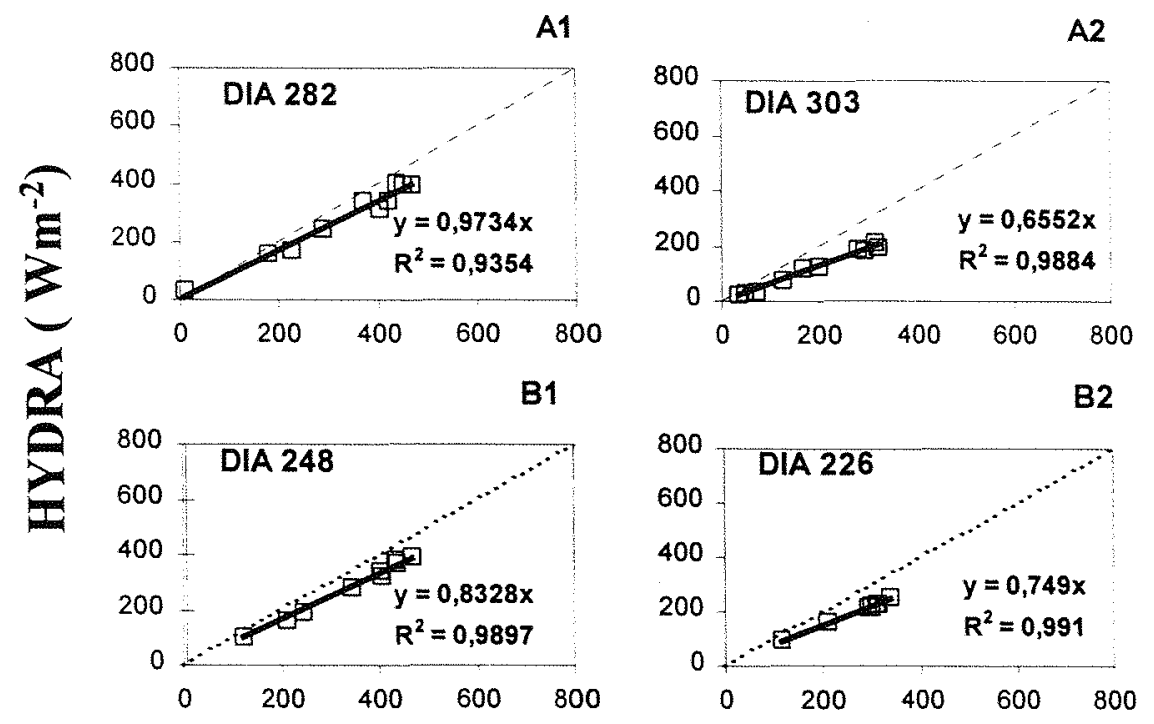

\section{PRIESTLEY-TAYLOR $\left(\mathrm{Wm}^{-2}\right)$}

Figura 7 - Fluxo de calor latente, na escala horária, para a Fazenda Dimona, Manaus, AM, para 1990 (coluna A) e 1991 (coluna B).

Com relação às condições micrometeorológicas, pode-se observar que, quanto ao balanço de energia medido, seguindo a disposição apresentada anteriormente para os dias julianos (Figuras 5 a 7), as Figuras 8, 9, e 10, representam o balanço de energia para os sitios na pastagem e na floresta. Os fluxos de calor latente (LE) e sensivel $(\mathrm{H})$ foram medidos pelo Hydra, enquanto que a Radiação liquida (Rn) e o fluxo de calor no solo $(G)$ foram medidos por uma estação meteorológica automática.

Foi observado que tanto para a floresta quanto para a pastagem, os melhores dias (colunas à esquerda), foram os que apresentaram os maiores valores para os fluxos de energia, principalmente para $\mathrm{Rn}$ e $\mathrm{H}$, exceto para o caso dos dias 188 (Figura 9B1). Este dia foi caracterizado por uma boa correlação, apesar dos fluxos serem pequenos (Figura 6B1). Na coluna à direita, ficou evidente que o total de energia para cada dia representado, foi bem menor, 
ocorrendo em muitos casos, quedas bruscas ou aumentos significativos nas variações de $\mathrm{Rn}, \mathrm{LE}, \mathrm{G}$ e H. Acredita-se que a variação nos balanços de energia para estes dias, se deva a nebulosidade na região, durante os dias considerados.

Os valores horários máximos para Rn, $\mathrm{LE}, \mathrm{H}$ e G, na floresta são apresentados pela Tabela 3, 4 e 5 . Os dias apresentados nas tabelas, estão dispostos segundo os maiores valores de $\mathrm{Rn}$.

Para a floresta, o maior valor de $\mathrm{Rn}$, dentre os demais neste sitio, foi de $715,5 \mathrm{Wm}^{-2}$, ocorrido às 12 horas, no dia juliano 271 (Figura 10A1). O menor valor foi de $491,3 \mathrm{Wm}^{-2}$, observado para o dia juliano 229 (Figura 8D2). Considerando-se somente a Reserva Jaru, o menor valor máximo foi de $551,40 \mathrm{Wm}^{-2}$ para o dia $233(8 \mathrm{C} 2)$, ocorrido às 12 horas.

Quanto a LE, considerando-se somente os máximo, o maior valor foi de $-490,15 \mathrm{Wm}^{-2}$, observado às 13 horas o dia juliano 228 . O menor valor observado foi de $-328,89 \mathrm{Wm}^{-2}$, no dia 195, às 12 horas.

Os maiores valores máximos de $\mathrm{H}$, observados na floresta foram $240 \mathrm{Wm}^{-2}$, (dia juliano 195) e de $208 \mathrm{Wm}^{-2}$ (dia juliano 271), encontrados respectivamente às 12 e 13 horas. Estes dias foram os que apresentaram as melhores estimativas (Figuras 5B1 e 5A1).

Para G, os máximos (apesar de desprezivel comparados com a pastagem) ocorreram para o dia juliano 195 , variando entre $7,6 \mathrm{Wm}^{-2}$ no início da manhã, decrescendo a $1,19 \mathrm{Wm}^{-2}$ no final da tarde (16 horas).

Quanto a pastagem, foi observado que entre os valores máximo de $\mathrm{Rn}$, o maior valor $\left(628,9 \mathrm{Wm}^{-2}\right)$ foi verificado para o dia 283 às 14 horas e o menor valor $194,2 \mathrm{Wm}^{-2}$ foi observado para o dia juliano 188 , às 12 horas (Tabela 4). 

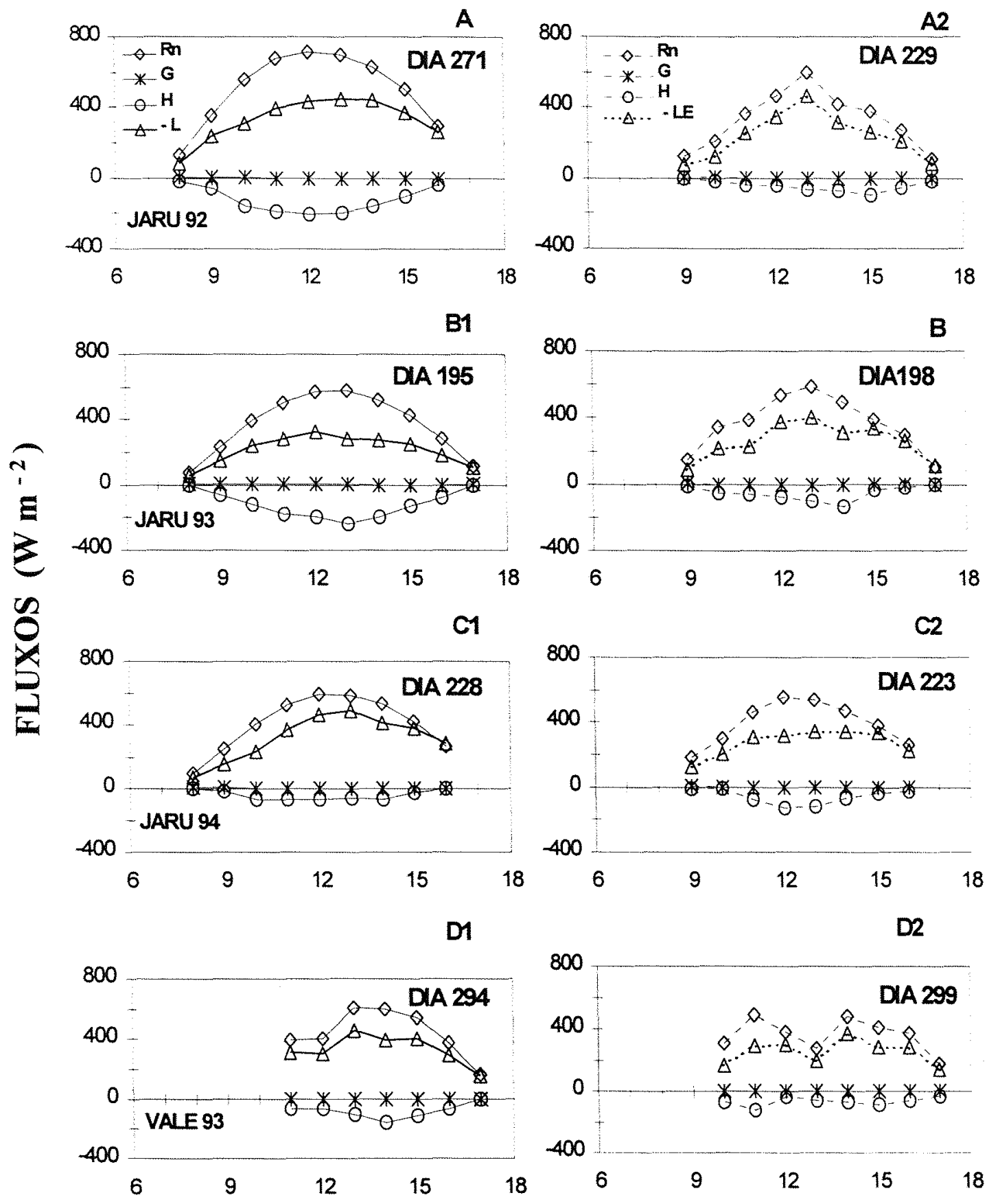

\section{HORA LOCAL}

Figura 8 - Balanço de energia medido pelo Hydra para as Reservas Biológica do Jaru (Ji-Paraná RO) e Vale do Rio Doce (Marabá PA), para: A (1992), B e D (1993) e C (1994). 
Quanto aos máximos de LE, estes foram observados às 11 horas para o dia $283\left(-405,0 \mathrm{Wm}^{-2}\right)$ sendo o maior e de apenas - 145,79 $\mathrm{Wm}^{-2}$ às 12 horas do dia 188.

Quanto a $\mathrm{H}$, o maior valor máximo foi de $-260 \mathrm{Wm}^{-2}$ às 11 horas para o dia juliano 283 e de $-46,77 \mathrm{Wm}^{-2}$ às 12 horas para o dia juliano 188.

Com relação a $G$, os valores máximos foram observados para o dia juliano 188.

Considerando-se o dia juliano 228 (Figuras $8 \mathrm{C} 1$ e 9C1) respectivamente, floresta e pastagem, estes apresentaram fluxos de energia superiores na Reserva Jaru. As diferenças pró Jaru foram: 33,2 $\mathrm{Wm}^{-2}$ para Rn e $147,35 \mathrm{Wm}^{-2}$ para LE. Quanto a $\mathrm{H}$, a diferença pró Fazenda Nossa Senhora Aparecida foi de $147 \mathrm{Wm}^{-2}$, sendo assim maior na Fazenda. Quanto ao fluxo de calor no solo, na Fazenda Nossa Senhora Aparecida foi de $20,3 \mathrm{Wm}^{-2}$.

Quanto ao dia juliano 233, (Figuras $8 \mathrm{C} 2$ e 9C2), floresta e pastagem, respectivamente. As diferenças pró floresta foram de 106,5 $\mathrm{Wm}^{-2}$ para $\mathrm{Rn}$ e de $98,46 \mathrm{Wm}^{-2}$ para LE. Quanto ao calor sensivel foi de $53 \mathrm{Wm}^{-2}$ pró pastagem. Quanto ao fluxo de calor no solo, apesar de desprezivel na floresta, na pastagem foram praticamente iguais, sendo de $20,2 \mathrm{Wm}^{-2}$ para o dia juliano 223 , tanto na floresta quanto na pastagem.

Na região de Marabá (Figuras 8D1 e 9D), observa-se que os dias, foram caracteristicos pela presença de nebulosidade. Os maiores valores de Rn, ocorreu na floresta, exceto para Marabá. 

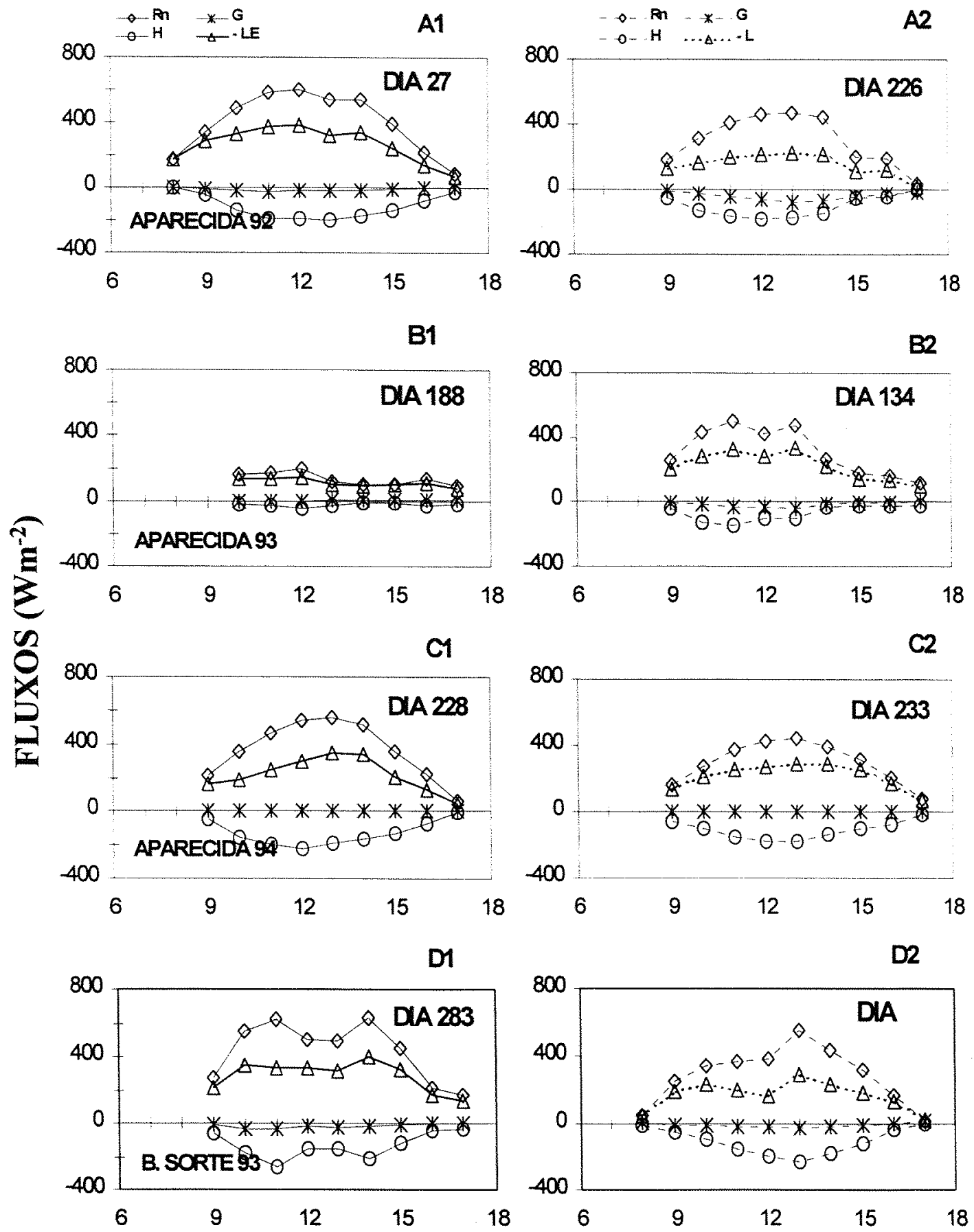

\section{HORA LOCAL}

Figura 9 - Balanço de energia medido pelo Hydra para as Fazendas Nossa Senhora Aparecida (Ji-Paraná RO) e Boa Sorte (Marabá PA), para: A (1992), B e D (1993) e C (1994). 

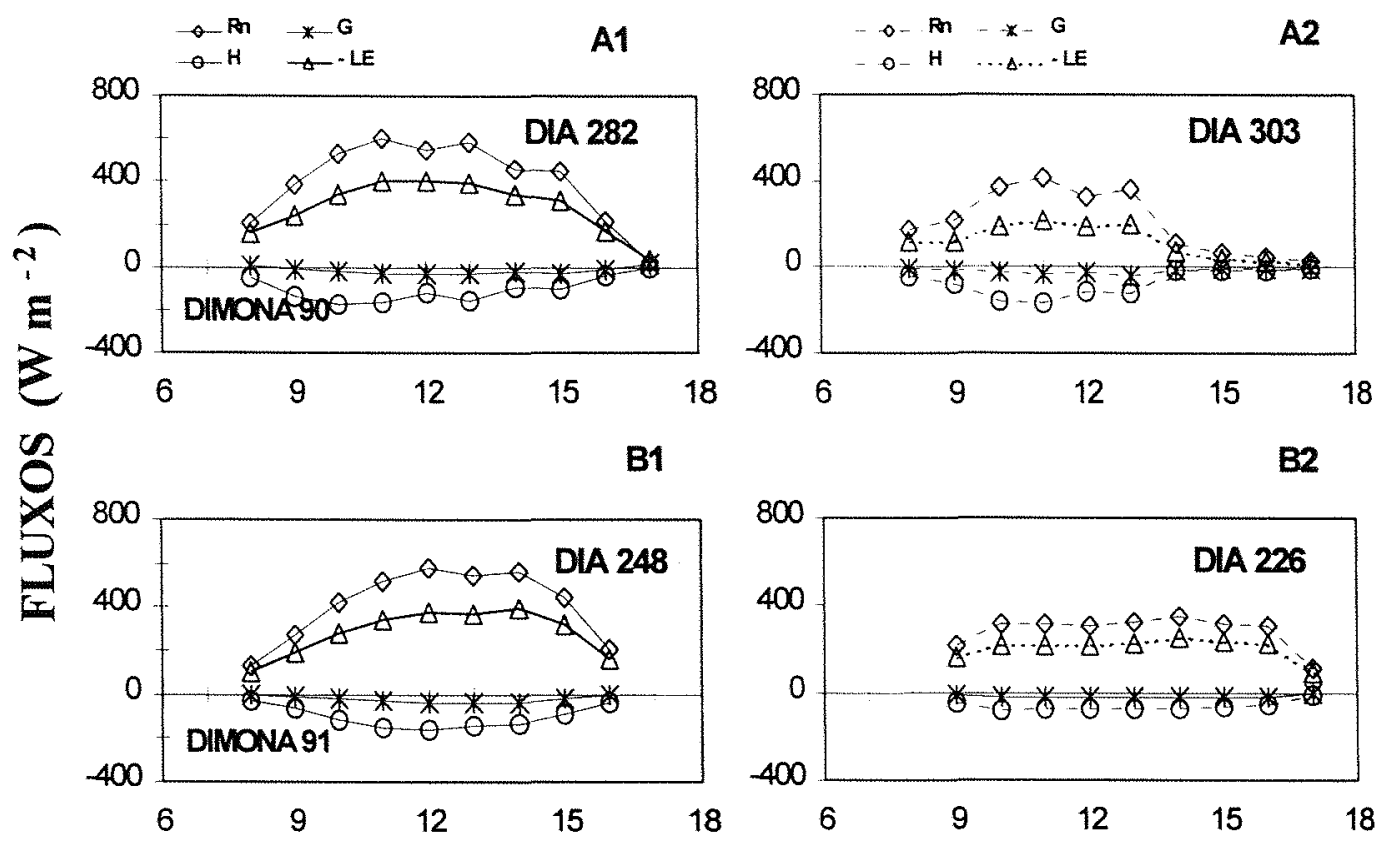

\section{HORA LOCAL}

Figura 10 - Balanço de energia medido pelo Hydra para a Fazenda Dimona (Manaus, AM) para: A (1990) e B (1991).

Tabela 3 - Balanço de energia na hora de Rn máximo, para os dias Julianos na Reserva Biológica Jaru (Ji-Paraná, RO) e Vale do Rio Doce (Marabá, PA).

\begin{tabular}{|c|c|c|c|c|c|c|c|c|}
\hline \multirow{3}{*}{ Variáveis } & \multicolumn{8}{|c|}{ DTAS JULTANOS } \\
\hline & \multicolumn{2}{|c|}{ JARU 92} & \multicolumn{2}{|c|}{ JARU 93} & \multicolumn{2}{|c|}{ JARU 94} & \multicolumn{2}{|c|}{ VALE 93} \\
\hline & 271 & 229 & 195 & 798 & 228 & 233 & 294 & 299 \\
\hline $\mathbf{R n}$ & 715,00 & 594,10 & 580,00 & 582,90 & 589,80 & 551,40 & 609,20 & 491,30 \\
\hline LE & $-431,33$ & $-466,39$ & $-288,59$ & $-405,84$ & $-462,74$ & $-322,40$ & $-462,86$ & $-296,57$ \\
\hline H & $-208,00$ & $-68,00$ & $-240,00$ & $-106,00$ & $-68,00$ & $-127,00$ & $-103,00$ & $-121,00$ \\
\hline G & $-1,50$ & $-1,46$ & 2,41 & $-2,30$ & $-2,20$ & $-1,60$ & $-0,23$ & 0,15 \\
\hline RESIDUO & 74,17 & 58,25 & 53,82 & 68,76 & 56,86 & 100,40 & 43,11 & 73,88 \\
\hline MEDIAS & 10,40 & 9,80 & 9,20 & 11,80 & 9,60 & 18,20 & 7,10 & 15,00 \\
\hline
\end{tabular}

Verifica-se que, nos sitios florestais, o balanço de energia, com os componentes médidos independentimente, resulta em residuo que não pode ser explicado por erros experimentais, indicando que houve armazenamento de energia, no periodo representado pelas 
medidas. Esta observação foi também constatada anteriormente por Moore e Fisch (1986).

Tabela 4 - Valores máximos medidos de Rn, LE, H e G para os dias Julianos nas Fazendas Nossa Senhora Aparecida (Ji-Paraná, RO) e Boa Sorte (Marabá, $\mathrm{PA})$.

\begin{tabular}{|c|c|c|c|c|c|c|c|c|}
\hline \multirow{3}{*}{ Variáveis } & \multicolumn{8}{|c|}{ DTAS JULTANOS } \\
\hline & \multicolumn{2}{|c|}{ APARECIDA 92} & \multicolumn{2}{|c|}{ APARECIDA 93} & \multicolumn{2}{|c|}{ APARECIDA 94} & \multicolumn{2}{|c|}{ BOA SORTE 93} \\
\hline & 276 & 226 & 788 & 134 & 228 & 233 & 283 & 280 \\
\hline Rि & 595,90 & 468,00 & 194,20 & 503,55 & 556,70 & 444,90 & 628,90 & 556,10 \\
\hline LE & $-381,74$ & $-223,85$ & $-145,79$ & $-329,24$ & $-342,80$ & $-245,00$ & $-396,00$ & $-296,17$ \\
\hline H & $-195,00$ & $-169,90$ & $-46,76$ & $-146,55$ & $-194,00$ & $-180,00$ & $-214,02$ & $-228,00$ \\
\hline G & $-19,16$ & $-74,25$ & $-1,65$ & $-27,76$ & $-19,90$ & $-19,90$ & $-18,88$ & $-31,93$ \\
\hline RESIDUOO & 0,00 & 0,00 & 0,00 & 0.00 & 0.00 & 0,00 & 0,00 & 0,00 \\
\hline
\end{tabular}

Tabela 5 - Valores máximos medidos de Rn, LE, H e G para os dias Julianos na Fazenda Dimona em Manaus (AM).

\begin{tabular}{c|c|c|c|c}
\hline \multirow{2}{*}{ Variáveis } & \multicolumn{3}{|c}{ DTAS JULTANOS } \\
\cline { 2 - 5 } & \multicolumn{2}{|c|}{ DIMONA 90} & \multicolumn{2}{c}{ DIMONA 91 } \\
\cline { 2 - 5 } & $\mathbf{2 8 2}$ & $\mathbf{3 0 3}$ & $\mathbf{2 2 6}$ & $\mathbf{2 4 8}$ \\
\hline Rn & 602,40 & 417,60 & 350,40 & 578,80 \\
LE & $-405,43$ & $-214,99$ & $-254,13$ & $-380,71$ \\
H & $-167,83$ & $-164,14$ & $-71,48$ & $-162,46$ \\
G & $-29,14$ & $-32,47$ & $-24,79$ & $-35,63$ \\
\hline RESIDUO & 0,00 & 0,00 & 0,00 & 0,00 \\
\hline
\end{tabular}

Verificando-se todos os sítios, foi observado que os dias em que os fluxos de energia foram maiores, foram aqueles em que a superestimativa entre o calor latente padrão (Hydra) mais se aproximou do estimado por Priestley-Taylor. Apesar de, em alguns casos, o calor sensivel ser maior em um dia considerado com pior superestimativa, comparando-se com um melhor dia (menor superestimativa), caso dos dias 228 (Figura 8C1) e 276 (Figura 9A1) estes, foram compensados pelo restante dos componentes do balanço de energia. Em vista disso, comparando-se as Figuras 5 a 9, pode-se associar que as melhores estimativas entre calor latente medido e estimado, estejam relacionados aos dias julianos em que o calor sensivel foi maior. 
De acordo com as Figuras de 8 a 10, na qual foram apresentados o balanço de energia para cada sitio, segundo cada dia distinto, serão mostradas nas Figuras seguintes (11 a 13) a correlação entre a Radiação líquida (Rn) e o calor latente (LE) medido pelo Hydra, para os sítios na floresta e na pastagem.

Para a Reserva Jaru foi observado que para o dia 228 (Figura $11 \mathrm{C} 1$ ) foi o dia em que a maior parte da energia (Rn) foi utilizada no processo da evapotrnaspiração. Ou seja, aproximadamente, $78 \%$, já o dia 195 (Figura 11B1), utilizou apenas 56\% da energia para o processo de evapotranspiração.

Considerando a Fazenda Nossa Senhora Aparecida, verificase que a maior percentagem de $\mathrm{Rn}$ utilizada na evapotranspiração ocorreu para no dia juliano 188 (Figura 12B1), sendo de $82 \%$ e a menor foi de 50\%, no dia juliano 226 (Figura 12A2).

Quanto a Reserva Vale do Rio Doce, foi verificado que a percentagem de energia utilizada para a evapotranspiração foi a verificada no dia 294 (Figura 11D1), sendo de aproximadamente 74\%. Para a pastagem (Fazenda Boa Sorte), quanto a maior porcentagem de energia utilizada na evapotranspiração ocorreu no dia 283 (Figura 12D2).

Para a Fazenda Dimona, foi verificado que a maior parte da radiação liquida utilizada na evapotranspiração foi a observada no dia 226 (Figura 13B2), sendo de aproximadamente, 72\%. A menor partição de energia foi verificada no dia juliano 303 , sendo de apenas $55 \%$ (Figura $13 \mathrm{~A} 2$ ). 

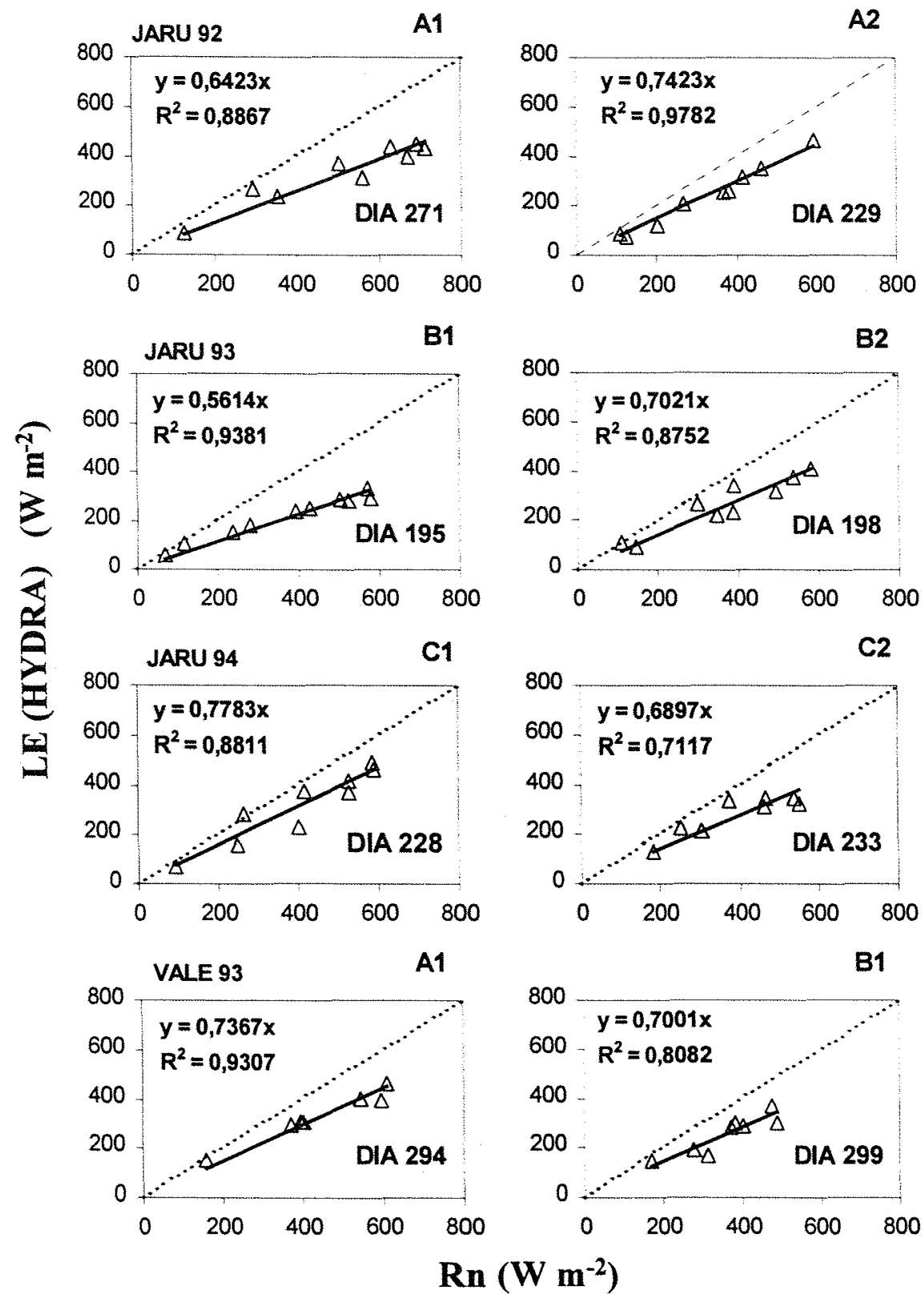

Figura 11 - Comparação entre o fluxo de calor latente medido e a Radiação liquida, na escala horária, para as Reservas Biológica do Jaru (Ji-Paraná RO) e Vale do Rio Doce (Marabá, PA), para: A (1992), B e C (1993) e C (1994). 

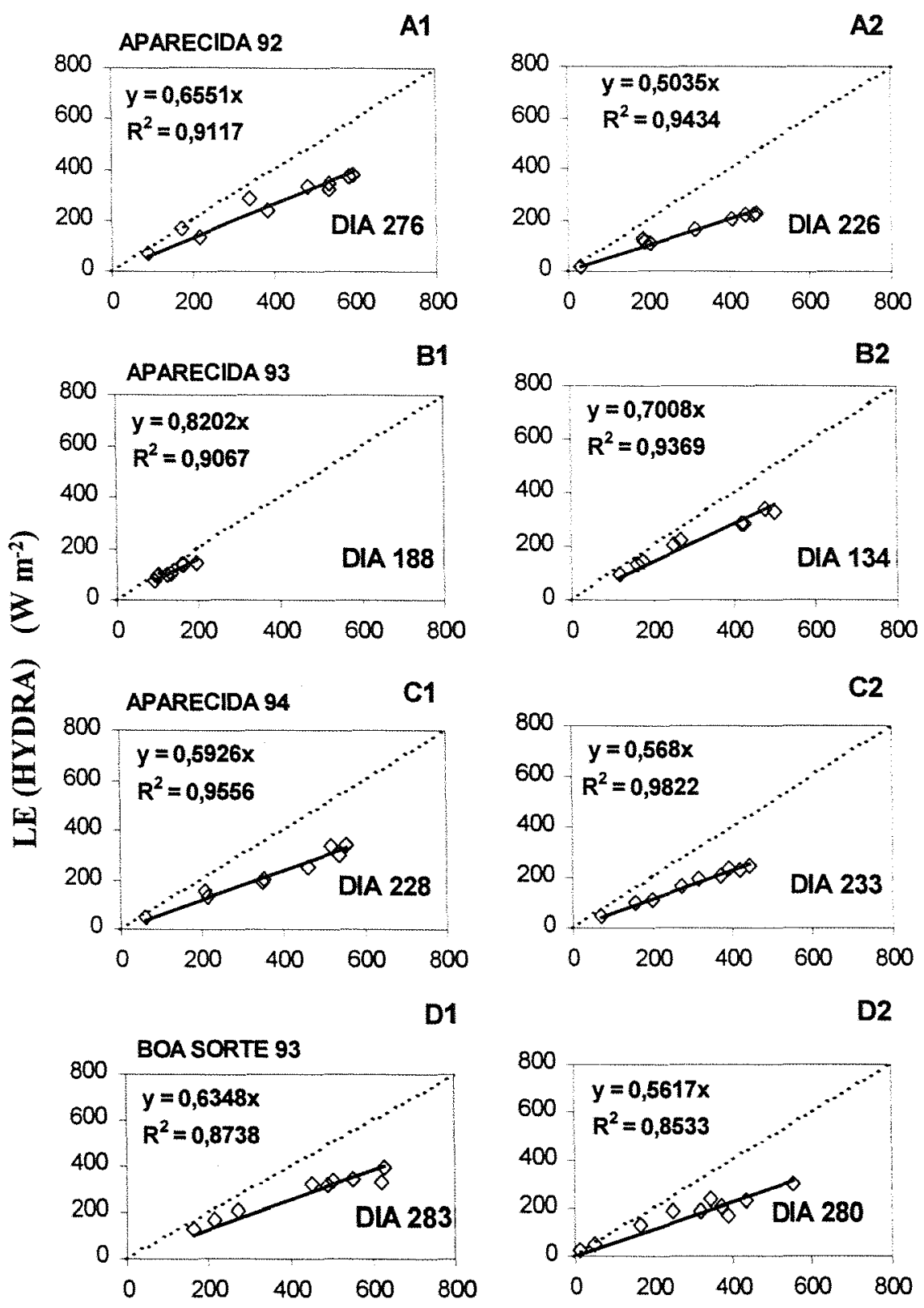

\section{$\operatorname{Rn}\left(\mathbf{W} \mathbf{m}^{-2}\right)$}

Figura 12 - Comparação entre o fluxo de calor latente medido e a Radiação líquida, na escala horária, para as Fazendas Nossa Senhora Aparecida (JiParaná RO) e Boa Sorte (Marabá PA), para: A (1992), B e D (1993) e C (1994). 


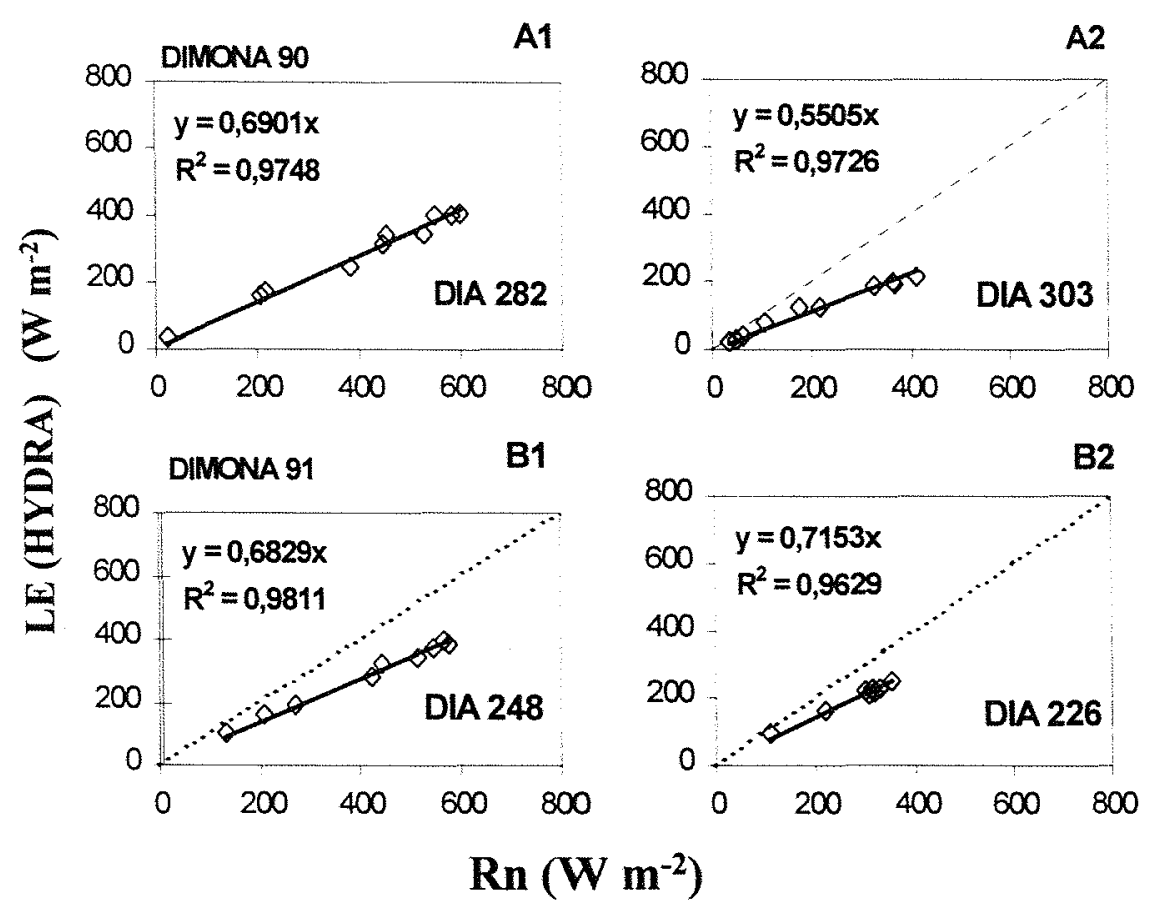

Figura 13 - Comparação entre o fluxo de calor latente medido e a Radiação liquida, na escala horária, para a Fazenda Dimona (Manaus AM), para: A (1990), B (1991).

As Figuras 14 a 16, referem-se a diferença entre o calor latente estimado por Priestley-Taylor e o medido pelo Hydra. As curvas à esquerda, são caracterizadas pelas menores diferenças, estas observadas próximas ao meio dia. As curvas à direita, são caracterizadas pelas superestimativas do calor latente estimado por Priestley-Taylor, ou seja, o LE estimado foi superior do medido.

$\mathrm{Na}$ Figura 14, estão representadas as curvas referentes aos sitos floresta. A diferença máxima $\left(100 \mathrm{Wm}^{-2}\right)$ às 10 horas foi observada no dia juliano 228 (Figura 14C1) e a diferença mínima $\left(-1,67 \mathrm{Wm}^{-2}\right)$ observada as 13 horas no dia 195 (Figura 14B1). 
Para o caso da pastagem, a maior diferença observada foi verificada para o dia juliano $303\left(60,22 \mathrm{Wm}^{-2}\right)$ às 16 horas (Figura 16A2). O dia juliano 188, (Figura 15A1), apresentou as menores diferenças, em torno $4 \mathrm{Wm}^{-2}$ ) desconsiderando o dia 188 , observou os dias julianos a esquerda (coluna 1), verificamos que existe uma tendencia de ocorrer as menores diferenças entre o calor latente estimado e o medido entre 11 e 14 horas. As menores diferenças, significa que o calor latente estimado (Priestley-Taylor) foi menor que o calor latente medido (Hydra). Vale salientar que, estes dias foram aqueles que apresentaram os maiores fluxos de energia (Figura 8, 9 e 10).

Se observarmos, somente a coluna 2 , tanto na floresta quanto na pastagem, podemos constatar que exceto para o dia juliano 280 (Figura 15D2), em todos os outros dias, LE estimado, superior LE medido, sendo pouco maior na floresta. 


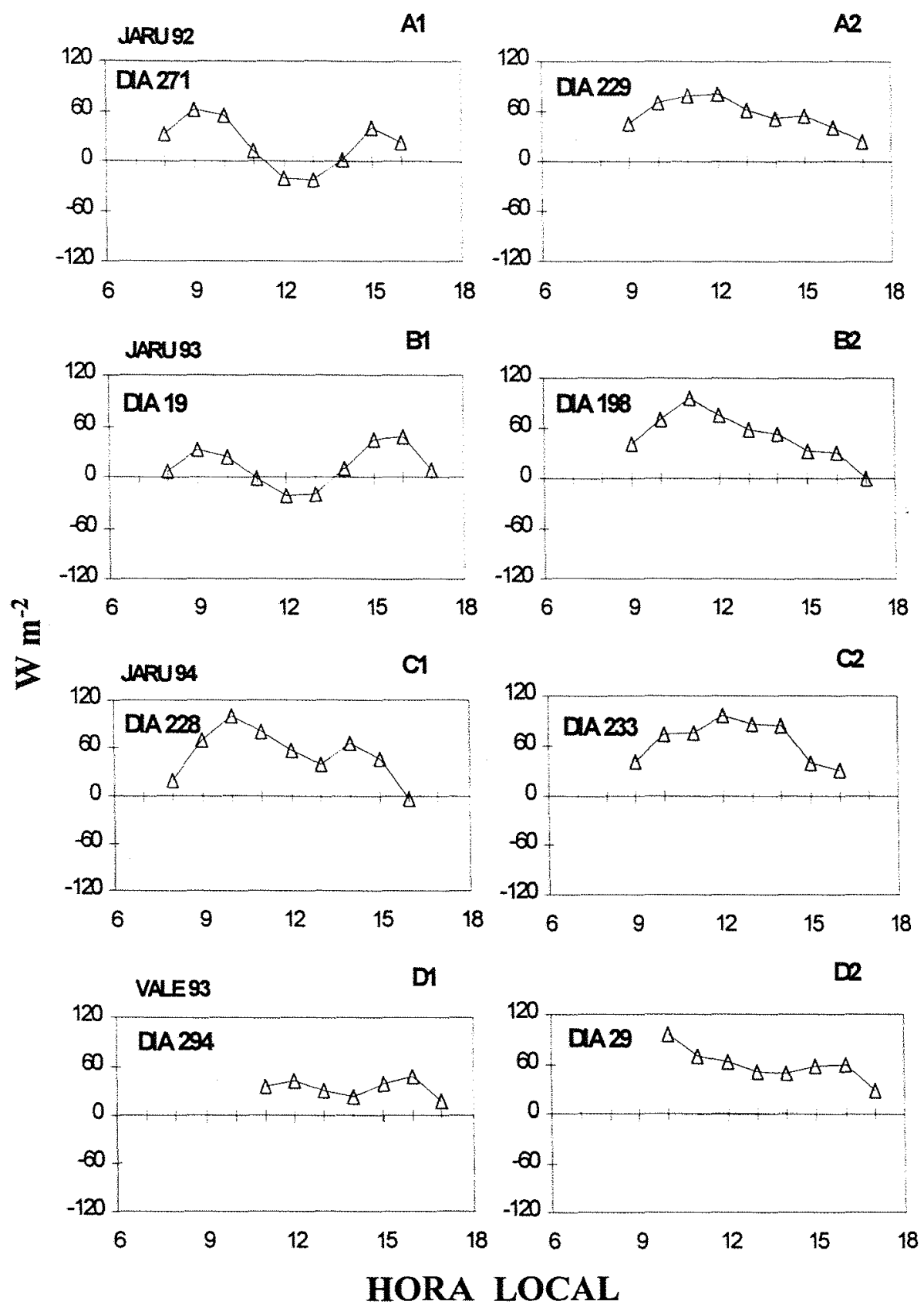

Figura 14 - Diferença entre o fluxo de calor latente estimado (Priestley-Taylor) e o medido (HYDRA), na escala horária, para as Reservas Biológica do Jaru (JiParaná RO) e Vale do Rio Doce (Marabá, PA), para: A (1992), B e D (1993), C (1994). 

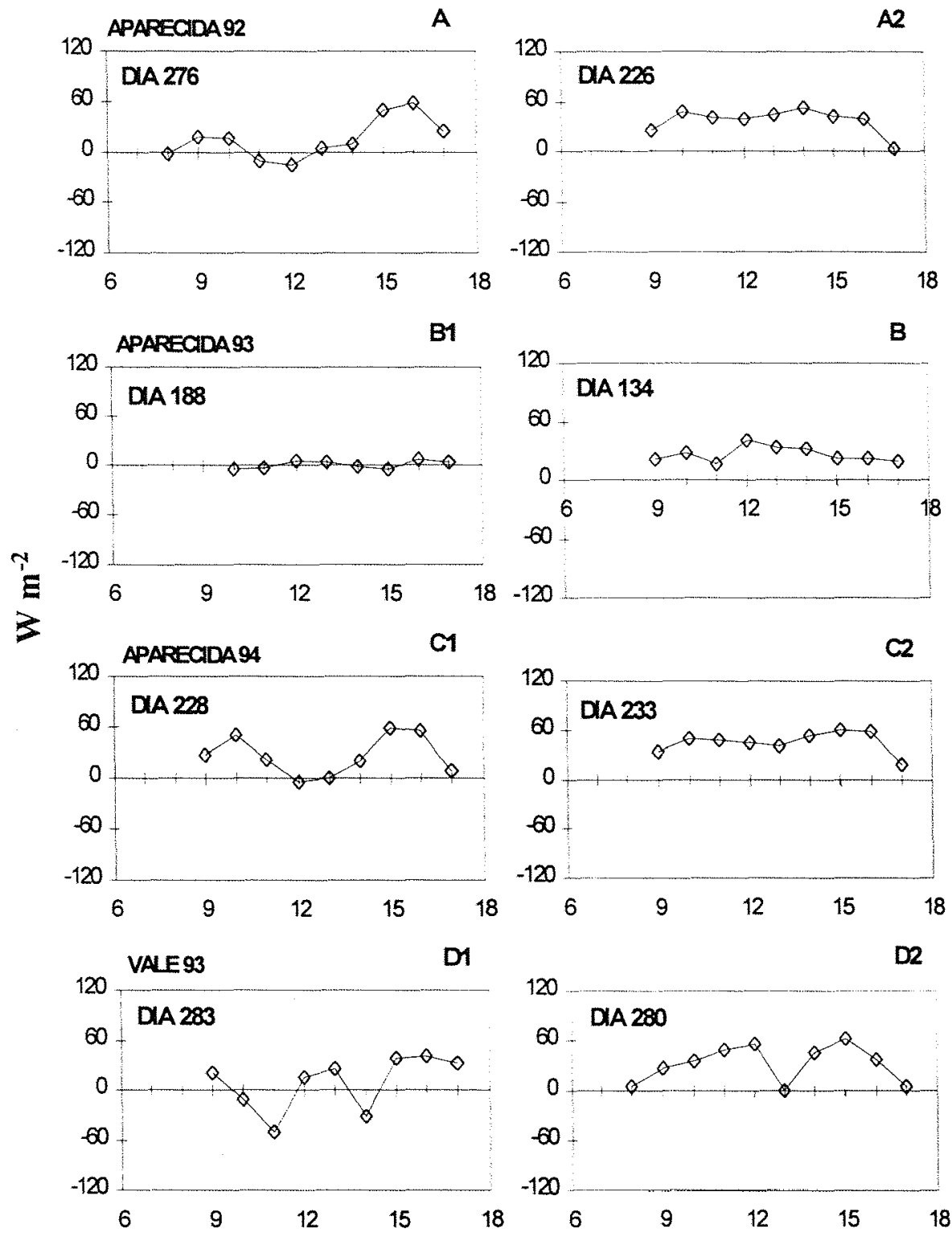

HORA LOCAL

Figura 15 - Diferença entre o fluxo de calor latente estimado (Priestley-Taylor) e o medido (HYDRA), na escala horária, para as Fazendas Nossa Senhora Aparecida (Ji-Paraná, RO) e Boa Sorte (Marabá, PA), para: A (1992), B e D (1993), C (1994). 


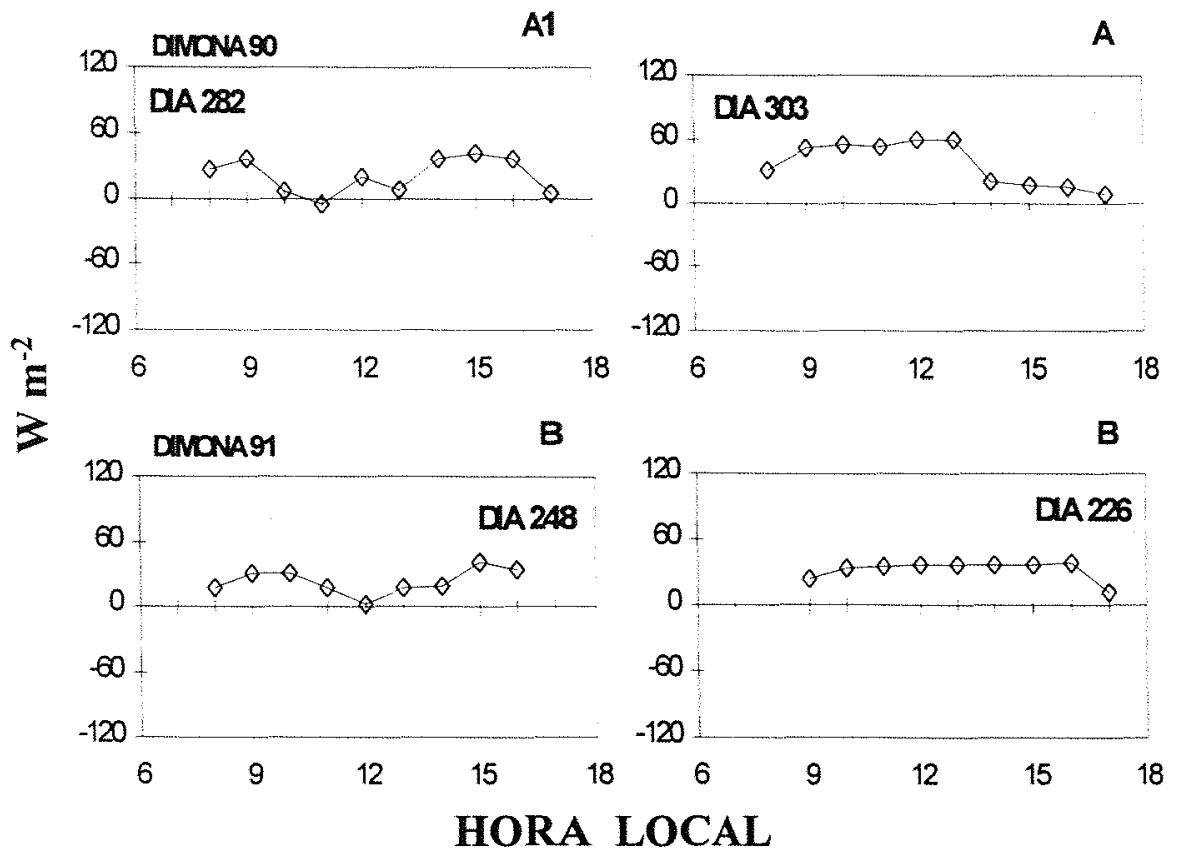

Figura 16 - Diferença entre o fluxo de calor latente estimado (Priestley-Taylor) e o medido (HYDRA), na escala horária, para a Fazenda Dimona (Manaus AM) para: A (1990), B (1991).

Verificando-se os sítios floresta, foi constatado que a melhor estimativa ocorreu para a Reserva Jaru em 1994 (Figura 17C1) e pior estimativa, foi constatada na reserva Vale em 1993 (Figura 17D1). Quanto aos sitios pastagem, a melhor estimativa foi verificada para a Fazenda Nossa Senhora Aparecida em 1993 (Figura 17B2). As melhores estimativas, foram observadas entre o calor latente medido e o estimado.

As Figuras 17 e 18, apresentam a correlação entre o calor sensivel e o parâmetro de Priestley-Taylor medidos. O parâmetro de Priestley-Taylor proposto por Pereira e Villa Nova $\left(\alpha=1,33+2,78 \cdot 10^{-3}\right.$ H) superestimado em todos os casos, esta correlação. 

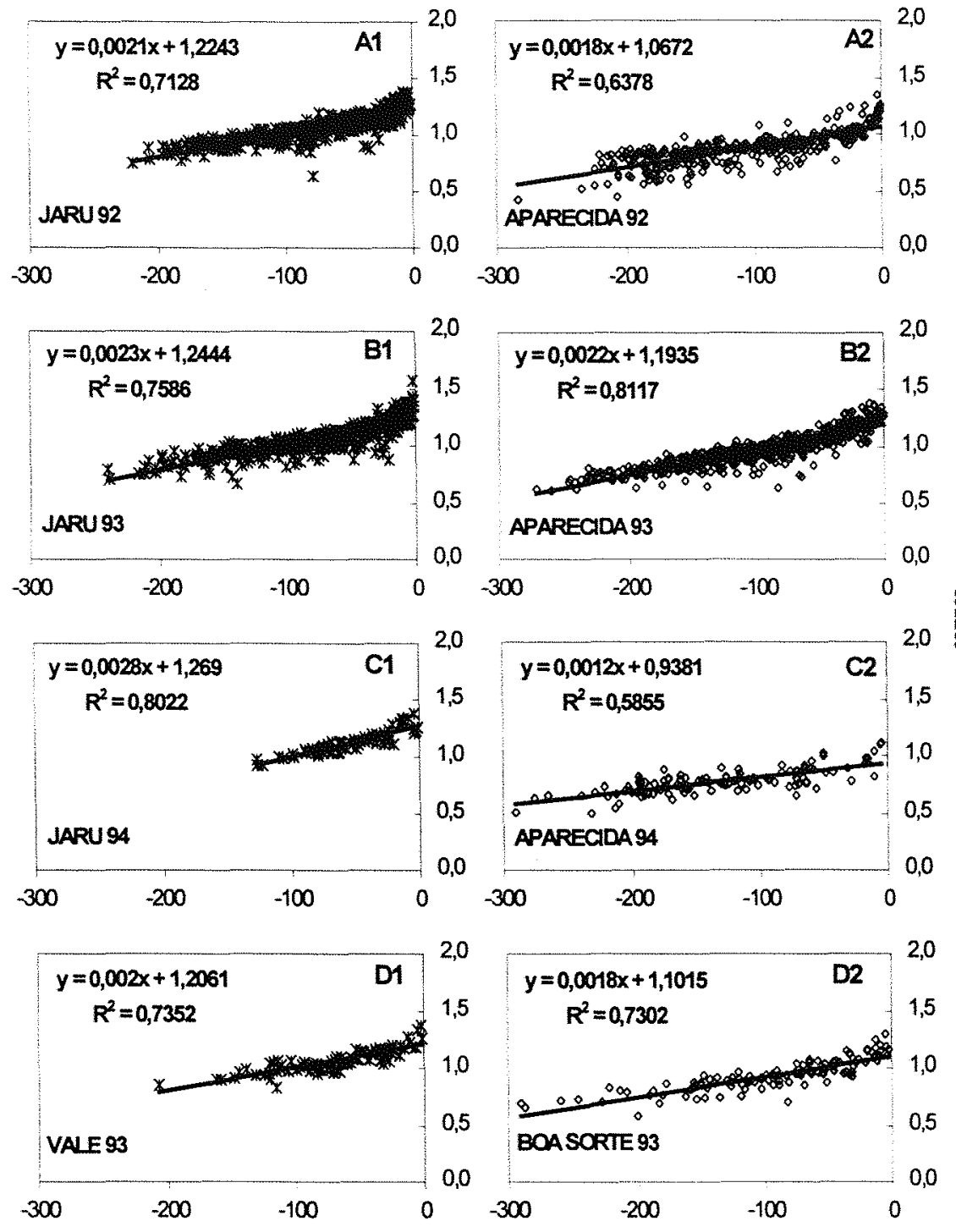

CALOR SENSÍVEL (W $\left.\mathbf{m}^{-2}\right)$

Figura 17 - Fluxo de calor sensivel e parâmetro de Priestley-Taylor medido durante todo o perido do experimento, na escala horária, para as Reservas Biológica do Jaru e Boa Sorte (coluna 1), e Fazendas Nossa Senhora Aparecida e Boa Sorte (coluna 2), para: A (1992), B e D (1993) e C (1994). 


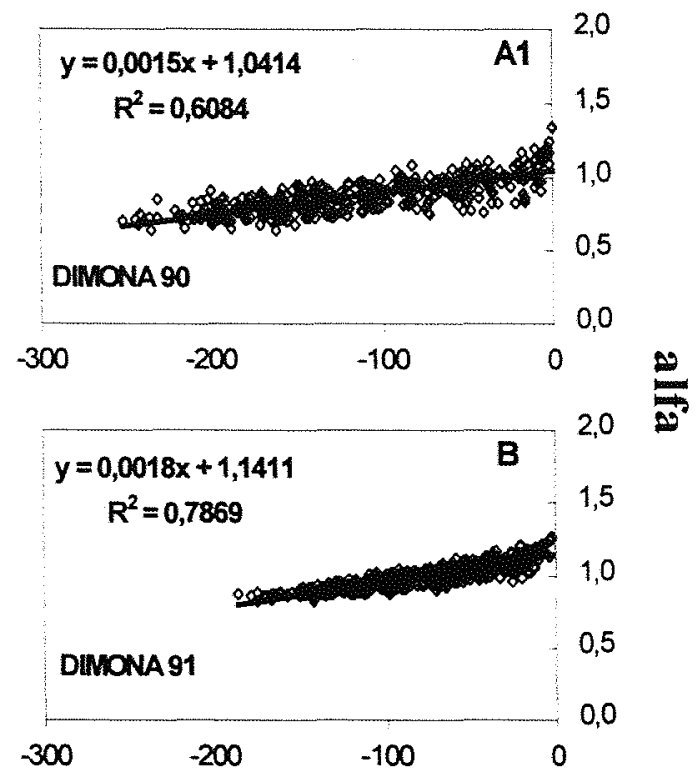

CALOR SENSÍVEL $\left(\mathrm{W} \mathrm{m}^{-2}\right)$

Figura 18 - Fluxo de calor sensivel e parâmetro de Priestley-Taylor medido durante todo o periodo do experimento, na escala horária, para a Fazenda Dimona (Manaus, AM) para: A (1990) e B (1991).

Considerando-se agora, a mesma correlação (calor sensivel medido $x$ alfa medido) e analizando-se para os dias julianos considerados, foi observado que ainda assim, a equação $\alpha_{1} \alpha=1,33+$ $2,7810^{-3} \mathrm{H}$ superestimou as equações das correlações, exceto para dois casos, dias julianos 195 (Figura 19B1) e 188 (Figura 20B1). 

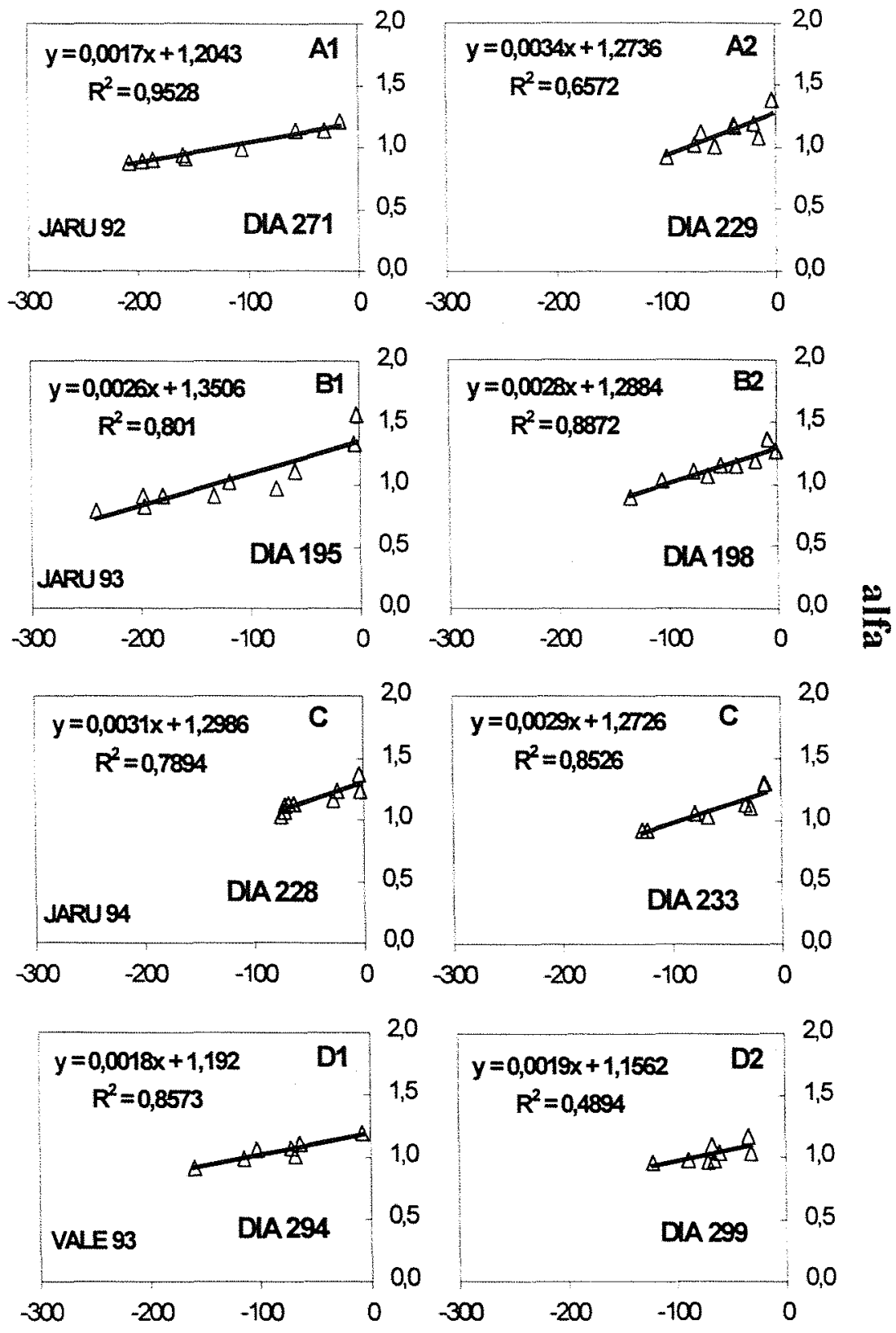

\section{CALOR SENSÍVEL $\left(\mathrm{W} \mathrm{m}^{-2}\right)$}

Figura 19 - Fluxo de calor sensivel e $\alpha$, medidos na escala horária, para as Reservas Biológica do Jaru (Ji-Paraná, RO), e Vale do Rio Doce (Marabá, PA), para: A (1992); B e D (1993); C (1994). 

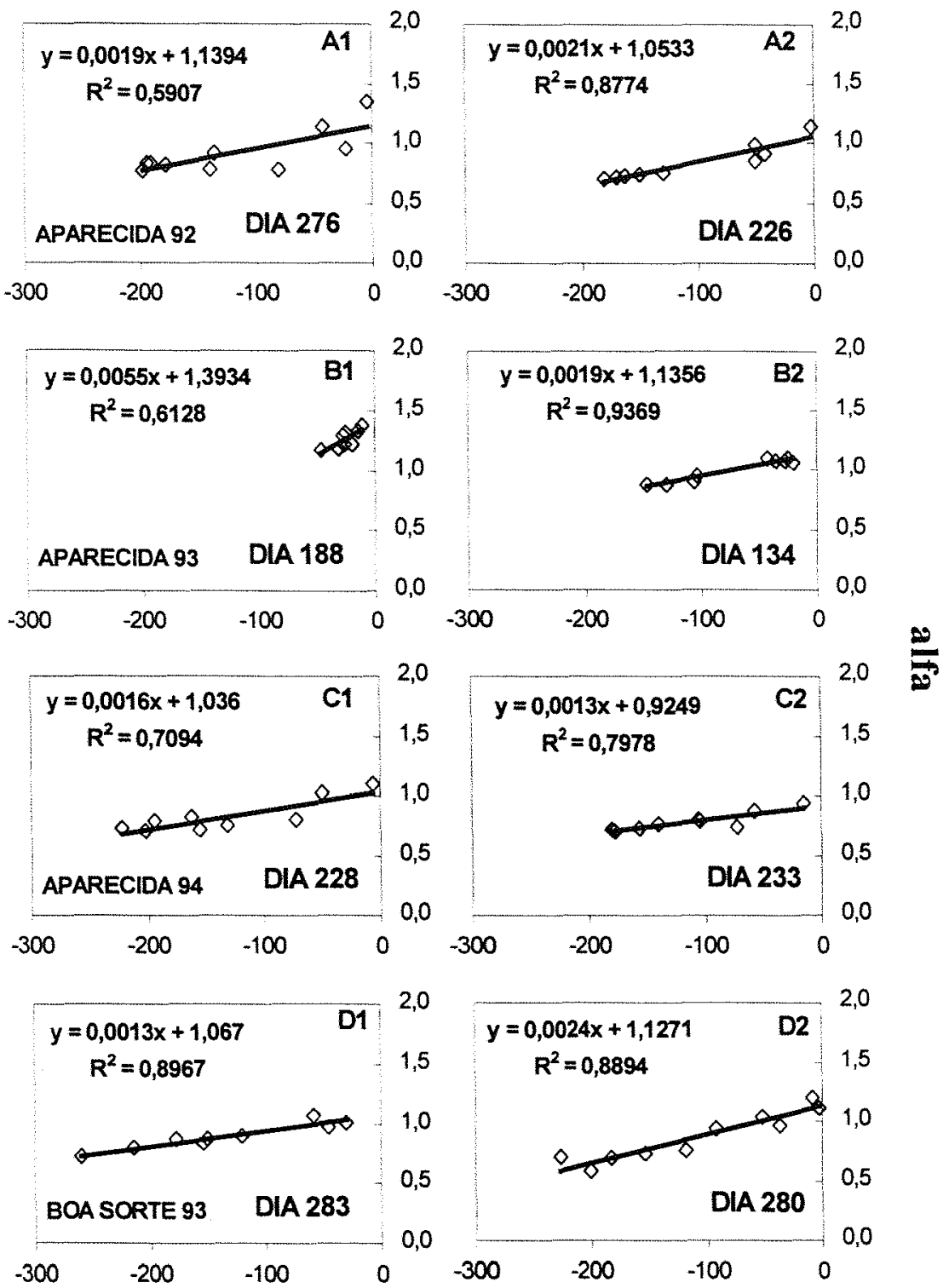

\section{CALOR SENSÍVEL $\left(\mathrm{W} \mathrm{m}^{-2}\right)$}

Figura 20 - Fluxo de calor sensivel e $\alpha$, medidos na escala horária, para as Fazendas Nossa Senhora Aparecida (Ji-Paraná, RO), e Boa Sorte (Marabá PA), para: A (1992); B e D (1993); C (1994). 


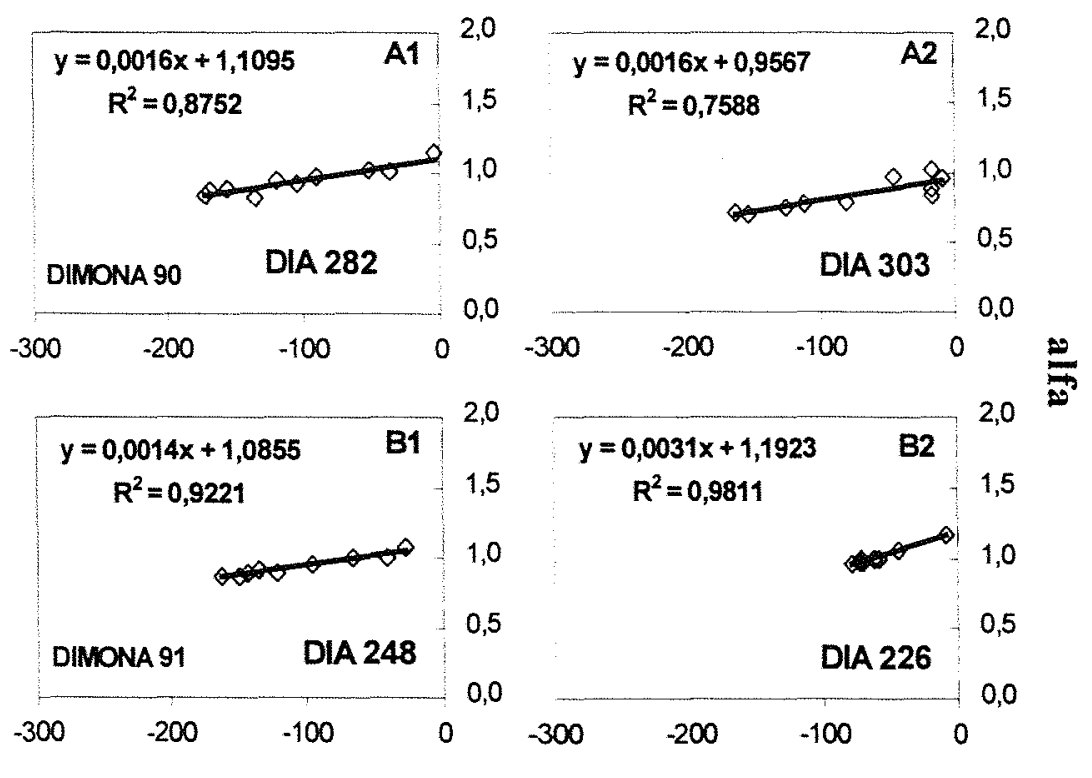

\section{CALOR SENSÍVEL $\left(\mathrm{W} \mathrm{m}^{-2}\right)$}

Figura 21 - Fluxo de calor sensivel e $\alpha$, medidos na escala horária, para a Fazenda Dimona (Manaus, PA), para: A (1990); B (1991).

Analisando as Figuras 22 a 24, representativas das correlações existentes entre $\alpha$ (estimado) e $\alpha$ (medido) vale salientar que o $\alpha$ estimado superestimou o medido em todos os casos. Vale salientar que estas correlações foram melhores que as observadas entre o calor latente medido e estimado (Figuras 5, 6 e 7).

No caso da floresta, (Figura 23), as estimativas foram ligeiramente melhores, que as observadas para a pastagem. As melhores estimativas para o sitio floresta referente a reserva Jaru, Ji-Paraná foram observadas para o dia juliano $271(\mathrm{~b} \approx 1)$ e a pior estimativa foi observada no dia juliano 228, superestimado em 15,6\% (Figura 23C1). 


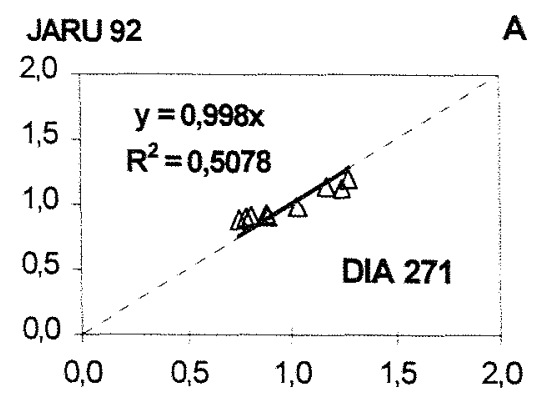

A
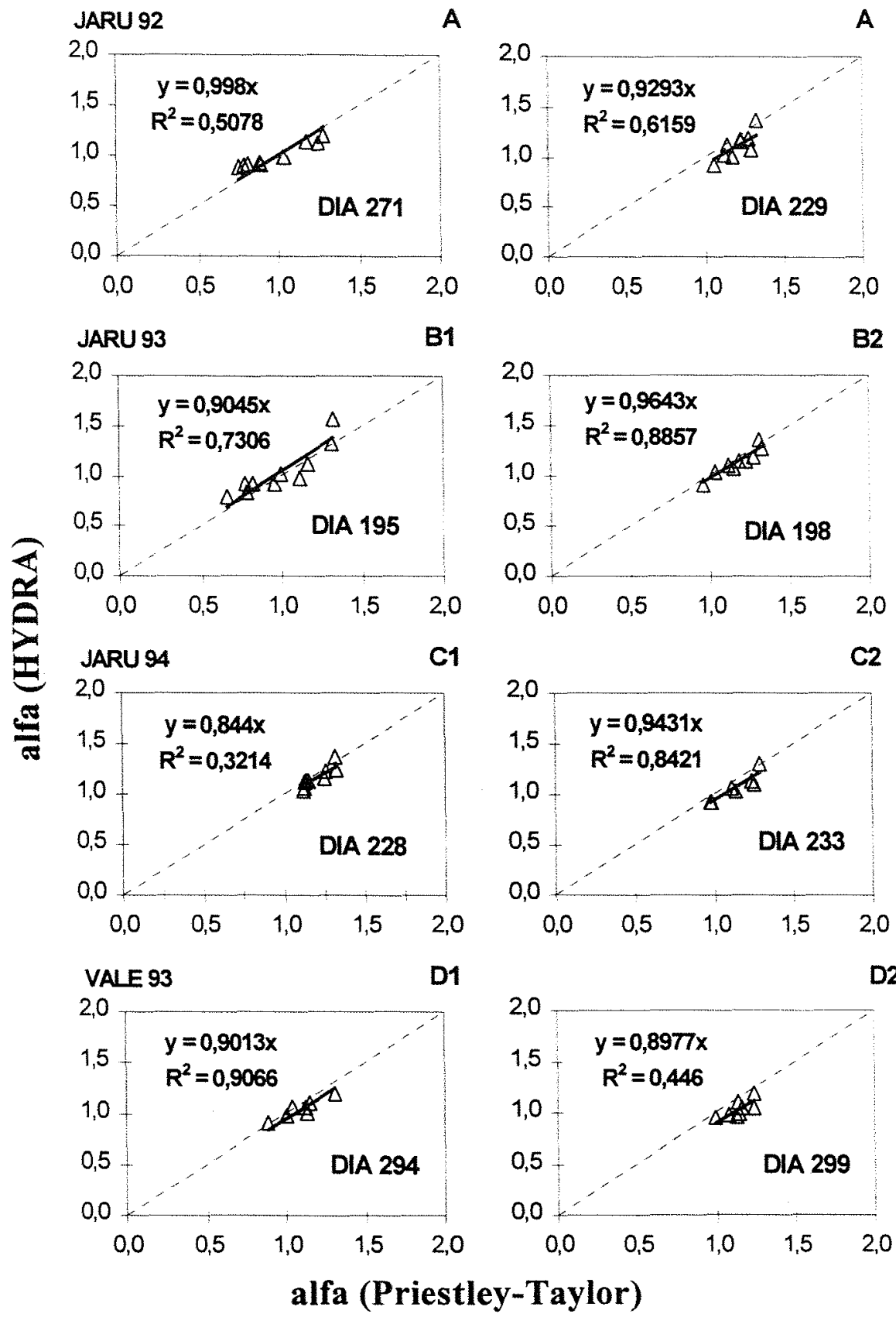

Figura 22- Parâmetro de Priestley-Taylor, na escala horária, para as Reservas Biológica do Jarú (Ji-Paraná, RO) e Vale do Rio Doce (Marabá, PA), para: A (1992); B e D (1993); C (1994). 
Quanto a Fazenda Nossa Senhora Aparecida, os valores superestimados variaram entre $1,52 \%$ no dia juliano 276 (Figura 34A1) e 23,65\%, verificado para o dia juliano 233 (Figura 34C2).
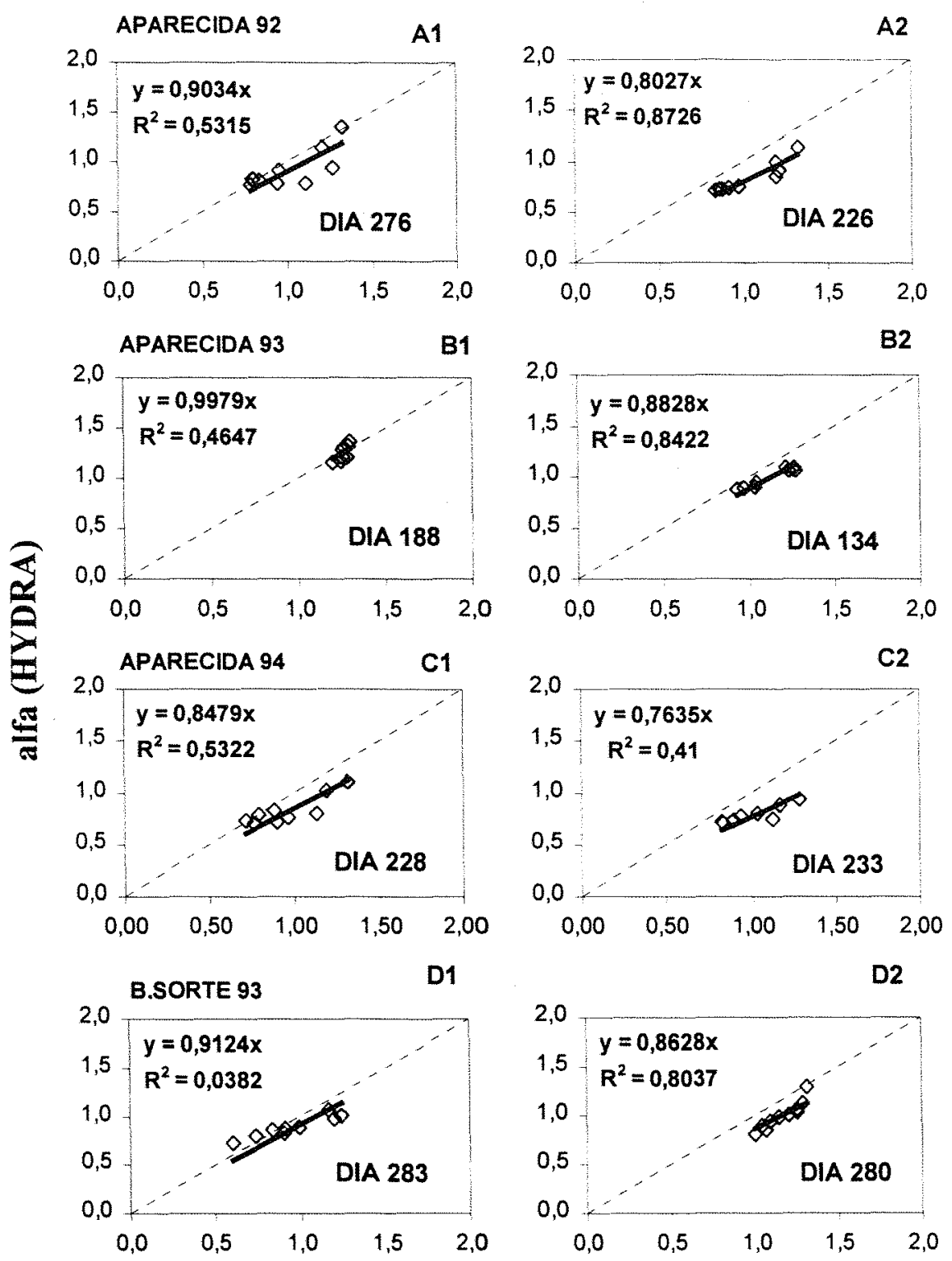

alfa (Priestley-Taylor)

Figura 23- Parâmetro de Priestley-Taylor, na escala horária, para as Fazendas Nossa Senhora Aparecida (Ji-Paraná, RO) e Vale do Rio Doce (Marabá, PA), para: A (1992); B e D (1993); C (1994). 
Para Marabá, a superestimativa na pastagem variou entre 8\% (Figura 23D1) e 13,7\% (Figura 23D2), considerando floresta e pastagem, caracterizando-se assim, a maior variação que as observadas para a floresta. Na floresta às estimativas praticamente foram iguais.

Para a Fazenda Dimona, a melhor superestimativa ocorreu para o dia juliano 282 (Figura 24A1), sendo de apenas 10\%. A pior superestimativa ocorreu para o dia juliano 303 (Figura 24A2), sendo de $25,8 \%$.

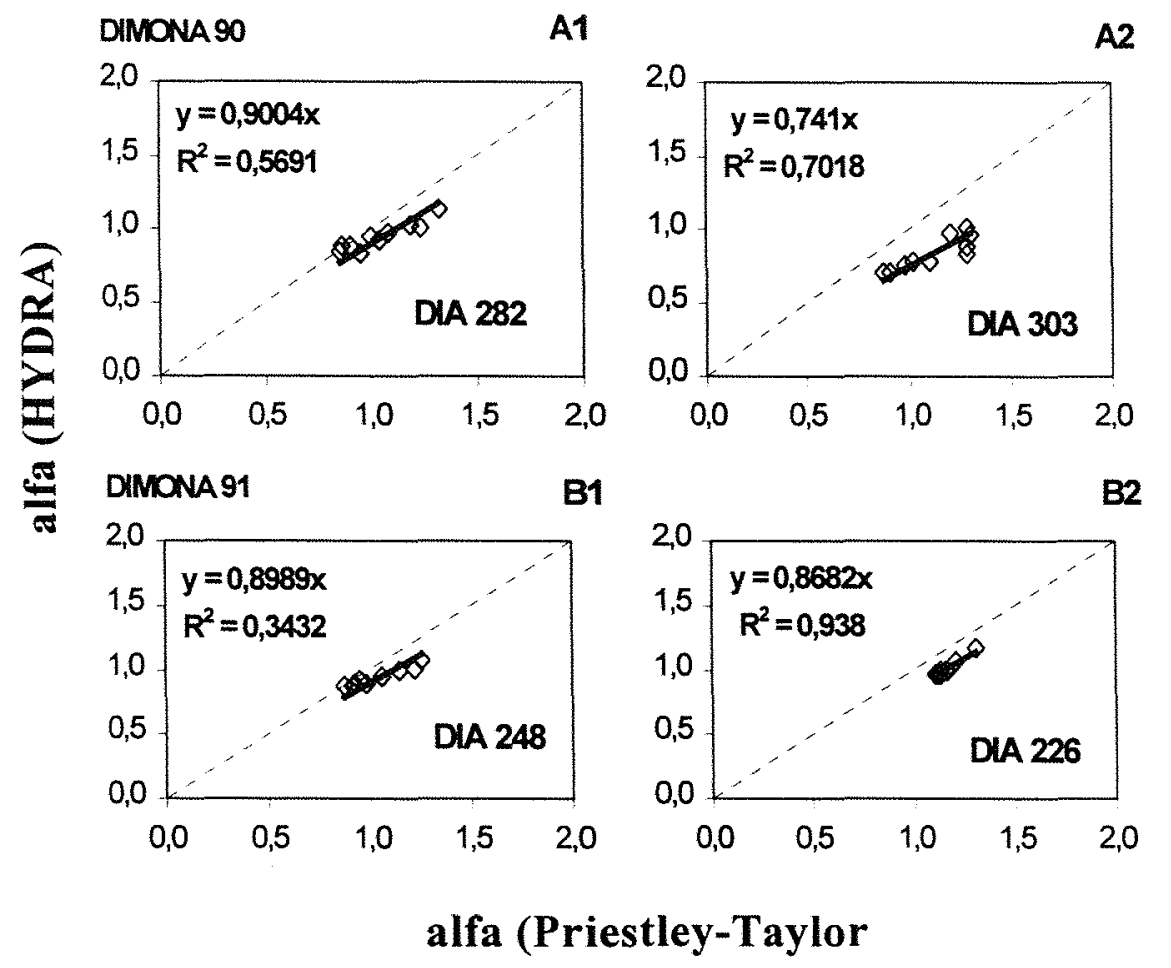

Figura 24- Parâmetro de Priestley-Taylor, na escala horária, para a Fazenda Dimona (Manaus, MA), para: A (1990); e B (1991).

As Figuras 25, 25 e 27, mostraram a variação do Parâmetro de Priestley - Taylor ( $\alpha$ medido e $\alpha$ estimado) e de razão de Bower ao longo do dia. Tanto $\alpha$ medido quanto estimado, variam igualmente ao longo do dia, condições observadas para os dias que apresentaram as melhores estimativas (Coluna 1). No entanto, se observar-mos as 
variações de $\alpha$ medido e estimado na Coluna 2, pode-se constatar que apesar da mesma variação, as maiores diferenças entre as curvas, ocorreram a partir do periodo da tarde, sendo maiores na pastagem que na floresta.
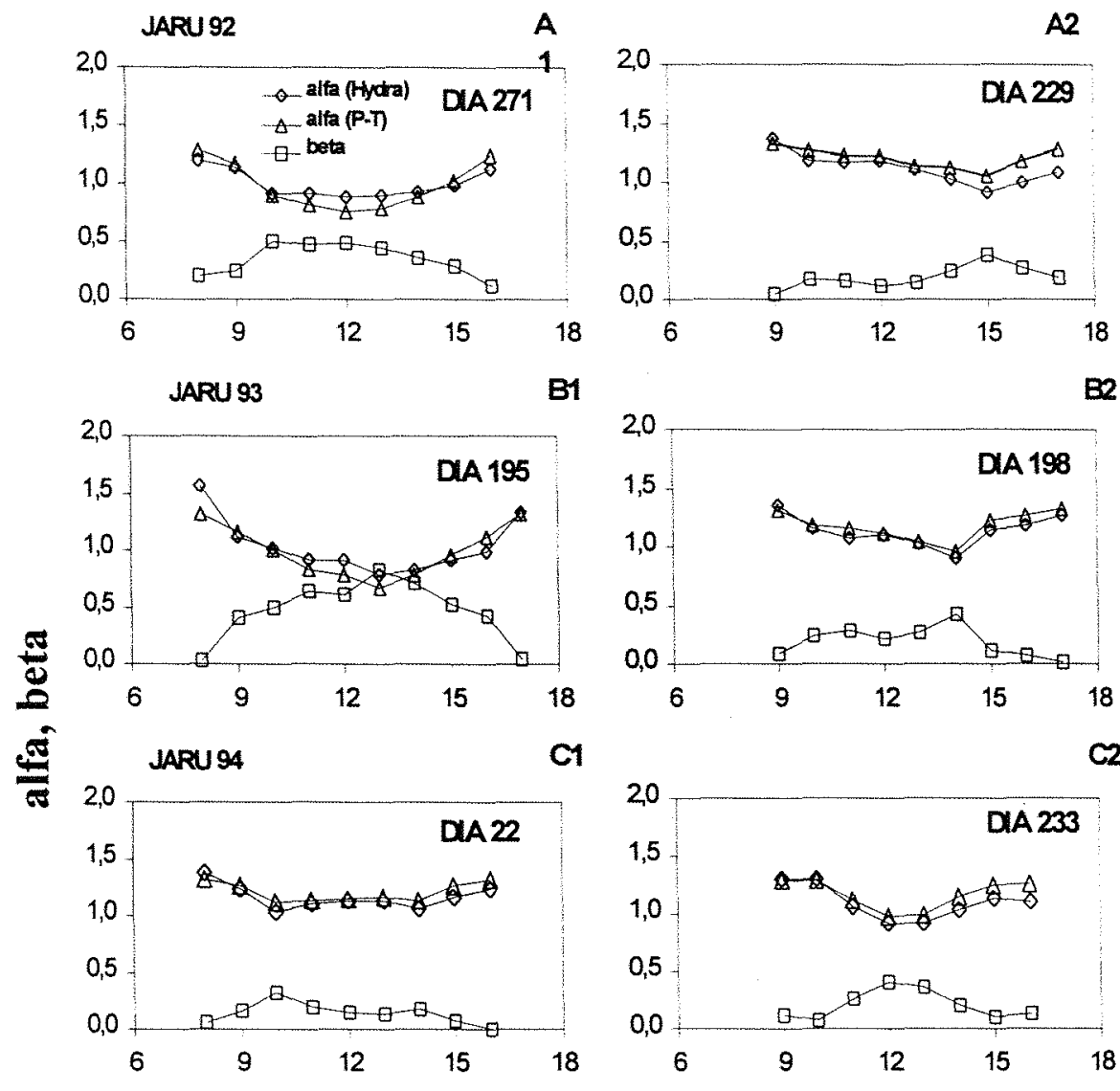

C1
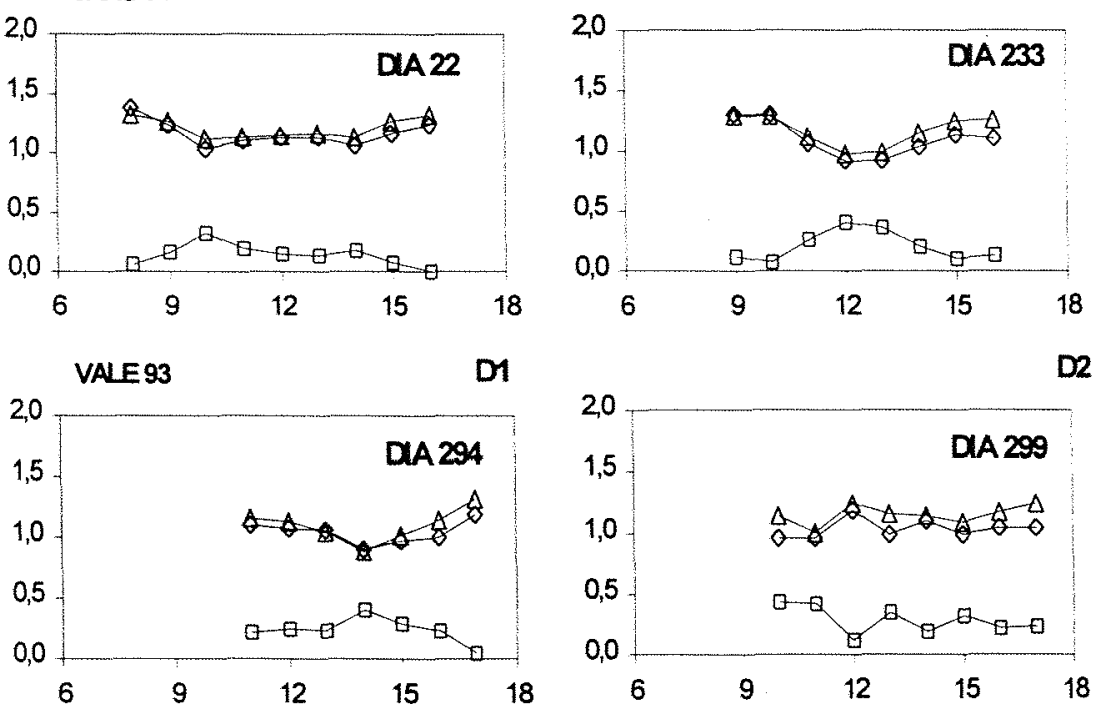

HORA LOCAL

Figura 25 - Variação horária de $\alpha$ (medido e estimado) e da razão de Bowen, para as Reservas Biológica do Jaru (Ji-Paraná, RO) e Vale do Rio Doce (Marabá, PA), para: A (1992); B e D (1993); C (1994). 
Para os sitios florestas, foi observado que para os dias julianos 271 e 195 (Figuras 25A1 e B1), foi verificada para os horários entre as 10 e 14 horas que o $\alpha$ medido foi maior que o estimado, situação diferente para os outros dias, neste mesmo sítio.

Para os sitios pastagem, observa-se que as variações para $\alpha$ ao longo do dia foram mais significativas que para a floresta (Figuras 26 e 27).

Quanto a razão de Bowen, tanto para as florestas quanto para as pastagens, variou segundo a relação inversa $\operatorname{com} \alpha$. 

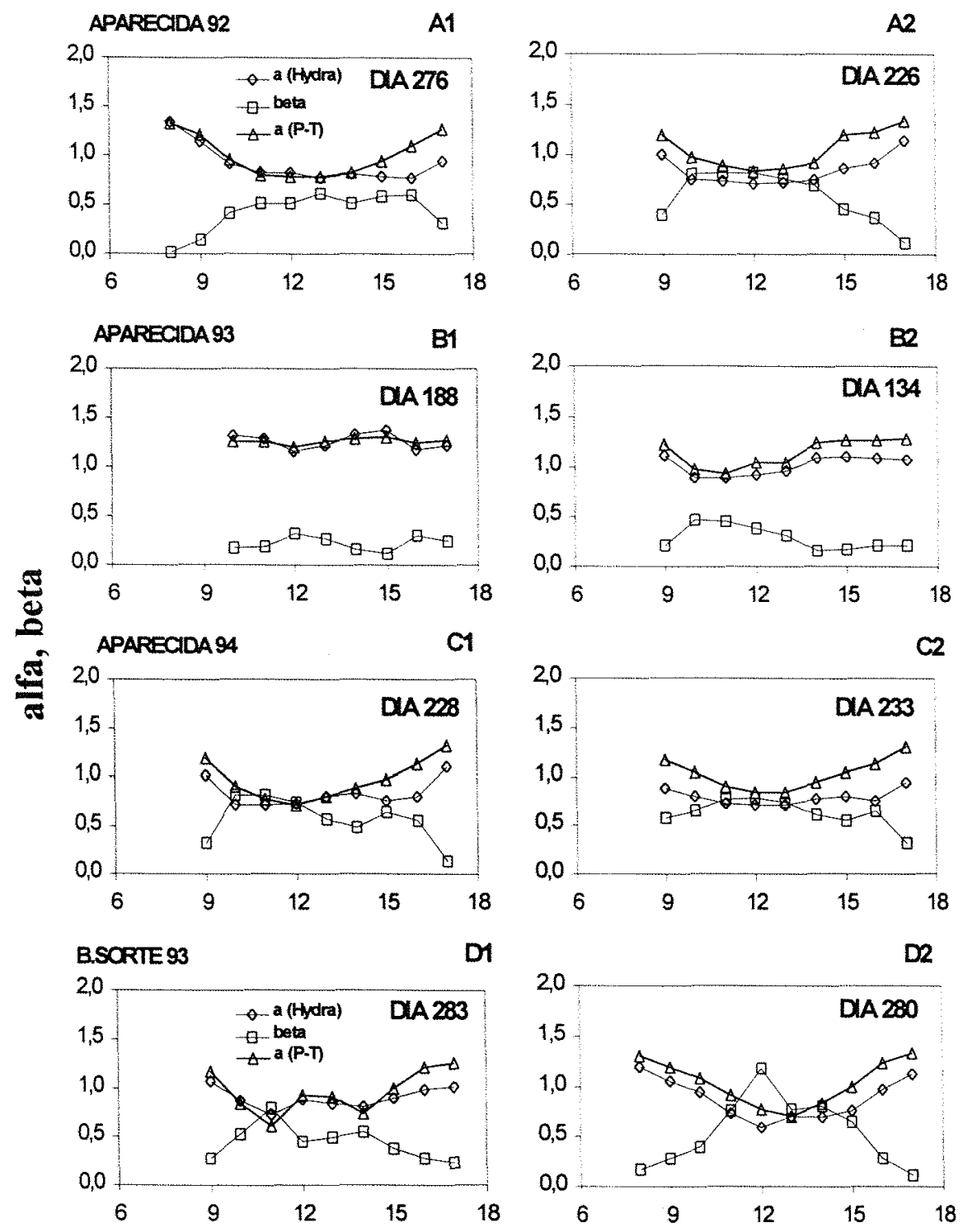

HORA LOCAL

Figura 26 - Variaçāo horária de $\alpha$ (medido e estimado) e da razão de Bowen, para as Fazendas Nossa Senhora Aparecida (Ji-Paraná RO) e Boa Sorte (Marabá, PA), para: A (1992), B (1993); e C (1994). 

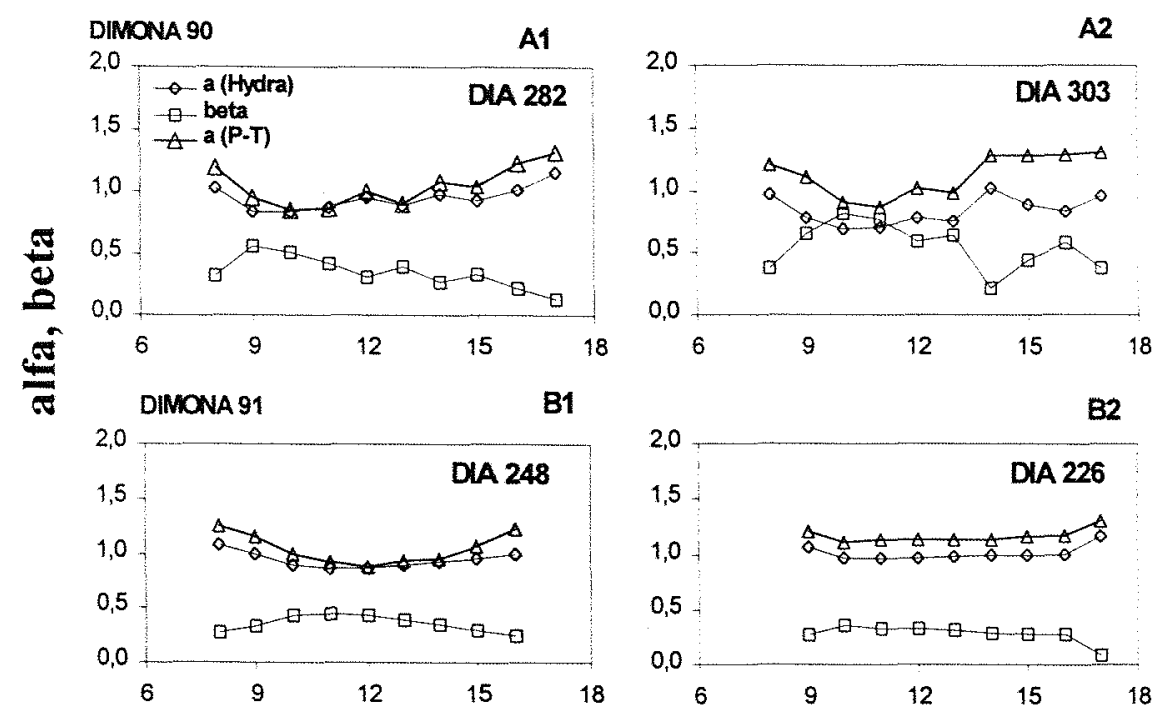

\section{HORA LOCAL}

Figura 27 - Variação horária de $\alpha$ (medido e estimado) e da razāo de Bowen, para a Fazenda Dimona (Manaus, AM), para: A (1990); B (1993).

\subsection{2 - Escala Diária}

As tabelas 6 e 8 , representam os totais diários dos fluxos de energia para cada dia juliano. Na floresta, observa-se que os dia juliano 271 e 195, foram os que apresentaram os maiores totais de $\operatorname{Rn}(16,40$ $\left.\mathrm{MJ} \mathrm{m}^{-2} \mathrm{~d}^{-1}\right)$ e $\left(13,38 \mathrm{MJ} \mathrm{m}^{-2} \mathrm{~d}^{-1}\right)$, respectivamente. No entanto, o dia juliano 195 apresentou o maior fluxo de calor sensivel de $-4,36 \mathrm{MJ} \mathrm{m}^{-2}$ $\mathrm{d}^{-1}$, sendo a diferença entre o calor latente estimado e medido de apenas 0,3 $\mathrm{MJ} \mathrm{m}^{-2} \mathrm{~d}^{-1}$, contra 8,69 $\mathrm{MJ} \mathrm{m}^{-2} \mathrm{~d}^{-1}$ no dia juliano 271 . O dia juliano 228, também apresentou um $\mathrm{Rn}$ de $13,17 \mathrm{MJ} \mathrm{m} \mathrm{m}^{-2} \mathrm{~d}^{-1}$, no entanto um $\mathrm{H}$ de somente $-1,46 \mathrm{MJ} \mathrm{m}^{-2} \mathrm{~d}^{-1}$. 
Tabela 6 - Total diário dos fluxos de energia, parâmetro de Priestley-Taylor (estimado e medido) biomassa e variâveis meteorológicas para os dias analisados na Floresta.

\begin{tabular}{|c|c|c|c|c|c|c|c|c|c|c|}
\hline Dia Juा. & $\begin{array}{l}\text { Periodo } \\
\text { (horas) }\end{array}$ & $\frac{\mathrm{kn}}{M J \mathrm{~m}^{2} \mathrm{~d}^{-1}}$ & $\frac{G}{M J m^{2} d^{-1}}$ & $\begin{array}{l}\text { LE(hydra) } \\
M J m^{2} d^{-3}\end{array}$ & $\begin{array}{c}\mathrm{T} \\
\mathrm{MJ} \mathrm{m}^{2} \mathrm{~d}^{-1}\end{array}$ & $\begin{array}{l}\text { EE(P-Taylor) } \\
M J m^{-2} d^{-1}\end{array}$ & $\begin{array}{l}\text { Temperatura } \\
{ }^{\circ} \mathrm{C}\end{array}$ & $\mathrm{ms}^{-1}$ & $\begin{array}{l}\text { Blomassa } \\
M \mathrm{~J} \mathrm{~m} \mathrm{~m}^{-2} \mathrm{~d}^{-4}\end{array}$ & $\begin{array}{c}\text { Precipitacia } \\
\text { mm }\end{array}$ \\
\hline 229 & $9-17$ & 70,54 & $-0,02$ & -7.68 & $-1,48$ & -9.54 & 28,04 & 1,33 & 1,36 & 0.0 \\
\hline 271 & $8-16$ & 16,40 & $-0,01$ & -10.74 & $-4,02$ & $-11,41$ & 27,18 & 2.22 & 1,63 & 0.0 \\
\hline 195 & $8-17$ & 13,38 & 0,13 & $-7,77$ & $-4,36$ & -8.07 & 19.89 & 3,39 & 1,38 & 0,0 \\
\hline 198 & $9-17$ & 11,84 & $-0,04$ & -8.45 & $-1,80$ & $-10,16$ & 26,90 & 1,89 & 1.55 & 0,0 \\
\hline 228 & $8-16$ & 13,17 & $-0,03$ & $-10,25$ & $-1,46$ & $-12,01$ & 27.69 & 1,97 & 1.43 & 0,0 \\
\hline 233 & $9-16$ & 11,31 & $-0,04$ & $-7,99$ & $-1,75$ & $-9,94$ & 28.75 & 1,10 & 1,53 & 0,0 \\
\hline 294 & $11-17$ & 11,09 & $-0,01$ & -8.31 & -2.12 & $-9,15$ & 29,65 & 2,45 & 0,66 & 0,0 \\
\hline 299 & $10-17$ & 10,41 & 0,00 & $-7,31$ & $-1,95$ & $-9,09$ & 28,36 & 1,19 & 1,15 & 0,0 \\
\hline
\end{tabular}

O dia 195, foi caracterizado por temperatura baixa, alta velocidade do vento, em relação aos demais dias na floresta. Com relação a biomassa, foi inferior a $23 \mathrm{MJ} \mathrm{m}^{-2} \mathrm{~d}^{-1}$ que o dia 271 .

Quanto a partição de energia para o fluxo de calor no solo, o dia 195, contribuiu com 0,13. As melhores correlações obtidas entre calor latente medido e estimado, na escala horária, foram melhores nestes dias, sendo caracterizados pelos maiores valores de $\mathrm{Rn}, \mathrm{H}$ e G. Quanto a partição de energia, podemos observar que, o dia 195, obteve a maior parte de Rn, para o calor sensivel $(0,33)$, seguido pelo dia 271 (Tabela 7).

Tabela 7 - Quociente diário dos fluxos de energia para o dias analisados na Floresta

\begin{tabular}{ccccc}
\hline DIAS & G/Rn & LE(HY)/Rn & H/Rn & LE (est.)/Rn \\
\hline 229 & 0,00 & $-0,73$ & $-0,14$ & $-0,91$ \\
271 & 0,00 & $-0,65$ & $-0,24$ & $-0,70$ \\
195 & 0,01 & $-0,58$ & $-0,33$ & $-0,60$ \\
198 & 0,00 & $-0,71$ & $-0,15$ & $-0,86$ \\
228 & 0,00 & $-0,78$ & $-0,11$ & $-0,91$ \\
233 & 0,00 & $-0,71$ & $-0,15$ & $-0,88$ \\
294 & 0,00 & $-0,75$ & $-0,19$ & $-0,82$ \\
299 & 0,00 & $-0,70$ & $-0,19$ & $-0,86$ \\
\hline \hline
\end{tabular}


Quanto as pastagens, podemos observar que o dia 283, foi o que apresentou o maior valor para o calor sensivel sendo de $-4,34 \mathrm{MJ}$ $\mathrm{m}^{-2} \mathrm{~d}^{-1}$ e também apresentou a segunda melhor estimativa $\mathrm{b}=98 \%$ (Figura 6D1). O dia 283 foi caracterizado por temperatura normal para a região, alta velocidade do vento. A umidade do solo foi de $0,23 \mathrm{~m}^{3} \cdot \mathrm{m}^{-3}$ (Tabela 8).

Tabela 8 - Total diário dos fluxos de energia, parâmetro de Priestley-Taylor (estimado e medido) variáveis meteorológicas para os dias analisados na pastagem.

\begin{tabular}{|c|c|c|c|c|c|c|c|c|c|c|}
\hline bia Jul. & $\begin{array}{l}\text { Periodo } \\
\text { (horas) }\end{array}$ & $\begin{array}{c}\text { Rn } \\
\text { MJ } m^{2} d^{-1}\end{array}$ & $M J m^{2} d^{1}$ & $\begin{array}{l}\text { LE(nydra) } \\
M \mathrm{~m}^{2} \mathrm{~d}^{-1}\end{array}$ & $M J m^{2} d^{-1}$ & $\begin{array}{l}\text { LE(P-Taylor) } \\
M J \mathrm{~m}^{2} \mathrm{~d}^{-4}\end{array}$ & $\begin{array}{l}\text { Temperatura } \\
{ }^{\circ} \mathrm{C}\end{array}$ & $\mathrm{ms}^{-1}$ & $\begin{array}{c}\text { umidade solo } \\
\mathrm{m}^{3} \mathrm{~m}^{3}\end{array}$ & $\begin{array}{c}\text { Preciptaçáo } \\
\text { mm }\end{array}$ \\
\hline 226 & 9.17 & 9,73 & $-1,30$ & $-5,04$ & $-3,38$ & $-8,22$ & 29,29 & 7.86 & 0,22 & 0.0 \\
\hline 276 & $8-17$ & 14,22 & $-0,39$ & $-9,56$ & $-4,27$ & $-10,63$ & 30,68 & 3,07 & 0.23 & 0.0 \\
\hline 134 & $9=17$ & 10.13 & $-0,52$ & $-7,32$ & $-2,30$ & $-9,01$ & 29,80 & 1,58 & 0.31 & 0,0 \\
\hline 188 & $10-17$ & 3,87 & 0,06 & $-3,21$ & $-0,72$ & $-3,12$ & 17,04 & 4.25 & 0,25 & 0,0 \\
\hline 228 & $9-17$ & 11,77 & $-0,43$ & $-7,04$ & $-4,30$ & $-17,26$ & 30,86 & 3,34 & 0,22 & 0,0 \\
\hline 233 & $9-17$ & 9,58 & $-0,45$ & $-5,49$ & $-3,64$ & $-13,60$ & 30,94 & 2,49 & 0,21 & 0,0 \\
\hline 283 & $8-17$ & 14,07 & $-0,54$ & $-9,19$ & $-4,34$ & $-10,18$ & 30,68 & 3,30 & 0,23 & 0,0 \\
\hline 280 & $9-17$ & 10,43 & $-0,39$ & $-6,17$ & $-3,87$ & $-7,80$ & 30,16 & 2,02 & 0.23 & 0,0 \\
\hline 282 & $8-17$ & 14,39 & $-0,61$ & -10.07 & $-3,72$ & $-11,75$ & 31,16 & 3,06 & 0,39 & 0,0 \\
\hline 303 & $8-17$ & 7,59 & $-0,61$ & $-4,32$ & $-2,66$ & $-6,64$ & 30,23 & 2,98 & 0,37 & 0,0 \\
\hline 226 & $9-17$ & 9,25 & $-0,65$ & $-6,66$ & $-1,93$ & 8,86 & 29,48 & 2,26 & 0,36 & 0,0 \\
\hline 248 & $8-16$ & 13,28 & $-0,74$ & $-9,16$ & $-3,38$ & -11.07 & 30,55 & 3,01 & 0,37 & 0,0 \\
\hline
\end{tabular}

Tabela 9 - Quociente diário dos fluxos de energia para o dias analisados na Floresta

\begin{tabular}{ccccc}
\hline DIAS & G/Rn & LE(HY/Rn & H/Rn & LE (est.)/Rn \\
\hline 226 & $-0,13$ & $-0,52$ & $-0,35$ & $-0,84$ \\
276 & $-0,03$ & $-0,67$ & $-0,30$ & $-0,75$ \\
134 & $-0,05$ & $-0,72$ & $-0,23$ & $-0,89$ \\
188 & 0,01 & $-0,83$ & $-0,19$ & $-0,81$ \\
228 & $-0,04$ & $-0,60$ & $-0,37$ & $-1,37$ \\
233 & $-0,05$ & $-0,57$ & $-0,38$ & $-1,29$ \\
283 & $-0,04$ & $-0,65$ & $-0,31$ & $-0,72$ \\
280 & $-0,04$ & $-0,59$ & $-0,37$ & $-0,75$ \\
282 & $-0,04$ & $-0,70$ & $-0,26$ & $-0,82$ \\
303 & $-0,08$ & $-0,57$ & $-0,35$ & $-0,87$ \\
226 & $-0,07$ & $-0,72$ & $-0,21$ & $-0,96$ \\
248 & $-0,06$ & $-0,69$ & $-0,25$ & $-0,83$ \\
\hline \hline
\end{tabular}

O dia 188, foi um dia totalmente atípico. O dia 226 apresentou o menor valor de calor latente $\left(-1,93 \mathrm{MJ} \mathrm{m}^{-2} \mathrm{~d}^{-1}\right)$ e foi 
também o que apresentou pior estimativa entre calor latente medido e estimado (Figura 6A2) e também o que menos contribuiu para o calor latente (Figura $12 \mathrm{~A} 2$ ).

Com relaçao as práticas de energia (Tabela 9) não foi constatado para o dia juliano 283, o maior valor para H/Rn.

Com relação as tabelas 10 e 11, observamos que exceto para alguns casos (dias 271 e 195), o $\alpha$ estimado superestima o medido.

Com relação aos dias julianos 228 e 233, verificou-se uma diferença entre $\alpha$ medido de 0,19 e de 0,5 em $\alpha$ estimado para o dia juliano 228. Para o dia 233, essa diferença ficou em torno de 0,16 par $\alpha$ medido e de 0,48 para $\alpha$ estimado.

Tabela 10 - Valores médios para $\alpha$ para os sitios na Floresta

\begin{tabular}{cccccc}
\hline Local & Dia Jul. & alfa (Hydra) & alfa (estimado) & bowen & W \\
\hline R.Jaru & 229 & 1,12 & 1,20 & 0,19 & 0,76 \\
1992 & 271 & 1,00 & 0,99 & 0,34 & 0,75 \\
\hline R.Jaru & 195 & 1,04 & 0,99 & 0,47 & 0,68 \\
1993 & 198 & 1,13 & 1,18 & 0,19 & 0,75 \\
\hline R.Jaru & 228 & 1,16 & 1,20 & 0,14 & 0,76 \\
1994 & 233 & 1,09 & 1,16 & 0,20 & 0,77 \\
\hline R. Vale & 294 & 1,04 & 1,10 & 0,23 & 0,78 \\
1993 & 299 & 1,03 & 1,14 & 0,28 & 0,77 \\
\hline \hline
\end{tabular}


Tabela 11 - Valores médios para $\alpha$ para os sitios na pastagem.

\begin{tabular}{lccccc}
\hline Local & Dia Jul. & $\begin{array}{c}\text { alfa (Hydra) } \\
\text { (adim.) }\end{array}$ & $\begin{array}{c}\text { alfa (estimado) } \\
\text { (adim.) }\end{array}$ & $\begin{array}{c}\text { bowen } \\
\text { (adim.) }\end{array}$ & w \\
\hline F. Aparec. & 226 & 0,84 & 1,04 & 0,58 & 0,78 \\
1992 & 276 & 0,91 & 1,00 & 0,42 & 0,79 \\
\hline F. Aparec. & 134 & 1,00 & 1,13 & 0,28 & 0,78 \\
1993 & 188 & 1,26 & 1,26 & 0,22 & 0,65 \\
\hline F. Aparec. & 228 & 0,83 & 0,96 & 0,56 & 0,79 \\
1994 & 233 & 0,78 & 1,02 & 0,62 & 0,79 \\
F. B.Sorte & 283 & 0,89 & 0,96 & 0,44 & 0,79 \\
1993 & 280 & 0,87 & 1,03 & 0,54 & 0,79 \\
F. Dimona & 282 & 0,95 & 1,04 & 0,34 & 0,79 \\
1990 & 303 & 0,84 & 1,12 & 0,54 & 0,79 \\
F. Dimona & 226 & 1,01 & 1,16 & 0,28 & 0,78 \\
1991 & 248 & 0,94 & 1,04 & 0,35 & 0,79 \\
\hline \hline
\end{tabular}




\section{5 - CONCLUSÕES}

Foi estimado o calor latente pelo método de Priestley e Taylor (1972), segundo a proposição de Pereira e Villa Nova (1992) para o parâmetro $\alpha$ e comparado com o calor latente medido (método das correlações dos turbilhōes), para cada sítio (floresta e pastagem) e época do experimento.

As melhores estimativas observadas para os sitios floresta e pastagem, entre o calor latente estimado e o medido, foram aquelas em que foi considerada a equação estatística proposta por Pereira-Villa Nova, sendo $\alpha=1,33+2,7810^{-3} \mathrm{H}$. Considerando-se esta equação, foi observado que as melhores correlações (maiores coeficientes angulares) foram obtidas para os sitios floresta do que para os sitios pastagem. O calor latente estimado (Priestley-Taylor) superestimou o calor latente medido (Hydra).

Para os sitios floresta, a melhor e a pior estimativa foi observada para a Reserva Jaru. Sendo o maior coeficiente angular observado em 1992, aproximadamente 0,89 e o menor observado para 1994, sendo de 0,84. Para 1993, o coeficiente angular foi de aproximadamente 0,88 . Quanto a Marabá, o coeficiente angular foi de aproximadamente 0,88 .

Para as pastagens, a melhor estimativa foi observada para a Fazenda Nossa Senhora Aparecida (1993), sendo de aproximadamente, $\mathrm{b} \approx 0,86$. A pior estimativa foi de $\mathrm{b}=0,77$, também para a Fazenda Nossa Senhora Aparecida (Ji-Paraná, RO) para o ano de 1992. Na 
Fazenda Boa Sorte (Marabá, PA), o coeficiente angular foi de aproximadamente 0,84 . Quanto a Fazenda Dimona, a melhor estimativa foi observada para o ano de 1991, sendo $b=0,79$.

Tanto nos sitios floresta quanto nos sitios pastagem, as melhores estimativas horárias diárias entre o calor latente estimado e o medido, foram observadas para os dias em que ocorreram os maiores fluxos de energia e mais especificamente os maiores valores para o calor sensivel. No entanto, para um dia atipico (dia 188) foi observado uma correlação quase perfeita quando os fluxos apresentados foram pequenos.

Quanto ao parâmetro de Priestley-Taylor medido e estimado, foram observadas boas correlações, sendo pouco maiores que as observadas entre o calor latente estimado e o medido. As melhores estimativas também foram observadas para os sitios floresta, ficando entre $b=1 \mathrm{e} b=0,84$. Quanto as pastagens, $\mathrm{b}$ variou entre aproximadamente 1 e 0,74 .

O parâmetro de Priestley-Taylor é função inversa do calor sensivel. 


\section{REFERÊNCIAS BIBLIOGRÁFICAS}

ANDRÉ, R. G. B.; VOLPE, C. A.; MALHEIROS, E. B. O parâmetro da equação de Priestley e Taylor para estimativa de evapotranspiração da cultura do milho. In IX CONGRESSO BRASILEIRO DE METEOROLOGIA, v. 1, Campos do Jordão, nov. 1996.

AYOADE, J. O. Introdução a climatologia para os trópicos. Rio de Janeiro, Bertrand Brasil, 1996. 332p.

BAILEY, W. G.; DAVIES, J. A. Evaporation from soybeans. BoundaryLayer Meteorology, v.20, p. 417-428, 1981.

BALDOCCHI, D. D.; DETLEF, R.M.; ROBERT, T. M.; BOYD, A. H. Evapotranspiration from an oak-hickory forest. In PROCEEDINGS OF THE NATIONAL CONFERENCE ON ADVANCES IN EVAPOTRANSPIRATION, Illinois, 1985. Anais. Chicago, American Society of Agricultural Engineers, p. 414-422.

BARTON, I. J. A parameterization of the evaporation from nonsaturated surfaces, Journal of Applied Meteorology, v.18, 1, p.43-47, Jan, 1979.

BLACK, T. A. Evapotranspiration from Douglas-fir stands exposed to soil water deficits. Water Resources Researches, v.15, p. 164-170, 1979.

BOWEN, I. S. The ratio of heat losses by conduction and by evaporation fron any water surface. Physical Review, v. 27, p. 779-786, june, 1926. 
BRUIN, H. A. R. A model for the Priestley-Taylor parameter $\alpha$. Journal of Applied Meteorology, v.22, p.572-578, Apr, 1983.

BRUIN, H. A. R. de; KEIJMAN, J. Q. The Priestley-Taylor evaporation applied to a large, shallow lake in the Netherlands. Journal of Applied Meteorology, v.18, 7, p.898-903, 1979.

BRUIN, H. A. R.; HOLTSLAC, A. M. A simple parameterization of the surface fluxes of sensible and latent heat during daytime compared with the Penman-Monteith concept. Journal of Applied Meteorology. Boston. V. 21. P. 1610-1621. 1982.

CHOUDHURY, B. J.; IDSO, S. B. An empirical model for stomatal resistance of field-grown wheat. Agricultural and Forest Meteorology. Amsterdam. V.36, p65-82. 1985.

CosTA, J. P. R.; ELOI, C. M. A.; MORAES, J. C. Avaliação do comportamento da evapotranspiração em áreas de floresta tropical úmida da Amazônia. In $\mathrm{X}$ CONGRESSO BRASILEIRO DE METEOROLOGIA, Brasilia, out. 1998.

CUNHA, G. R. e BERGAMASCHI, H. Coeficientes das equações de Makking e Priestley-Taylor para a estimativa da evapotranspiração máxima da alfafa. Revista Brasileira de Agrometeorologia, v.2, p.33-36, 1994.

DALlAROSA, R. L. G. Evapotranspiração em floresta da Amazônia equatorial. Porto Alegre, 1996. 101p. Dissertação (M.S.) - Instituto de Recursos Hidricos.

DAVIES, J. A.; ALLEN, G. D. Equilibrium potential and actual evaporation from cropped surfaces in Southern Ontario. Journal of Applied Meteorology, v.12, p.649-656. 1973.

FRITSCHEN, L. J.; SIMPSON, J. R. Evapotranspiration from forests: measurement and modeling. In PROCEEDINGS OF THE NATIONAL CONFERENCE ON ADVANCES IN EVAPOTRANSPIRATION, Illinois, 
1985. Anais. Chicago, American Society of Agricultural Engineers, p. 393-404.

GASH, J. H. C.; NOBRE, C. A.; ROBERTS, J. M.; VICTORIA, R. L. Amazonian deforestation and climate. England, John Wiley $\&$ Sons, 1996. $611 \mathrm{p}$.

GASH, J. H. C.; SHUTTLEWORTH, W. J. Tropical deforestation: albedo and surface - energy balance. Climate Change, v.19, n.1-2, p.123-134, 1991.

INSTITUTO DE HYDROLOGIA (HI). Amazônia, florestas, pastagens e o clima: resultados do Projeto ABRACOS,. Oxford, 18p. 1994.

JURY W. A.; TANNER, C. B. Advection modification of the Priestley and Taylor evapotranspiration formula. Agronomy Journal. V. 67, p. 840-842 Nov-Dec, 1975.

KANEMASU, E. T.; STONE, L. R.; POKIERS, W. L. Evapotranspiration model tested for soybean and sorghum. Agronomy Journal. V.68, p.569-572. 1976.

LHOMME, J. P. An examination of the Priestley-Taylor equation using a convective boundary layer mode. Water Resources Research. V.33, 11, p.2571-2578, 1977.

LLOYD, C.R.; SHUTTLEWORTH, W.J.; GASH, J.H.C.; TURNER, M. A microprocessor system for eddy-correlation. Agricultural and Forest Meteorology, v.33, p.67-80, 1984

LYRA, R.; NOBRE, C.; FISCH, G.; ROCHA, E.; ROCHA, H.; SOUZA, S. S. Efeitos do desmatamento sobre a termodinâmica da baixa atmosfera. In CONGRESSO BRASILEIRO DE METEOROLOGIA, Belo Horizonte, 1994. Anais. Belo Horizonte: SBMET, v.1, p.81-84.

MARSH, P.; ROUSE, W. R.; WOO, M. K. Evaporation at a high Artic site. Journal of Applied Meteorology, v.20, p.713-716, 1981. 
McNAUGHTON, K. G.; BLACK, T. A. A study of evapotranspiration from a Douglas fir forest using the energy balance approach. Water Resources Researches, v.9, p.1579-1590, 1973.

MOLION, L. C. B. A Amazônia e o clima da Terra. Ciência Hoje, v.8, n.48, p.44-47, 1988.

MOLION, L. C. B. A Amazônia e o clima do globo terrestre. Revista Brasileira de Geografia, v.52, n.2, p.89-94, Rio de Janeiro, 1990.

MOORE, C. J. Frequency response corrections for eddy correlation systems. Boundary Layer Meteorology, v.37, p.17-35, 1986.

MOORE, C. J.; FISCH, G. Estimating heat storage in Amazonian tropical forest. Agricultural and Forest Meteorology, v. 38, p. 147-169, 1986.

MORGAN, D. L.; PRUITT, W. O.; LOURENCE, F. J. Analysys of energy, momentum, and mass transfers above vegetative surfaces. Final Report, University of California, Davis, CA, 1971. 128p.

MUKAMMAL, E. I.; NEUMANN, H. H. Application of the Priestley-Taylor evaporation model to assess the influence of soil moisture on the evaporation from a large weighing lysimeter and class A pan. Boundary Layer Meteorology, v.12, p.234-256, 1977.

OMETTO, J.C. Bioclimatologia Vegetal. Ed. Agronômica Ceres, São Paulo, 440p. 1981.

PENMAN, H. L. Natural evaporation from open water, bare soil and grass. Proc. R. Soc. London, A193. 120-146p. 1948.

PEREIRA, A. R.; VILLA NOVA, N. A.; Analysis of the Priestley-Taylor parameter. Agricultural and Forest Meteorology, v.61, p.1-9, 1992.

PEREIRA, A. R.; VILLA NOVA, N. A.; SENTELHAS, P. C. O parâmetro de Priestley-Taylor para estimativa da evapotranspiração de referência 
na escala mensal. Revista Brasileira de Agrometeorologia, v. 5 1, p.83-87, 1997.

PEREIRA, A. R.; VILlA NOVA, N. A: SEDIYAMA, G. C. Evapo(transpi)ração. Piracicaba, Fealq. 183p. 1997. PERES, J. G.; PEREIRA, A. R; FRIZONE, J. A.; VILLA NOVA, N. A. Calibração do modelo de Priestley-Taylor para estimar a evapotranspiração potencial da cana-de-açúcar . Revista Brasileira de Agrometeorologia, v.5, n.1, p.77-82, 1997.

PRIESTLEY, C. H. B; TAYLOR, R. J. On the assessment of surface heart flux and evaporation using large-scale parameters. Monthly Weather Review, v.100, n.2, p.81-92, Fev. 1972.

PRUITT, W. O.; LOURENCE, F. J. Tests of aerodynamic energy balance and other evaporation equations over grass surface. Chapter IV, in Investigation of energy, momentum and mass transfer near the ground. Final Report, University of California, Davis, CA, pp. 37$63,1965$.

RIBEIRO, J. B. M. Análise comparativa das caracteristicas microclimáticas entre áreas de floresta e de pastagem na Amazônia. Viçosa, 1994. 67p. Dissertação (M.S.) - Universidade Federal de Viçosa.

RIBEIRO, M. de N. G.; VILLA NOVA, N. A. Estudos climatológicos da reserva florestal Duck, Manaus, AM. III. Evapotranspiração. Acta Amazônica, v.9, n.2, p.305-309, 1979.

SEDIYAMA, G. C. Estimativa da evapotranspiração: histórico, evolução e análise critica. Revista Brasileira de Agrometeorologia, v.4, n.1, p. i-xii, 1996.

SENTElHAS, P. C.; PEREIRA, A. R.; FOlEGATTI, M. V.; PEREIRA, F. A. C.; VILLA NOVA, N. A.; MAGGIOTTO, S. R. Variação sazonal do parâmetro de Priestley-Taylor para estimativa diária da 
evapotranspiração de referência. Revista Brasileira de Agrometeorologia (submetido).

SHUTTLEWORTH, W. J.; NOBRE, C. A. Wise forest management and climate change. In: CONGRESSO BRASILEIRO DE METEOROLOGIA, São Paulo, 1992. Anais. São Paulo: SBMET, 1992, v.1, p.287-292.

SHUTTLEWORTH, W. J. Evaporation from Amazonian rain forest. Proceedings of Royal Society of London, série B, v.233, n.1272, p.321-346, 1988.

SHUTTLEWORTH, W. J.; CALDER, I. R. Has the Priestley-Taylor equation any relevance to forest evaporation? Journal of Applied Meteorology, v.18, p.639-646, May, 1979.

SLATYER, R. O.; McILROY, I. C. Pratical microclimatology. Canberra, CSIRO, p.328, 1961.

SOUZA, S. S. A substituição da floresta amazônica por pastagem e sua repercussão ao nivel da termodinâmica da camada limite atmosférica: Projeto RBLE. Campina Grande, 1997. 110p. Dissertação (M.S.) - Universidade Federal da Paraiba.

STEWART, R. B.; ROUSE, W. R. A simple method for determining the evaporation from shallow lakes and ponds. Water Resources Research, v.12, n.4, p.623-628, Aug, 1976.

STEWART, R. B.; ROUSE, W. R. Substantiation of the Priestley and Taylor parameter $\alpha=1.26$ for potential evaporation in high latitudes. Journal of Applied Meteorology, v.16, p.649-650, Jun, 1977.

SWINBANK, W. C. The measurement of vertical transfers of heat and water vapor by eddies in the lower atmosphere. Journal of Meteorology., v.8, p. 135-145, 1951.

TANNER, B. D.; TANNER, M. S.; DUGAS, W. A.; CAMPBELL, E. C.; BLAND, B. L. Evaluation of operational eddy correlation system for 
Evapotranspiration measurement. In PROCEEDINGS OF THE NATIONAL CONFERENCE ON ADVANCES IN EVAPOTRANSPIRATION, Illinois, 1985. Anais. Chicago, American Society of Agricultural Engineers, p. 87-99.

TANNER, C. B.; JURY, W. A. Estimating evaporation and transpiration from a row crop during incomplete cover. Agronomy Journal, 68. 239-242p. 1976.

THOMPSON, J.R. Energy budgets for three small plots-substantiation of Priestley and Taylor's large-scale evaporation parameter. Journal of Applied Meteorology, v.14, p.1399-1401, Oct, 1975.

THORNTHWAITE, C. W. An approach toward a rational classification of climate. Geogr. Ver. 38. 55-94p. 1948.

TSANN-WANG, Y. Parametrization of surface evaporation rate for use in numerical modeling. Journal of Applied Meteorology, v. 16, p. 393-400, 1977.

VISWANADHAM, Y.; SILVA FILHO, V. P.; ANDRE, R. G. B. The PriestleyTaylor parameter $\alpha$ for the Amazon forest. Forest Ecology Management Journal, v.38, p.211-225, 1991.

WILLIAMS, R. J.; BRERSMA, K. VAN RYSWYK, A. L. Equilibrium and actual evapotranspiration from a very dry vegeted surface. Journal of Applied Meteorology, v.17, n.12, p.1827-1832, Dec, 1978.

WILSON, R.G.; ROUSE, W.R. Moisture and temperature limits of the equilibrium evapotranspiration model. Journal of Applied Meteorology, v.11, p.436-442, Apr, 1972.

WRIGHT, I. R.;GASH, J. H. C.; ROCHA, H. R.; SHUTTLEWORTH, W. J.; NOBRE, C. A.; MAITELlI, G. T. M.; ZAMPARONI, C. A. G. P.; CARVALHO, P. R. A. Dry season micrometeorology of central Amazonian ranchland. Quarterly Journal of Royal Meteorology Society, v.118 n.508, p.1083-1099, 1992. 